\title{
ELIZABETH PULITI
}

Avaliação comparativa entre bruxômanos e não bruxômanos quanto à qualidade de vida e a presença de desarmonias orofaciais

São Paulo

2012 


\section{ELIZABETH PULITI}

Avaliação comparativa entre bruxômanos e não bruxômanos quanto à qualidade de vida e a presença de desarmonias orofaciais

Dissertação apresentada à Faculdade de Odontologia da Universidade de São Paulo para obter o título de Mestre, pelo

Programa de Pós-Graduação em Odontologia.

Área de Concentração: Dentística.

Orientador: Profo ${ }^{\circ}$ Dr. Glauco Fioranelli Vieira

São Paulo 
Puliti E. Avaliação comparativa entre bruxômanos e não bruxômanos quanto à qualidade de vida e a presença de desarmonias orofaciais. Dissertação apresentada à Faculdade de Odontologia da Universidade de São Paulo para obtenção do título de Mestre em Odontologia.

Aprovado em: / /2012

\section{Banca Examinadora}

Prof(a). Dr(a). Instituição:

Julgamento: Assinatura:

Prof(a). Dr(a). Instituição:

Julgamento: Assinatura:

$\operatorname{Prof}(\mathrm{a}) . \operatorname{Dr}(\mathrm{a})$. Instituição:

Julgamento: Assinatura: 


\section{AGRADECIMENTO ESPECIAL}

Ao Profo. Dr. Glauco Fioranelli Vieira pela confiança e por possibilitar a realização de um sonho, participando desta evolução. Obrigada pela oportunidade de vivenciar este crescimento...

Ao Prof. Dr. Carlos Martins Agra, pelo apoio, incentivo e experiência científica. Obrigada pelo incentivo, conselhos... e que de tantos auxílios, parece-me impossível enumerá-los. Meu carinho e admiração.

Esta dissertação é dedicada às minhas maiores conquistas, meus filhos Bruno e Bianca. Desculpo-me pelos momentos de ausência, mas deixo a história de que nunca é tarde... é preciso evoluir... e no caminho aproveitar... para realizar sonhos.

Aos meus pais, Milton Puliti (in memoriam) e Melitta, pelo esforço, carinho e abnegação em me proporcionar a melhor formação que poderia almejar. Hoje como mãe, tomo-os como exemplo... nas diversas facetas desta grande jornada...

\section{Matar o sonho é matarmo-nos. É mutilar a nossa alma. O sonho é o que temos de realmente nosso, de impenetravelmente e inexpugnavelmente nosso.}

Fernando Pessoa 


\title{
Meus sinceros e profundos agradecimentos
}

\begin{abstract}
À Faculdade de Odontologia da Universidade de São Paulo - FOUSP responsável pela minha formação acadêmica, por proporcionar mais uma oportunidade de desenvolvimento profissional e pessoal.
\end{abstract}

Às Profa ${ }^{\text {. Dra Margareth Oda e Profa }}$. Dra Miriam Lacalle Turbino, pela paciência, compreensão e disponibilidade para a remissão das dificuldades.

Ao David Lascalla, responsável pela Secretaria do Departamento de Dentística, pelo acolhimento, esclarecimentos e condução nos diversos fluxos necessários para a conclusão deste ciclo.

À "Selminha", funcionária da Secretaria do Departamento de Dentística, pela simpatia, atenção e prestatividade na resolução das necessidades administrativas.

Aos amigos que acreditaram, torceram e dividiram minhas alegrias e desafios.

Aos voluntários da pesquisa pela participação que viabilizou este estudo. 


\section{RESUMO}

Puliti E. Avaliação comparativa entre bruxômanos e não bruxômanos quanto à qualidade de vida e a presença de desarmonias orofaciais [dissertação]. São Paulo: Universidade de São Paulo, Faculdade de Odontologia; 2012. Versão Original.

O bruxismo, uma desordem funcional dentária complexa e destrutiva, é representado por duas entidades que possuem diferentes patogêneses, o Bruxismo diurno ou de vigília (BD), e o Bruxismo do Sono (BS). Este estudo objetivou avaliar as características clínicas apresentadas por indivíduos bruxômanos, comparando-os a não bruxômanos. De um universo de 85 indivíduos foram formados um grupo de bruxômanos, e outro de não bruxômanos (grupo controle), utilizando um questionário de auto-relato para o diagnóstico do bruxismo. Ao exame clínico foram observaddas a ocorrência de diferentes fatores referidos na literatura. Nos resultados, após Análise de Variância com medidas repetidas (ANOVA), foi observado que entre o grupo controle e o grupo de bruxômanos, não houve diferenças estatisticamente significantes para a presença de interferência oclusal em protrusiva; lateralidade direita/esquerda; presença de guia de incisivos; presença de guia de caninos bilateral; desvio de linha média; mobilidade dental; recessão gengival; mordida aberta anterior; mordida cruzada anterior; mordida cruzada posterior unilateral; sobremordida; sobressaliência; salto condilar; clicks/estalos na ATM (nos questionários de auto-relato e no exame clínico); ruídos na ATM; limitação da abertura bucal; assimetria facial e para outros hábitos bucais (onicofagia, morder lábios, morder objetos). Entre o grupo controle e o grupo de bruxômanos, houve diferenças estatisticamente significantes para a dor musculatura face; estresse funcional dental; guia de canino unilateral; ausência de guias de caninos; presença de facetas de desgaste; fratura de dentes e/ou restaurações; presença de abfração; hipertonia do músculo masseter. No questionário de qualidade de vida, proposto pela OMS, The WHOQOL Group (1998), Oral Health Impact Profile (OHIP-14) versão simplificada em português, o "cansaço" foi o único quesito que apresentou diferença estatisticamente significante, no que diferenciou o grupo de bruxômanos do de não bruxômanos.

Palavras-Chave: Bruxismo. Bruxismo do Sono. Bruxismo Diurno. 


\begin{abstract}
Puliti E. Comparative evaluation between bruxists and non bruxists regarding life quality and the presence of orofacial disharmonies [dissertation]. São Paulo: Universidade de São Paulo, Faculdade de Odontologia; 2012. Versão Original.
\end{abstract}

Bruxism, a functional disorder and destructive dental complex, is represented by two entities that have different pathogenesis, as the Diurnal Bruxism (DB), and Sleep Bruxism (SB). This study aimed to evaluate the clinical characteristics displayed by bruxists, comparing them to non bruxists. From a universe of 85 individuals were selected a group of bruxists, and other non bruxists (control group), using a selfreport questionnaire for the diagnosis of bruxism. On clinical examination were observaddas the occurrence of different factors reported in the literature. In the results, after Analysis of Variance with repeated measures (ANOVA), was observed between the control group and the bruxists group, there were no statistically significant differences in occlusal interference in protrusive; laterality right / left; guide incisors; canines bilateral guide; midline deviation; tooth mobility; gingival recession; anterior open bite; anterior crossbite; unilateral crossbite; overbite; overjet; jump condylar; clicks / TMJ clicking (on self-report questionnaires and clinical examination); TMJ sounds; limited mouth opening; facial asymmetry and other oral habits (onychophagia, biting lips, biting objects). Between the control group and the group of bruxists, statistically significant differences were observed for pain face muscles; functional dental stress; guide unilateral canine; absence of canine guides; presence of wear facets; broken teeth and / or restorations; presence of abfraction; masseter hypertony; lingual indentations and line Alba. In quality of life questionnaire, proposed by OMS, The WHOQOL Group, 1998, Oral Health Impact Profile (OHIP14) simplified version in Portuguese, the factor "fatigue" was the only that showed statistically significant difference distinguishing the bruxists group of the group of non bruxists.

Keywords: Bruxism. Sleep Bruxism. Diurnal Bruxism. 


\title{
LISTA DE ABREVIATURAS E SÍMBOLOS
}

\author{
AASM American Academy of Sleep Medicine \\ ARMM Atividade rítmica muscular mastigatória \\ ASDA American Sleep Disorders Association \\ ATM Articulação temporomandibular \\ BD Bruxismo diurno \\ BS Bruxismo do sono \\ CIDS Classificação Internacional dos Distúrbios do Sono \\ DCM Distúrbio Craniomandibular \\ DTM Disfunção Temporomandibular \\ DVO Dimensão Vertical de Oclusão \\ EEG Eletroencefalograma \\ EMG Eletromiografia \\ IMC Índice de Massa Corporal \\ Kgf Quilograma-força \\ LILACS Literatura Latino-Americana e do Caribe em Ciências da \\ Saúde \\ MEDLINE Medical Literature Analysis and Retrieval System Online \\ Mm Milímetros \\ NREM Non Rapid Eye Movement \\ OFA Orofacial Activities (Atividades Orofaciais) \\ OHIP Oral Health Impact Profile \\ PubMed National Library of Medicine \\ RDC/TMD Research Diagnostic Criteria for Temporomandibular Disorders \\ REM Rapid Eye Movement \\ $S \quad$ Segundos \\ SciELO Scientific Electronic Library Online \\ SMA Sleep Motor Activities (Atividades Motoras durante o Sono) \\ SNC Sistema Nervoso Central \\ SUS Sistema Único de Saúde \\ WHOQOL World Health Organization Quality of Life
}


1 INTRODUÇÃO

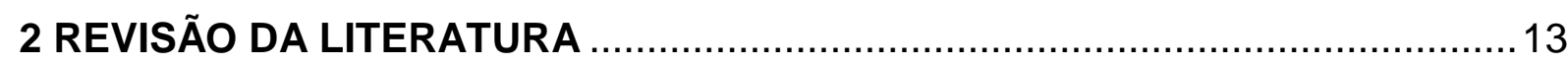

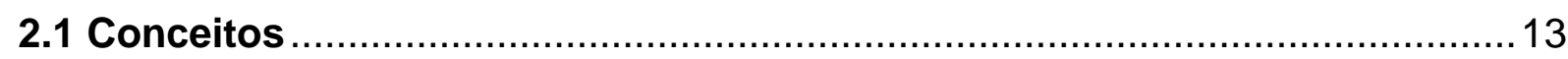

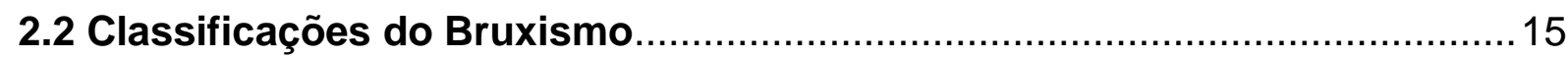

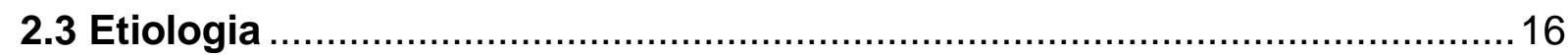

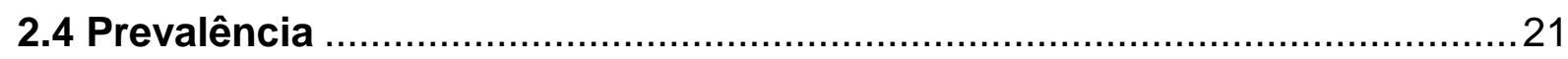

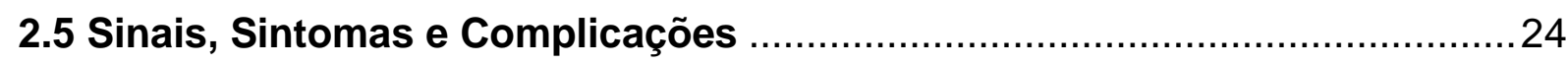

2.6 Atividade Rítmica da Musculatura Mastigatória (ARMM) ............................35

2.7 Evidências para o Diagnóstico do Bruxismo por meio da Polissonografia. 38

2.8 Diagnóstico Clínico do Bruxismo ……….............................................. 42

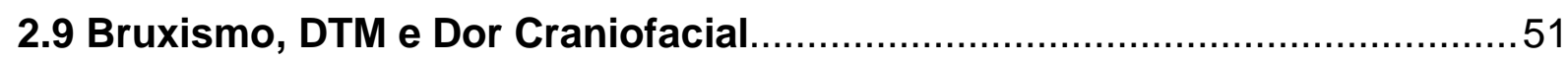

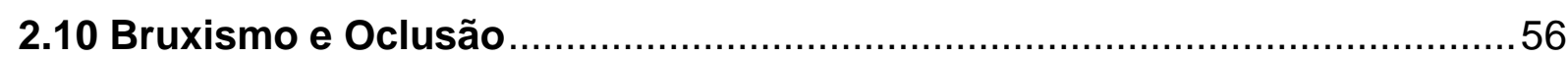

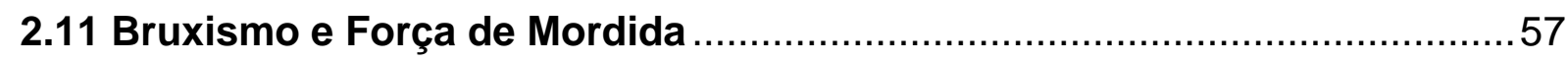

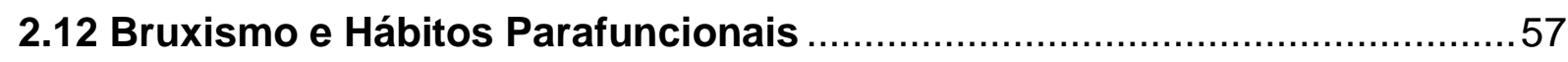

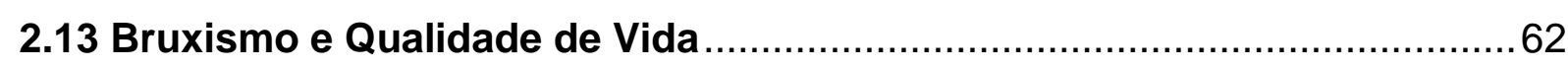

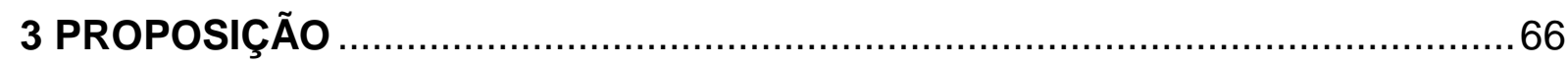

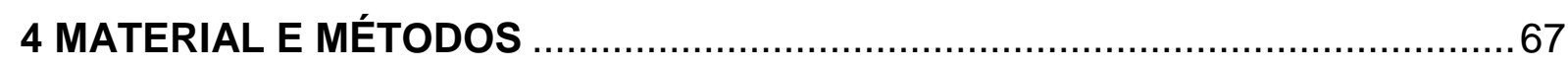

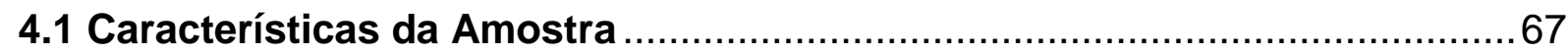

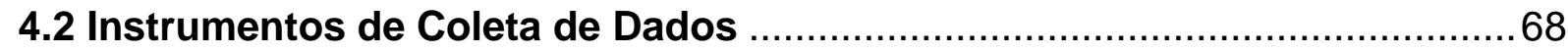

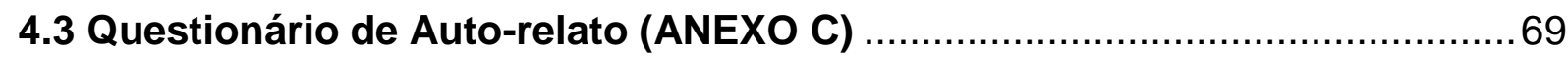

4.4 Questionário Qualidade de Vida (ANEXO D) …….................................

4.5 Questionário Anamnético e Exame Clínico (ANEXO E) ……........................72

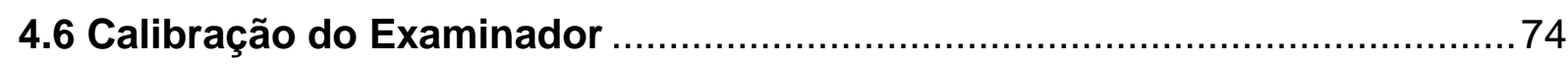

5 RESULTADOS

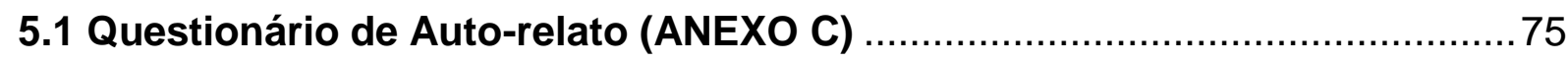

5.2 Questionário Anamnético e Exame Clínico (ANEXO E) ……....................... 78

5.3 Questionário de Qualidade de Vida (ANEXO D) ……............................... 79

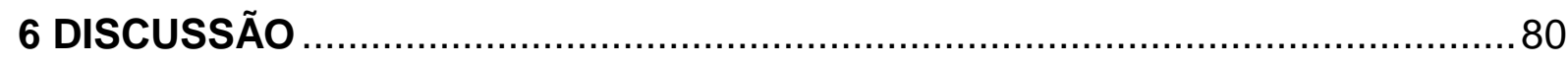

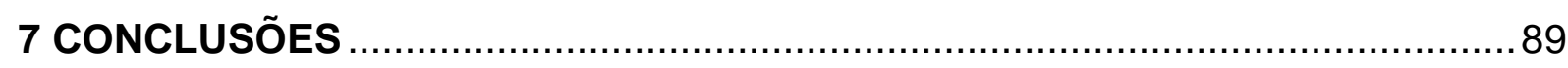

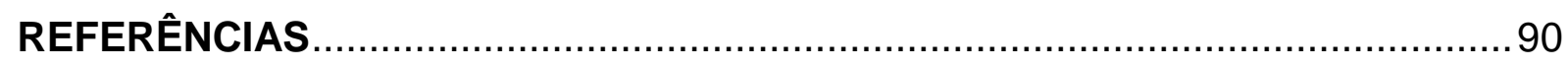

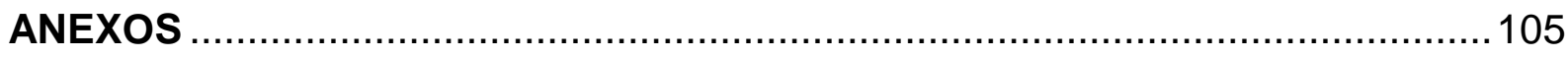




\section{INTRODUÇÃO}

A parafunção Bruxismo tem despertado a atenção dos profissionais pelas alterações que acarreta no sistema estomatognático e em especial no aparelho mastigatório.

O bruxismo é uma das desordens funcionais dentárias mais prevalentes, complexas e destrutivas que existem, podendo ter uma origem tão antiga quanto o próprio homem (Cariola, 2006) e é considerada a atividade parafuncional mais deletéria do sistema estomatognático (Attanasio, 1997; Lobbezoo; Lavigne, 1997; AASM, 2005). Consiste em um relevante problema da saúde bucal, pois impacta de forma significativa no sistema estomatognático representando uma ameaça à integridade de suas estruturas, caso a magnitude e a direção das forças exercidas exceda sua capacidade adaptativa (de La Hoz-Aizpurua et al., 2011).

Historicamente o bruxismo não é um fenômeno contemporâneo, tendo sido citado nos tempos bíblicos, nos Salmos de Davi e Evangelho de Mateus em, aproximadamente, 600 a 200 a.C. e 75 a 90 d.C., respectivamente (Teixeira et al., 1994; Rodrigues et al., 2006), e associado ao sofrimento e punição divina (Attanasio, 1991; Rodrigues et al., 2006).

Black em 1886 realizou uma das primeiras anotações sobre o ranger de dentes. Comentou que "a abrasão dos dentes tende a remover rapidamente as cúspides dentais” (Vaughn, 2009). Marie Pietkiewicz ${ }^{1}$ (1907) apud Bader e Lavigne 2000 utilizou o termo "bruxomanie", apertamento, fricção ou atrito dos dentes sem finalidade funcional, para indicar a presença do bruxismo de uma forma geral. A introdução do verbete na literatura francesa em 1901 ocorreu com a descrição de casos de ranger de dentes durante o dia. O bruxismo designado como "bruxomania", sugere o hábito de ranger e apertar os dentes durante o dia (BD). Já o vocábulo "bruxismo" ficou com o significado de um hábito de ranger e apertar os dentes que ocorre durante o sono (BS). No entanto, não há fator que impeça a presença dos dois tipos de bruxismo (Seraidarian et al., 2001). Em 1931, Frohman observou uma

\footnotetext{
${ }^{1}$ Pietkiewicz M. La bruxomanie: memoires originaux. Rev Stomatol. 1907;14:107-16.
} 
relação entre problemas odontológicos e formas psicológicas de tratamento. Também utilizou o termo "bruxismo" para descrever "um comportamento oral disfuncional de caráter psicológico" (Molina et al., 2006). Assim o "bruxismo" ficou conhecido como o hábito de atritar os dentes de forma repetitiva (Vaughn, 2009), sem finalidade fisiológica e frequentemente inconsciente (Okeson, 1992).

O bruxismo do sono BS, atividade motora orofacial, é considerado uma parafunção para a Odontologia e uma parassonia na Medicina do Sono (Kato et al., 2003a).

Assim a atividade dos músculos da mastigação pode ocorrer de forma fisiológica, isto é funcional, como na mastigação, deglutição e fonação, ou de maneira não funcional, como no hábito parafuncional bruxismo (Attanasio, 1991; Zuanon et al., 1999; Rodrigues et al., 2006).

Esta parafunção é caracterizada pelo contato não funcional dos dentes, com a oclusão dos dentes de maneira estática ou dinâmica, e que pode ocorrer de forma consciente ou inconsciente (Okeson, 1992). Manifesta-se pelo ranger de dentes, pelo apertamento dental, ou uma combinação de ambos, preferencialmente durante o sono (Teixeira et al., 1994; Rodrigues et al., 2006). Podem-se somar a ele outros hábitos bucais como o roer de unhas (onicofagia); a mordedura de objetos, lábios e/ou bochechas; chupar dedo, entre outros.

O Bruxismo pode levar a uma redução significativa da coroa dental pelo desgaste dental (Attanasio, 1997; Holt et al., 2000; Chapotat et al., 2001; Davies et al., 2002; Inocente, 2002; Carlsson et al., 2003; Yip, 2003; Bernhardt et al., 2004; Rodrigues et al., 2006; Cuccia, 2008; de La Hoz-Aizpurua et al., 2011); fraturas de dentes e/ou restaurações (Rodrigues et al., 2006; de La Hoz-Aizpurua et al., 2011); produção de sons de ranger de dentes (ASDA, 1990; Dworkin; Le Resched, 1992; Kampe et al., 1997b; Bader, Lavigne, 2000; Lavigne et al. 2001a; Lavigne et al., 2003; Winocur et al., 2003; AASM, 2005; Van Der Zaag et al., 2005; Saletu et al., 2005; Van Der Zaag et al., 2007; Cuccia, 2008; Macedo, 2008; Lavigne et al., 2008; Pomponio, 2010; Sutin et al., 2010; de La Hoz-Aizpurua et al., 2011); hipersensibilidade dental (Inocente, 2002; de La Hoz-Aizpurua et al., 2011); recessão gengival (de La Hoz-Aizpurua et al., 2011); inflamação gengival, perda de osso alveolar (Inocente, 2002; Rodrigues et al., 2006); mobilidade dental (Inocente, 
2002; de La Hoz-Aizpurua et al., 2011); presença de tórus maxilar e/ou mandibular (de La Hoz-Aizpurua et al., 2011); desconforto mastigatório e/ou sintomatologia dolorosa da musculatura mastigatória, mialgias (Gavish et al., 2000; Ciancaglini et al., 2001; Inocente, 2002; de La Hoz-Aizpurua et al., 2011); hipertrofia dos músculos mastigatórios; dores faciais (Manfredine et al., 2003); limitação da abertura da boca, trismo mandibular (Ciancaglini et al., 2001; Inocente, 2002; de La Hoz-Aizpurua et al., 2011); dificuldades na mastigação de alimentos duros (Inocente, 2002); fadiga muscular (Ciancaglini et al., 2001; Inocente, 2002; Rodrigues et al., 2006); zumbidos no ouvido (Inocente, 2002); otalgias reflexas (Inocente, 2002); estalos, ruídos na ATM (Gavish et al., 2000; Ciancaglini et al., 2001; Inocente, 2002); desordens temporomandibulares, DTM (Okeson, 1992; Vanderas, 1995; Attanasio, 1997; Goulet et al., 1998; Gavish et al., 2000; Inocente, 2002; Manfredine et al., 2003); dores na ATM (de La Hoz-Aizpurua et al., 2011); cefaleias, dores de cabeça (Inocente, 2002; Rodrigues et al., 2006; de La Hoz-Aizpurua et al., 2011); cervicalgias (Ciancaglini et al., 2001; Inocente, 2002; de La Hoz-Aizpurua et al., 2011); hipertonia do músculo masseter (de La Hoz-Aizpurua et al., 2011); diminuição do fluxo salivar (de La Hoz-Aizpurua et al., 2011); endentações na língua (de La Hoz-Aizpurua, 2011); linha Alba na mucosa jugal (de La Hoz-Aizpurua et al., 2011); pobre qualidade do sono (Pereira et al., 2006; Müller; Guimarães, 2007; de La HozAizpurua et al., 2011); aumento da atividade muscular (de La Hoz-Aizpurua et al., 2011); cansaço (de La Hoz-Aizpurua et al., 2011), além de sintomas emocionais como alto grau de ansiedade, estresse e depressão (Inocente, 2002).

Como o bruxismo pode causar perturbações no sono e consequentes alterações no funcionamento físico, ocupacional, cognitivo e social, pode também influenciar substancialmente a qualidade de vida do indivíduo (Pereira et al., 2006; Müller; Guimarães, 2007).

O Bruxismo pode ser dividido em Bruxismo Diurno e Bruxismo Noturno ou Bruxismo do Sono, tendo cada qual etiologias distintas (Okeson, 1992). A atividade parafuncional diurna consiste em apertar os dentes, e parece estar relacionada à concentração mental ou atividades que requeiram extremo esforço físico (Lavigne et al., 2008). De maneira isolada e/ou concomitante pode ocorrer outros hábitos bucais, realizados sem que o indivíduo tenha consciência deles, como morder a 
língua/bochecha, chupar dedos, morder objetos como canetas, lápis (Okenson, 1989).

Segundo a Classificação Internacional dos Distúrbios do Sono (ICSD), International Classification of Sleep Disorders (AASM, 2005), o bruxismo do sono é definido como uma parassonia, uma atividade oromotora caracterizada por uma desordem de movimentos esteriotipados que deflagram o ranger e/ou apertar de dentes durante o sono. Habitualmente o bruxixmo está associado com microexcitações (microdespertares) e geralmente está acompanhado por sons (de La Hoz-Aizpurua et al., 2011).

Tem-se discutido o papel de diferentes fatores etiológicos para o Bruxismo. Um de ordem periférica, como as desarmonias oclusais, e outro de ordem central (Lobbezoo; Naeije, 2001; Kato et al., 2003a; Ahlberg et al., 2004), como as desordens no sistema dopaminérgico (Chen et al., 2005; Saletu et al., 2005) e o estresse (Haddad et al., 1994; Kampe et al., 1997a; Goulet et al., 1998; Inocente, 2002; Ahlberg et al., 2004).

Em razão de sua multifatoriedade e dificuldade de compreensão, o bruxismo não tem seus fatores etiológicos totalmente elucidados e, portanto, as alternativas terapêuticas são voltadas à prevenção dos efeitos patológicos que afetam o sistema estomatognático e atenuação dos efeitos deletérios deste hábito (de La HozAizpurua et al., 2011). Também parece haver um efeito genético na variação do fenótipo nas parassonias, sonambulismo, terror noturno, enurese, pesadelos e bruxismo (Hublin; Kaprio, 2003). 


\section{REVISÃO DA LITERATURA}

\subsection{Conceitos}

Para Okeson (1992) o bruxismo é uma atividade parafuncional do sistema mastigatório que inclui apertar ou ranger os dentes, em que ocorrem contrações rítmicas musculares (Lavigne et al., 2003), sendo mais frequente durante o sono, também chamado de bruxismo excêntrico noturno. Esta atividade parafuncional ocorre quase que inteiramente em nível subconsciente, enquanto os mecanismos de proteção neuromuscular estão ausentes (Okeson, 1992), o que pode acarretar danos ao sistema mastigatório e desordens temporomandibulares (Okeson, 1989; Haddad et al., 1994; Vanderas, 1995; Shinkai et al., 1998; Lavigne et al., 2003).

A American Academy of Sleep Medicine (AASM, 2005), definiu o bruxismo como um distúrbio de movimento caracterizado pelo apertamento e/ou ranger dos dentes durante o sono (Lavigne et al., 2003), seguido de desgaste dentário, ruídos e desconforto nos músculos mastigatórios [American Sleep Disorders Association (ASDA) 1990].

Segundo a American Sleep Disorders Association (ASDA) 1990, o bruxismo do sono é uma atividade oral caracterizada pelo ranger ou apertar de dentes durante o sono que, geralmente, está associada com microdespertares cuja duração é de 3 a 15 segundos.

No bruxismo o contato não funcional pode ocorrer de forma consciente ou inconsciente (Lavigne et al., 2003; Miyawaki et al., 2003; Pergamalian et al., 2003; AASM, 2005). Portanto, o bruxismo não é uma doença (Machado et al., 2011), mas quando exacerbado pode ocasionar desequilíbrio e alteração das estruturas orofaciais e desequilíbrio fisiopatológico do sistema estomatognático (AASM, 2005; Machado et al., 2011).

O bruxismo é definido pela American Academy of Orofacial Pain (1996), como uma atividade parafuncional diurna ou noturna caracterizada pelo hábito de apertar 
(cerrar os dentes), e o ranger dental. Mesmo que o individuo desconheça a presença do bruxismo, o mesmo pode ser detectado pela presença de facetas de desgaste que não são decorrentes da função mastigatória (Lobbezoo; Naeije, 2001; Pomponio, 2010).

De acordo com a Classificação Internacional de Doenças, o bruxismo está inserido no capitulo de "Desordens Mentais e Comportamentais". Isto sugere que variáveis psicossociais e de estresse desempenham um papel preponderante em sua patogênese (Saletu et al., 2005).

O bruxismo abrange duas entidades distintas, com diferentes patogêneses de difícil distinção clínica, e pode ser classificado em bruxismo de vigília (BD), e bruxismo durante o sono (BS) (Bader; Lavigne, 2000). A maioria da população, em algum momento de sua vida range ou aperta seus dentes, muitas vezes desconhecendo este hábito (Rodrigues et al., 2006). Estes distintos estados de consciência, vigília e sono, apresentam diferentes estados fisiológicos, com diferentes influências na excitabilidade oral motora (Bader; Lavigne, 2000; Kato et al., 2003a; Macedo, 2008). Também fica caracterizado o BD quando se mordem lápis, objetos ou dedos. O apertamento em geral não produz ruídos, é mais comum durante o dia e pode ser mais destrutivo, uma vez que as forças desenvolvidas são contínuas e menos toleradas (Shinkai et al., 1998). O ato de ranger dental ocorre frequentemente durante o sono (BS), em períodos de preocupação, estresse e excitação, e pode ser acompanhado por um ruído característico (Bader; Lavigne, 2000).

Lavigne et al. (2008), definiram o bruxismo diurno como o hábito de realizar o apertamento da mandíbula enquanto consciente, que pode estar associado a "tics nervosos", hábitos e reações a estímulos ou estresse. Algumas vezes também pode ocorrer ranger de dentes concorrentes ao apertamento, no BD (Lavigne et al., 2003). Geralmente o BD não deixa sequelas de desgaste dental, mas pode ser decorrente de hábitos perniciosos como morder objetos, chupar dedos, morder língua e bochechas (Alóe et al,. 2003; Silva; Cantisano, 2009). Por estar consciente, o sujeito pode apresentar maior controle sobre suas emoções e consequentemente sobre 0 BD (Lavigne et al., 2003; Carra et al., 2011). 
O bruxismo do sono é uma atividade involuntária da musculatura mandibular, inconsciente e caracterizado pelo ranger ou apertar dos dentes, geralmente produzindo sons, e pode ocorrer durante o sono diurno ou noturno (ASDA, 1990; Kampe et al., 1997b; Bader, Lavigne, 2000; Lavigne et al. 2001a; Lavigne et al., 2003; AASM, 2005; 2005; Saletu et al., 2005; Macedo, 2008).

Este distúrbio de movimento estereotipado torna-se patológico quando provoca severo desgaste dental e/ou sono não restaurador (Bader; Lavigne, 2000). Nos episódios de BS ocorrem contrações rítmicas musculares, em que há apertamento com deslizamento da mandíbula no sentido lateral ou transversal (Alóe et al., 2003; Silva; Cantisano, 2009).

Wolf (2000) considera o bruxismo (apertamento e atrição) uma resposta de escape, porque a cavidade bucal possui um grande potencial afetivo e é um local privilegiado para a expressão dos impulsos reprimidos, de emoções e de conflitos latentes. Por não conseguirem obter a satisfação de seus desejos e necessidades importantes, alguns indivíduos utilizam o rangimento e o apertamento dos dentes como um mecanismo compensador ou como uma resposta de autoagressão. Esse hábito manifesta-se de forma mais acentuada durante o sono, quando as defesas estão relaxadas.

Existem três tipos de hábitos parafuncionais orais segundo WigdorowiczMakowerowa et al. (1979): os que realizam contato entre dentes e corpo estranho (ato de morder lápis, caneta, cachimbo); o de contato entre dentes e membrana mucosa (ato de morder lábio, bochechas); e o de contato entre dentes (fora das funções de mastigação ou deglutição), quando recebem a denominação de bruxismo.

\subsection{Classificações do Bruxismo}

O bruxismo pode ser classificado como bruxismo de vigília (BD) e bruxismo do sono (BS) (Lavigne et al., 2003; Macedo, 2008). Também pode ser classificado como primário ou secundário. O bruxismo primário tem origem idiopática, e não está 
relacionado a nenhum fator clínico ou psiquiátrico. O bruxismo primário parece ser um distúrbio crônico persistente, que pode evoluir da infância ou adolescência para a idade adulta. $\mathrm{O}$ bruxismo secundário geralmente está associado com transtornos clínicos podendo ocorrer frente a distúrbios neurológicos ou psiquiátricos (depressão, doença de Parkinson, esquizofrenia); assim como estar associado ao uso de medicamentos e/ou drogas, como os antidepressivos, inibidores da recaptação da serotonina, neurolépticos e as anfetaminas (Bader; Lavigne, 2000; Huynh et al., 2007; Macedo, 2008).

O bruxismo pode ser classificado como cêntrico, quando ocorrem movimentos isométricos, isto é, apertamento maxilo-mandibular, geralmente durante o sono, em posição de relação cêntrica ou em máxima intercuspidação habitual sem que ocorra deslizamento. O bruxismo excêntrico é caracterizado pelo movimento isotônico (rangimento), onde há apertamento e deslizamento dos dentes nas posições protrusivas e latero-protrusivas em que podem ocorrer desgastes tanto nos dentes anteriores como em posteriores. O bruxismo também pode ser classificado como crônico, quando há uma adequação funcional e biológica do organismo, e em agudo quando o processo se torna agressivo e ultrapassa a capacidade biológica de adaptação e defesa do sistema, o que pode originar sinais clínicos (Teixeira et al., 1994; Rodrigues et al., 2006; Silva; Cantisano, 2009).

\subsection{Etiologia}

A historia natural do BS é pouco conhecida. Porém, existe um consenso sobre a natureza multifatorial na etiologia do bruxismo (Lobbezoo; Lavigne, 1997; Gusson, 1998; AASM, 2005; Diniz et al., 2009), em que se diferenciam os fatores periféricos, também denominados morfológicos, e os fatores de ordem central, como os patofisiológicos e os psicológicos (Lobbezoo; Naeije, 2001). Fatores neuroquímicos, o sistema nervoso autônomo e excitações do sono (Miyawaki et al., 2003; Lavigne et al., 2003), também podem estar envolvidos na gênese do BS. São considerados fatores periféricos (morfológicos), as discrepâncias oclusais e a anatomia das estruturas ósseas da região orofacial assim como os excessos de 
material restaurador, maloclusões, traumatismos oclusais, contatos prematuros, interferências oclusais, reabsorção radicular, discrepâncias oclusais, presença de cálculo dental, cistos dentígeros, e tensão muscular (Diniz et al., 2009). Alguns autores observaram que a presença de maloclusão não aumentou a probabilidade de desenvolvimento do bruxismo principalmente durante a infância (Petit et al., 2007; Diniz et al., 2009), e que a anatomia das estruturas ósseas da região orofacial desempenham apenas um papel menor como condição do seu desencadeamento (Vanderas, 1995; Gusson, 1998; Shinkai et al.. 1998; Petit et al., 2007; Diniz et al., 2009). Assim, a literatura científica tem demonstrado que estes fatores morfológicos/periféricos possuem pouco ou nenhum papel na etiologia do bruxismo (Kato et al., 2003a).

Feinstein em 1970 adotou o termo comorbidade no sentido de indicar uma associação entre duas doenças em estudos clínicos. O conceito evoluiu e em 1994, Lipton e Silberstein (1994) agregaram o sentido de uma associação mais do que coincidente entre duas doenças. A comorbidade pode ser patogênica, quando duas ou mais doenças estão etiologicamente relacionadas; diagnóstica quando manifestações da doença associada simulam as da doença índex, e prognóstica quando alguma doença predispõe ao desenvolvimento de outra doença (Marques et al., 1994).

Também são consideradas na gênese do bruxismo as condições de favorecimento sistêmico, ou seja, comorbidades como: asma/rinite, distúrbios do SNC, deficiências nutricionais e vitamínicas, alergias, parasitoses intestinais, desordens endócrinas, distúrbios otorrinolaringológicos, distúrbios gastrintestinais, paralisia cerebral, Síndrome de Down e deficiência mental (Vanderas, 1995; Gusson, 1998; Shinkai et al., 1998; Diniz et al., 2009). Entretanto, Ferreira e Toledo em 1997 observaram que quanto mais prolongado o aleitamento materno, menor a ocorrência de hábitos orais nocivos, como o bruxismo. Condições psicológicas como estresse e ansiedade (Vanderas, 1995; Gusson, 1998; Shinkai et al., 1998); fatores ocupacionais (prática de esportes de competição) e fatores hereditários (Vanderas, 1995; Gusson, 1998; Shinkai et al., 1998; Diniz et al., 2009). A utilização de cafeína, o tabagismo e o consumo de bebidas alcoólicas (Lavigne et al., 2008), drogas, trauma (Cuccia, 2008), parecem ter um papel importante na gênese do BS. O 
consumo de bebidas xânticas (café, chá, chocolate, refrigerante tipo cola), anfetaminas, álcool e tabaco podem estar envolvidos, uma vez que, estimulando o sistema nervoso central (SNC), aumentam a ansiedade e o estresse (Alóe et al., 2003; Silva; Cantisano, 2009). Também o BS parece ser uma perturbação no sistema dopaminérgico (Diniz et al., 2009). O bruxismo pode estar associado a distúrbios do sono, ou seja, a parassonias, que são fenômenos que ocorrem exclusivamente durante o sono, e estão associados a diferentes graus de excitação como sono agitado, enurese noturna e falar dormindo (Gusson, 1998; Diniz et al., 2009). Correlações entre maloclusão e bruxismo parecem ser inconsistentes. Já os distúrbios neurológicos, como autismo e a paralisia cerebral, são indicados como fatores de risco (Shinkai et al., 1998). Moduladores exógenos como a depressão, ansiedade, o estresse emocional, as influencias ambientais (hábitos), interferências oclusais, medicações (L-dopa, neurolépticos, anfetaminas, inibidores seletivos da recaptação da serotonina), drogas (álcool e cocaína) (Van Der Zaag et al., 2005; Huynh et al., 2007) desempenham um importante papel na iniciação, perpetuação, tratamento, frequência, duração e severidade do bruxismo (Rugh; Harlan, 1988).

Quanto aos fatores patofisiológicos, o bruxismo parece fazer parte de uma resposta de despertar do sono e vem sendo considerado uma atividade oromotora secundária ao microdespertar (Kato et al., 2001). Na somatória de todas as evidências, o bruxismo parece ser principalmente regulado centralmente e não perifericamente.

Bader e Lavigne (2000) relataram que a etiofisiopatologia do bruxismo ainda é incerta, porém frequentemente está associado a interferências oclusais; fatores psicológicos e ambientais; disfunções dos transmissores cerebrais. No delineamento dos traços de personalidade dos bruxômanos, aparece maior vulnerabilidade ao estresse e ansiedade, embora ainda haja controvérsias.

De Boever e Carlsson (2000) acreditam que três tipos de fatores estão envolvidos na etiologia do Bruxismo. A oclusão e a ATM corresponderiam aos fatores anatômicos além dos fatores neuromusculares e dos psicogênicos. Segundo os autores, caso dois ou três destes grupos estiverem presentes, os riscos de que se desenvolva dor e disfunção estarão aumentados. 
Sári e Sonmez (2001) realizaram um estudo com o objetivo de investigar a relação entre fatores oclusais (sobremordida, mordida profunda, classificação de Angle de molares e caninos, a relação dos molares decíduos, mordida aberta anterior/posterior, mordida cruzada) e o bruxismo nas dentições permanente e mista em crianças. Foram incluídas no estudo 182 crianças turcas com dentição mista e 212 crianças com dentição permanente. O bruxismo foi avaliado por meio de entrevistas e questionários. Os autores verificaram que nas dentições decídua e permanente, alguns fatores oclusais estiveram relacionados com o bruxismo, são eles: overjet $>6 \mathrm{~mm}$ (sobressaliência), overbite $>5 \mathrm{~mm}$ (sobremordida), overjet negativo, mordida aberta na dentição permanente; vários dentes com mordida cruzada (plano anteroposterior), maloclusão Classe I de Angle na dentição mista.

Em revisão da literatura Lobbezoo e Naeije (2001) designaram o Bruxismo como um fenômeno controverso com etiologia multifatorial, complexa e de difícil interpretação e comprovação. Subdividiram os fatores etiológicos em fatores de origem periférica (morfológicos) e de origem central (fisiopatológicos e psicológicos). Afirmaram acreditar que as interferências oclusais, as desarmonias articulares, desarmonias anatômicas, e a mutilação da oclusão (origem periférica), desempenham papel muito pequeno na etiologia do bruxismo. Fatores como: distúrbios do sono; alterações químicas cerebrais; alguns medicamentos; drogas; tabagismo; álcool; a ansiedade e o estresse, distúrbios do sono e fatores genéticos têm demonstrado papel importante na iniciação e perpetuação do bruxismo. Os autores concluíram que o bruxismo deve ser mediado por fatores de origem central, isto é, fatores fisiopatológicos e psicológicos.

Para Inocente (2002), o bruxismo é um mecanismo indispensável na liberação do estresse no qual o sistema mastigatório entra em ação em situações de angústia, a taxa de adrenalina aumenta o nível de ansiedade correlata à atividade noturna dos músculos masseteres. Quando exacerbado, o bruxismo pode desencadear sinais e sintomas da disfunção temporomandibular e acometer as estruturas do sistema estomatognático como: músculos, dentes, periodonto e articulação temporomandibular. Os sintomas biológicos mais frequentes são: hipersensibilidade, desgaste dental, mobilidade dental, comprometimento gengival, mialgias mastigatórias; mímica facial com limitação da abertura da boca, trismo mandibular 
pela manhã, dificuldades na mastigação de alimentos duros, fadiga muscular, algias, zumbidos no ouvido, otalgias reflexas, estalos, ruídos na ATM, cefaleias e cervicalgias; sintomas emocionais como alto grau de ansiedade, estresse e depressão.

Kato et al. (2003a) revisaram a literatura com o objetivo de entender os possíveis mecanismos envolvidos na gênese do bruxismo do sono. Relataram que influências periféricas podem estar envolvidas na regulação sono-vigília e na gênese dos movimentos rítmicos da mandíbula. Vários estudos com animais e humanos indicam que durante a vigília ou a anestesia, receptores orofaciais sensoriais (no periodonto, mucosa, e músculo) podem influenciar a atividade da musculatura mandibular. Durante o sono, a mandíbula está normalmente aberta devido à supressão da atividade motora. O contato dental parece ocorrer de forma associada com a estimulação do sono. Recentes evidências fisiológicas apoiam uma associação entre as excitações do sono e SB. Alterações sequenciais desde autônomas cardíacas e atividades na cortical cerebral precedem a atividade motora da mandíbula no bruxismo do sono. Isto sugere que o sistema nervoso central e/ou autônomo, ao invés de fatores sensoriais periféricos tenha um papel dominante na gênese do SB. Porém, alguns fatores sensoriais periféricos podem exercer uma influência no bruxismo noturno pela interação com os mecanismos sono-vigília.

Demir et al. (2004), realizaram um estudo com o objetivo de investigar a relação entre fatores oclusais e o bruxismo entre 965 indivíduos turcos (472 meninos e 493 meninas) com idade média de 12,8 anos (7 - 19 anos), e identificar possíveis diferenças sexuais. A amostra foi dividida em grupo de bruxômanos e não bruxômanos, com diagnóstico baseado em exame clínico e auto-relato. Foram registrados: a classificação de Angle de molares (bilateralmente), a severidade de apinhamento anterior, a ocorrência de mordida cruzada anterior e posterior, a presença de mordida aberta e profunda, alterações funcionais e, excessiva sobressaliência. Frente aos resultados ficou demonstrado que o bruxismo foi diagnosticado em $12,6 \%$ dos sujeitos. A avaliação dos dados não indicou uma relação estatisticamente significativa entre bruxismo e fatores oclusais. Não houve diferenças entre os sexos relacionados a fatores oclusais e bruxismo. A prevalência de bruxismo em meninos e meninas foi semelhante, sem que houvesse diferenças 
estatisticamente significantes. Concluíram que nenhum dos fatores oclusais parece influenciar o desenvolvimento de bruxismo.

De acordo com Petit et al. (2007), forte tensão emocional, problemas familiares, crises existenciais, estados de ansiedade, depressão, medo e hostilidade, crianças em fase de autoafirmação, provas escolares ou mesmo a prática de esportes competitivos e campeonatos podem atuar como fatores de origem psicológica e ocupacional para o desencadeamento do bruxismo.

Um estudo sobre a predisposição genética confirmou que pais que possuíam o hábito na infância frequentemente apresentavam filhos com apertamento ou rangimento, portanto, mais suscetíveis ao hábito. Esta condição pode sugerir uma predisposição hereditária, no entanto seu modo de transmissão ainda é desconhecido (Diniz et al., 2009).

Assim no bruxismo do sono, os fatores oclusais vêm perdendo força e evidência como seus agentes etiológicos. Recentes pesquisas sugerem que o BS é um comportamento secundário e está relacionado com micro-despertares (definidos por um aumento da atividade cardíaca autonômica e respiratória, que tende a se repetir de 8-14 vezes por hora de sono). Ainda estão sob investigação o papel da hereditariedade (genética) e dos fatores de resistência das vias aéreas superiores na gênese da atividade rítmica muscular mastigatória (ARMM) e do bruxismo do sono (Lavigne et al., 2008).

\subsection{Prevalência}

Embora a prevalência do bruxismo na população em geral seja difícil de ser estabelecida, segundo Kampe et al. (1997b), 80\% a 90\% da população apresentam atividades parafuncionais, e muitos indivíduos rangem e/ou apertam os dentes sem que estejam cientes desta parafunção. Assim, literatura é controversa, pois Attanasio (1997) apresenta valores que variam de $6 \%$ a $90 \%$, assim como Hublin et al. (1998), afirmaram que o ranger de dentes durante o sono é comum em cerca de $85 \%$ a $90 \%$ das pessoas, e que estes episódios ocorrem durante algum período de 
suas vidas. Lobbezoo e Naeije (2001) afirmam que segundo a American Academy of Orofacial Pain (1996), o bruxismo compromete aproximadamente $6 \%$ a $20 \%$ da população. Bader e Lavigne (2000) relatam que entre $5 \%$ a $20 \%$ dos pacientes com bruxismo noturno tem consciência dos episódios de ranger de dentes, e que pelo menos uma vez na vida de $85 \%$ a $90 \%$ da população apresentarão episódios de bruxismo, sendo a prevalência é estimada para a população adulta de $5 \%$ a $8 \%$. Para diversos autores o bruxismo do sono (BS) ocorre em cerca de $8 \%$ da população (Ohayon; LI; Guilleminault, 2001; Lavigne et al., 2003; Miyawaki et al., 2003; Huynh et al., 2007; Lavigne et al., 2008). Estas afirmações conflitantes podem estar relacionadas à falta de homogeneidade entre as amostras utilizadas nos estudos, aos diferentes critérios de definição do bruxismo e ao emprego de diferentes metodologias para sua identificação. Ainda há deficiência na padronização dos critérios e meios de diagnóstico utilizados na avaliação do bruxismo (Attanasio, 1997). Diferentes metodologias como, entrevista, questionário, exame clínico ou combinação de métodos, e faixas etárias abrangidas podem dificultar a comparação entre os dados entre pesquisas (Vanderas, 1995; Shinkai et al., 1998).

O bruxismo em vigília (BD) tem prevalência estimada em cerca de $20 \%$, na população em geral. É relatado que o bruxismo em crianças até 11 anos tem prevalência de $14 \%$ a $20 \%$, decresce para $13 \%$ em adultos jovens (18-29 anos), em adultos acomete $9 \%$ e em pessoas com mais de 65 anos, atinge o patamar de $3 \%$ (Lavigne et al., 2001a; Lavigne et al., 2003; AASM, 2005; Huynh et al., 2007; Sutin et al., 2010).

Garcia et al. (1995) relataram uma prevalência de $40 \%$ de bruxismo em préescolares de 3 - 6 anos de idade, $17 \%$ na faixa de seis a sete anos e $24 \%$ na faixa dos oito aos nove anos. O bruxismo esteve presente em $40 \%$ das crianças examinadas, sendo que destas, $60 \%$ apresentavam o hábito de ranger os dentes, $8 \%$ apenas apertavam e $32 \%$ rangiam e apertavam os dentes simultaneamente. Em bebês, o bruxismo pode ser observado logo após a erupção dos incisivos decíduos por volta de um ano de idade.

Shinkai et al. (1998), afirmaram que existe uma grande variação de prevalência de bruxismo infantil na literatura $(5 \%$ a $81 \%)$ fato que dificulta 0 
estabelecimento de parâmetros comparativos. Assim, realizaram um levantamento epidemiológico exploratório com o objetivo de determinar a prevalência do bruxismo excêntrico noturno em crianças de 2 a 11 anos de idade, e entre outros, verificar a presença de outros hábitos bucais parafuncionais tais como: sugar o dedo/chupeta/lábio; morder lábio/objetos; roer unhas e outros. Relataram que o bruxismo pode ser relacionado com níveis de desgaste da superfície dentária e com desconfortos musculares e articulares, e que devido às forças não axiais geradas nos dentes, o bruxismo excêntrico pode atua como coadjuvante na progressão da doença periodontal destrutiva em crianças. O Bruxismo pode também contribuir para o desenvolvimento de falsas "Classe III", acelerar a rizólise de dentes decíduos, provocar alterações na cronologia de erupção dos permanentes, e favorecer o desenvolvimento de apinhamentos dentais. Observaram alta prevalência do bruxismo em crianças: $43 \%$ entre crianças com idade de dois a três anos, $35 \%$ entre quatro e cinco anos e $34 \%$ entre dez e 11 anos de idade. Frentes aos dados os autores concluíram que, o bruxismo não pôde ser correlacionado às variáveis: sexo, presença de outros hábitos bucais parafuncionais, grau de maloclusão, e também, que a maioria das crianças bruxômanas apresenta comportamento do tipo ansioso ou hiperativo.

Um dos mais representativos estudos realizado em larga escala epidemiológica para o bruxismo foi conduzido por inquérito via telefone. Ohayon et al. (2001) verificaram a prevalência e os fatores de risco associados ao bruxismo do sono avaliando-o em relação às variáveis: dados sociodemográficos; outras variáveis do sono [horário sono/vigília, ronco, sonilóquio (fala durante o sono), narcolepsia (sonolência diurna)]; uso de substâncias psicoativas e variáveis psicológicas ou psiquiátricas. Os autores entrevistaram por telefone 13.057 indivíduos de 15 a 100 de idade, nos países: Reino Unido, 4.972 pessoas; Alemanha, 4.115 pessoas e Itália, 3970 pessoas. Utilizaram os critérios da ASDA para a presença do Bruxismo: a) ocorrência de ranger dental durante o sono; b) ocorrência de pelo menos um dos sinais: desgaste anormal dos dentes, sons associados ao ranger de dentes, desconforto nos músculos mandibulares. Os resultados demonstraram diagnóstico de bruxismo para 1.059 indivíduos, com uma prevalência de $8.2 \%$ da amostra. Destes bruxistas, 568 indivíduos preencheram os critérios da ASDA, enquanto 491 indivíduos, ou seja, 3,8\% da amostra 
apresentavam ranger de dentes durante o sono, porém sem a presença de outros fatores associados. Muitos bruxômanos não têm consciência de que são acometidos por este hábito, realizam-no de forma inconsciente, portanto, estes resultados podem estar subestimados, uma vez que foram obtidos pelo autorrelato do ranger de dentes. Os autores concluíram que o Bruxismo é comum na população em geral, diminui com a idade, e sua maior prevalência ocorre entre os 19 e 44 anos.

Petit et al. (2007), realizaram um estudo para determinar a prevalência de dissonias e parassonias na primeira infância e descrever sua evolução temporal. Em relação ao bruxismo, a prevalência detectada no período estudado, compreendido entre as idades de 2,5 e seis anos, foi de $45,6 \%$ e a mesma aumentou significativamente com a idade. Relataram que a parafunção noturna persistente se relacionava à permanência dos pais junto aos filhos até que adormecessem. Os autores não notaram diferença estatisticamente significante quanto à prevalência entre os sexos.

\subsection{Sinais, Sintomas e Complicações}

A maioria dos estudos sugere que o bruxismo afeta uma grande parcela da população e que suas consequências podem ser altamente destrutivas para alguns indivíduos (Rugh; Harlan, 1988). Entretanto, ainda é preciso esclarecer quando o bruxismo, como comportamento em uma população saudável, torna-se uma desordem, que associa consequências como danos dentais, dores e, possivelmente, conflitos sociais (Lavigne et al., 2008).

A American Academy of Sleep Medicine (2005), admite que haja uma grande variação na intensidade e duração do bruxismo, porém é típico ocorrer 100 episódios durante a noite que podem produzir micro-despertares do sono. Tanto crianças quanto adultos são afetadas pelo bruxismo, sendo que mais de $50 \%$ das crianças normais apresentam bruxismo, cujo início pode se dar na faixa etária dos 10.5 meses, quando da erupção dos incisivos decíduos. No adulto pode ter início entre os 10 e 20 anos. 
Relatado por Diniz et al. (2009) a instalação do bruxismo pode ser precoce. Em bebês pode ser observado logo após a erupção dos incisivos decíduos por volta de um ano de idade. Segundo Gusson (1998), na criança o bruxismo pode se desenvolver após a erupção dos incisivos centrais decíduos, e eventualmente ocasionar dilacerações gengivais nos casos em que os antagonistas ainda não erupcionaram. Também é possível detectar a presença de facetas de desgaste nas superfícies dentais, desconforto muscular e articular, que podem induzir à instalação da doença periodontal destrutiva e contribuir para o desenvolvimento de uma falsa Classe III, além de acelerar a rizólise de dentes decíduos e provocar alterações na cronologia de erupção dos dentes permanentes.

O sinal clínico mais evidente nesta parafunção consiste nas facetas de desgaste das superfícies incisais dos dentes anteriores e oclusais dos posteriores. A perda de superfície dentária pode ser fisiológica e ocorrer como uma consequência natural do avanço da idade. No entanto, vários fatores incluindo a abrasão, erosão, atrição, e mesmo as abfrações (lesões por estresse), podem culminar com a perda patológica de superfície dental, caracterizadas pelas lesões dentais não cariosas (Davies et al., 2002). Portanto, é importante diferenciar o padrão de desgastes, na realização do diagnóstico do bruxismo.

A erosão é decorrente de um processo químico, em que estão inclusas bebidas, tais como sucos de frutas frescas, refrigerantes, licores e bebidas alcoólicas, além de alguns alimentos e processos industriais. O fator intrínseco é representado pelo refluxo gastro-esofágico, pelos transtornos alimentares, como a bulimia, entre outros. No processo de abrasão há a atuação de agentes externos que produzam efeito abrasivo sobre os dentes. Incluem-se as cerdas das escovas dentais, os alimentos abrasivos, além de outros fatores da dieta (Davies et al. (2002).

A atrição é o processo pelo qual o tecido dental é removido como resultado do contato entre superfícies de dentes antagônicos, durante a função mastigatória ou frente à parafunção. Este desgaste pode ser significante em pacientes com dieta baseada em alimentos não industrializados e com maior poder de abrasão. Porém, a causa mais comum de efeitos deletérios da atrição são as atividades parafuncionais, como o bruxismo (Davies et al., 2002; Gimenes, 2008). 
As abfrações, caracterizadas como lesões de esforço ou estresse, surgem em decorrência da atuação de forças excêntricas sobre a dentição. Fadiga, flexão e deformação são proporcionadas através de carga biomecânica incidente na estrutura dental, principalmente na região cervical. Uma força de flexão sobre a cúspide resulta em estresse na porção do fulcro cervical, o que resulta em perda de estrutura dental. A lesão decorrente, geralmente tem formato de cunha, com ângulos nítidos. Também pode ocorrer abfração oclusal, apresentadas como invaginações circulares. A magnitude da perda tecidual depende do tamanho, da duração, direção, frequência e localização da força aplicada (Davies et al., 2002).

A magnitude das forças oclusais geradas pelo BD e BS resulta em cargas adicionais sobre a dentição, o osso alveolar, o periodonto e a articulação temporomandibular. O contato forçado entre as superfícies oclusais dentais durante os movimentos mandibulares pode causar o rangimento e possível emissão de sons desagradáveis ao companheiro de sono (Pizzol et al., 2006).

Dentre as queixas mais comuns dos pacientes bruxômanos, estão inclusas as dores crônicas faciais, de cabeça, pescoço, e ouvido (Pergamalian et al., 2003; Van Der Zaag et al., 2005; Camparis; Siqueira, 2006), além de dores e distúrbios na articulação temporomandibular (ATM) (Attanasio, 1997; Diniz et al., 2009). Também pode ocorrer pulpites, odontalgias, cálculos pulpares, fraturas radiculares, fraturas parciais de coroas, migração de dentes e ainda perda de substância dentária na interface esmalte-cemento, caracterizadas pelas lesões de abfração em nível do colo dental. Além disso, um sintoma muito comum no BS é uma musculatura mastigatória dolorida à palpação, que pode levar a uma limitação dos movimentos mandibulares ao despertar, (trismo) e alterações na oclusão (Davies et al., 2002). Dentre as alterações musculares, pode ocorrer a hipertrofia do músculo masseter, estalido articular (Attanasio, 1997; Diniz et al., 2009) em decorrência da atividade do bruxismo. As alterações musculares podem ser a causa de dores de cabeça, cefaleias (Teixeira et al., 1994; Attanasio, 1997; Gimenes, 2008; Diniz et al., 2009) e, embora esta relação não esteja totalmente esclarecida, acredita-se que este fato seja produzido devido a um distúrbio circulatório na musculatura orofacial, ainda que esta relação não esteja totalmente esclarecida (Teixeira et al., 1994; Gimenes, 2008). 
Em caso de bruxismo severo pode ocorrer desgaste marcante da superfície oclusal que pode acarretar comprometimento do periodonto de suporte com consequente mobilidade dental, podendo também estar associado com espasmos musculares e fraturas de dentes e restaurações. A ação do bruxismo no periodonto promove o alargamento do espaço periodontal, podendo acarretar sua necrose e decorrente mobilidade dentária (Attanasio, 1997; Davies et al., 2002; Alóe et al., 2003; Diniz et al., 2009; Silva; Cantisano, 2009).

Yip (2003) em revisão de literatura e descrição de caso clínico sobre a reabilitação de bruxistas considerou que o desgaste dental está associado à sensibilidade dentinária, mudanças no relacionamento oclusal e redução excessiva da altura de coroa clínica.

Para Lopes et al. (2007) as facetas de desgaste dentárias são características amplamente encontradas na população, e se apresentam como desgastes que podem variar de pequenas proporções localizadas em esmalte até grandes destruições que podem atingir esmalte e dentina.

Há pesquisadores que afirmam que a hiperatividade muscular decorrente da atividade parafuncional bruxismo, ocasiona: espasmo, fadiga e sobrecarga, o que pode resultar em um ciclo vicioso de espasmo-dor-espasmo. Esta teoria foi utilizada para explicar a etiologia das disfunções temporomandibulares (DTM), além de outras condições similares (Lund, 2006).

Kampe et al. (1997a), realizaram um estudo com o objetivo de descrever bruxistas crônicos ( 5 anos de atividade) através das variáveis: saúde geral; sinais e sintomas de Disfunção Temporomandibular (DTM); ocorrência e frequência de hábitos parafuncionais; diferenças dos sintomas de Disfunção Crânio-muscular (DMC) entre bruxistas e não bruxistas; ranger de dentes; apertamento dental, entre outras. Selecionaram 29 indivíduos bruxistas com idade entre 23 e 68 anos, e diagnóstico confirmado pela constatação de ruídos de ranger de dentes no período noturno, hipertrofia do músculo masseter, desgaste dental, dor na ATM e dor nos músculos da mastigação. Houve confirmação de que 55\% dos indivíduos apresentavam sintomatologia diariamente. Os sintomas mais comuns foram dor na face ou na ATM (48\%) e rigidez mandibular pela manhã. Os sinais clínicos mais 
prevalentes foram sensibilidade à palpação muscular (76\%) e ruídos articulares (55\%). Os autores argumentaram que os bruxistas do sono podem reclamar no período matutino de desconforto da musculatura mandibular que tende normalmente a melhorar no decorrer do dia. Alguns pacientes apresentavam danos significativos nos dentes, hipersensibilidade térmica dental, hipermobilidade, hipercementose, ou a necessidade de reparação dental. Concluíram que o toque dental geralmente acontece nas extremidades incisais dos dentes anteriores e nas cúspides dos dentes posteriores. As forças laterais geradas pelo atrito dental (ranger), dependendo da intensidade, frequência, direção e duração, podem ser extremamente destrutivas. Adicionalmente, o bruxismo pode produzir ulcerações e sulcamento da mucosa jugal na região de molares. Embora o bruxismo do sono seja uma desordem comum, permanece obscuro com que frequência ocorre sequelas diurnas. As evidências não apoiaram a premissa de que todos os indivíduos com bruxismo do sono apresentam desordens craniomandibulares e dores de cabeça decorrentes da contração muscular. No entanto houve uma correlação estatisticamente significante entre apertamento dental frequente e dores de cabeça, dor no pescoço, costas, garganta ou ombros, distúrbios do sono e contagens elevadas do índice de disfunção clínica. Os resultados indicaram uma relação causal entre apertamento dental frequente e sinais e sintomas de Disfunção Craniomandibular (DCM), incluindo dor de cabeça e dor no pescoço, costas, garganta ou ombros e alta patogenicidade para apertamento dental frequente.

Em trabalho realizado com outro grupo, Kampe et al. (1997b), avaliaram bruxistas crônicos quanto aos sinais e sintomas somáticos, psicossociais e de dor relacionados ao sono. Analisaram também sinais e sintomas específicos de DTM. Os resultados demonstraram a ocorrência de dores frequentes na nuca, costas, garganta ou ombros em $69 \%$ da amostra estudada; cefaleias frequentes em $48 \%$; rigidez dos maxilares pela manhã em $44 \%$; sons na ATM em $34 \%$ e fadiga durante a mastigação em 38\% da amostra. Quanto aos sinais clínicos mais comuns encontrados, a sensibilidade muscular à palpação ocorreu em $76 \%$ da amostra e dor na região da ATM em $66 \%$ da amostra. Baseados nos resultados os autores concluíram que o apertamento dental frequente pode ser a causa do aparecimento de sinais e sintomas nos pacientes bruxômanos. 
O desgaste gerado pelo bruxismo não está restrito às faces dentais atuantes na oclusão e articulação. São geradas nos dentes também lesões de flexão em forma de cunha (abfrações) (Roeters; Stel, 2000). Assim o desgaste dental de natureza patológica resultante da atrição pode causar alterações na aparência dental, e os elementos podem apresentar sensibilidade a estímulos térmicos, diminuição da altura vertical, histórico de hipermobilidade, movimentação dentária, sensibilidade a estímulos térmicos (Chapotat et al., 2001), pulpites, odontalgias, cálculos pulpares, fraturas radiculares, fraturas parciais de coroas, migração de dentes e lesões de abfração em nível de colo dental (Teixeira et al., 1994).

Ahlberg et al. (2004), em um estudo longitudinal, relacionaram sintomas de bruxismo e comportamentos biopsicossociais em funcionários de 30-50 anos de idade $(n=211)$ da Companhia de Radiodifusão da Finlândia (YLE). Os inquiridos responderam a questionários entre 1999 e 2000, contendo itens sobre dados demográficos, tabagismo, níveis de auto-percepção de bruxismo, transtornos afetivos, distúrbios do sono, sintomas somáticos, e sintomas de dor e disfunção temporomandibular (DTM). Observaram que o Bruxismo foi significativamente mais prevalente entre fumantes $(p=0,012)$. Não observaram associação com bruxismo para as variáveis, idade, estado civil e sexo. Porém notaram que no grupo de indivíduos que apresentavam bruxismo frequente $(n=74)$ os sintomas de DTM eram menos dolorosos $(p=0,004)$, enquanto que as perturbações afetivas e a insônia ocorriam com maior frequência do que a média.

Bernhardt et al. (2004) realizaram um estudo epidemiológico transversal com uma amostra de base populacional na Pomerania ( $n=2.529$ indivíduos), usando um modelo de regressão logística multivariada para avaliar se fatores oclusais, sociodemográficos, além do sexo e idade constituíam fatores de risco para a presença de alto desgaste dental. Observaram uma correlação entre o acentuado desgaste oclusal e as seguintes variáveis independentes: sexo masculino, odds ratio 2,2; bruxismo frequente, odds ratio de 2,5, a perda de contato oclusal em molar (classificação de Eichner), odds ratio 1,5-3,1; a relação cúspide a cúspide vestíbulolingual unilateral, odds ratio 1,8; e o desemprego, odds ratio 1.6. Em contraste, ao mordida cruzada anterior e a mordida cruzada posterior representaram elementos de proteção para a ocorrência de altos níveis de desgaste oclusal. Numa análise 
diferenciada para a variável gênero, o relato de bruxismo mostrou ser um fator de risco apenas para os homens. Os autores concluíram que além de alguns fatores oclusais, os principais fatores associados com o desgaste oclusal foram o bruxismo e o gênero.

Em seu estudo Rompré et al. (2007), relataram que cerca de metade dos indivíduos avaliados com história clínica de ranger de dentes apresentavam baixas frequências de contrações musculares da mandíbula (episódios/hora), e eventos de ranger de dentes na avaliação polissonográfica. Um elevado número de participantes relatou dor nas articulações e fadiga na musculatura mastigatória, embora não ocorresse queixa de DTM. A explicação para este fato baseia-se na justificativa de que pessoas que experimentam a dor durante o bruxismo, tendem a diminuir sua frequência. Este fato está em concordância com o "modelo adaptativo à dor" (Camparis et al., 2006; Rompré et al., 2007). Portanto, a dor parece estar associada com frequências mais baixas de atividades orofaciais.

A fim de verificar os efeitos do bruxismo sobre a atividade elétrica da musculatura mastigatória, Li et al. (2008), avaliaram por meio de exame clínico e eletromiografia, 24 sujeitos com bruxismo e 16 sem bruxismo nas situações de repouso e contração voluntária máxima. Os autores verificaram que na situação de repouso os sujeitos com bruxismo obtiveram resultados significativamente maiores que os do grupo sem bruxismo, ocorrendo o contrário na contração voluntária máxima. Além disso, puderam observar a ocorrência mais elevada de assimetria nos sujeitos com bruxismo, quando comparados aos sem bruxismo, embora sem significância estatística.

Segundo Rispolib et al. (2008), a hipertrofia idiopática do músculo masseter é uma patologia pouco frequente, de causa desconhecida e geralmente correlacionada ao hábito de mascar gomas; disfunção da articulação temporomandibular (ATM); hipertrofias congênitas e funcionais; e distúrbios emocionais (nervosismo e ansiedade). A queixa principal está relacionada com a alteração estética decorrente da assimetria facial, podendo ocorrer sintomas como trismo, protrusão e bruxismo. O exame físico é realizado por meio da palpação intra e extraoral da massa muscular, e a ausência de sinais inflamatórios corrobora para o seu diagnóstico. Os principais diagnósticos diferenciais são massas tumorais de 
glândulas salivares maiores (parótida e submandibular), tumores ósseos do terço médio e inferior da face, processos inflamatórios musculares ou salivares, neoplasias vasculares e aumentos nodulares.

Sutin et al. (2010) afirmaram que com a etiologia complexa do bruxismo, e em muitos casos em que há antecedentes psicológicos, o bruxismo é particularmente mais severo durante os períodos de tensão e elevada ansiedade. Assim, o bruxismo crônico pode resultar em sensibilidade mandibular, dor facial, perda auditiva, incômodo ao companheiro de quarto, desordens temporomandibulares (DTM) (Winocur et al., 2003; Van Der Zaag et al., 2007; Lavigne et al., 2008), desgaste do esmalte e consequente exposição dos tecidos subjacentes, perda dental, fraturas de dentes e restaurações (Winocur et al., 2003; Van Der Zaag et al., 2007; Lavigne et al., 2008), lesões dentais cervicais não cariosas, endentações nas bordas linguais, linha Alba na mucosa jugal. Como as sequelas do bruxismo têm caráter clínico permanente, é difícil dizer com certeza se os mesmos denotam um bruxismo do passado ou atual (Lavigne et al., 1996). Desta forma a elaboração de um questionário para o BS sofre limitações dadas pela sua intermitência, e pelo fato de que geralmente quem relata sua existência é o companheiro de quarto (Lavigne et al., 2001a), e pelo fato de que bruxômanos que realizam apertamento dental geralmente não emitem sons. Diferentes teorias têm sido postuladas para identificar a etiopatogenia do BS. Inicialmente o BS foi relacionado como consequência de alterações na oclusão dentária. Atualmente estudos parecem apoiar a hipótese da gênese multifatorial em que fatores genéticos, a estrutura do sono (microdespertares) (Lavigne et al., 2002), o ambiente emocional, angústia, ansiedade e outros fatores psicológicos (Schneider et al., 2007), o equilíbrio catecolaminérgico do sistema nervoso central (Lobbezoo et al., 1997), o sistema nervoso autônomo,e algumas drogas (álcool, ecstasy, cafeína, tabaco) e medicamentos (inibidores seletivos da recaptação da serotonina, benzodiazepínicos, drogas dopaminérgicas) têm uma relação com a etiopatogenia da BS. As teorias que sustentam uma possível predisposição genética para o BS foram realizadas principalmente a partir de estudos com base em questionários ou análises de populações de gêmeos monozigóticos (Hublin et al., 1998). 
Yachida et al. (2012) compararam a atividade eletromiográfica (EMG) dos músculos mandibulares durante o sono em diferentes grupos: pacientes com dor craniofacial $(n=63)$; pacientes sem condições dolorosas $(n=52)$; pacientes com cefaleia do tipo tensional (CTT: $n=30$ ) e em indivíduos saudáveis de um grupo controle $(n=30)$. Todos os participantes utilizaram um dispositivo portátil EMG (Medotech A / S) de canal único durante quatro noites. Quanto aos resultados os autores não encontraram diferenças significativas na atividade EMG entre os grupos: com dor craniofacial (24,5 \pm 17,9 eventos / hora), sem condições dolorosas (19,7 \pm $14,5)$, ou entre cefaleia do tipo tensional (CTT) $(20,8 \pm 15,0)$ e indivíduos controles saudáveis $(15,2 \pm 11,6, p>0,050)$. Houve sim correlações positivas entre a atividade EMG e o número de músculos doloridos $(r=0,188, p=0,044)$, intensidade da dor $(r=0,187, p=0,046)$. Os pacientes que apresentaram condições dolorosas apresentaram em noites sucessivas uma variabilidade significativamente maior, quando comparados aos indivíduos com ausência dolorosa $(p<0,05)$. Os autores acreditam que, embora este estudo observacional seja de curto prazo, não existem grandes diferenças entre pacientes com diferentes condições de dor craniofaciais e indivíduos isentos de dor quanto à atividade dos músculos mandibulares durante o sono.

Descobertas recentes indicam que o bruxismo pode estar envolvido na acidificação do esôfago e na depuração ácida. Com o objetivo avaliar a associação entre o bruxismo e relatos de sintomas da azia Dalberto et al. (2012), estudaram 68 voluntários do Serviço de Gastroenterologia do Hospital de Clínicas de Porto Alegre / Brasil, que foram divididos em dois grupos: com ausência de azia $(A, n=26)$ ou com presença de azia $(B, n=42)$. Foram excluídos os Indivíduos com má oclusão, menos de 24 dentes nas arcadas, obesidade mórbida. Os sinais e sintomas de queimação foram avaliados por um questionário. Já o Bruxismo foi diagnosticado sob condição cega por meio da avaliação do desgaste dos dentes, do desconforto muscular e do auto-relato do paciente, de acordo com os Critérios da Academia Americana de Medicina do Sono. O estresse foi investigado pelo Lipp Stress SymptomInventory (SSI). Também foi calculado $\mathrm{O}$ índice de massa corporal (IMC) para a avaliação da obesidade. Utilizaram a regressão logística para ajustar os preditores de gênero, idade, estresse (SSI) e IMC ( $\alpha=0,05$; poder $85 \%$ ). $\mathrm{Na}$ avaliação dos resultados foi observado que os participantes eram do sexo feminino 
(75\%), brancos (73,5\%), não obesos (76,5\%; IMC = 26,2 $\pm 4.5 \mathrm{~kg} / \mathrm{m} 2)$, com idade de 44,3 $\pm 13,7$ anos. Uma alta prevalência de estresse foi detectada no grupo $B$ (com presença de azia - 38,2\%) quando comparado ao grupo A (16,2\%). O grupo B apresentou relatados de azia em mais de 3 vezes por semana $(40,5 \%)$. A prevalência do bruxismo foi de $8,8 \%$ e $38,2 \%$ nos grupos A e B, respectivamente. $O$ melhor modelo de regressão mostrou que apenas a variável azia esteve significativamente associada ao bruxismo ( $p=0,03$; OR =3,92, IC 95\%: 1,14-13,44), ajustado para o IMC, SSI e idade. Assim os autores concluíram que o bruxismo está fortemente associado com a azia, embora, novas pesquisas sejam necessárias devido a complexos mecanismos estarem relacionados tanto com o refluxo (azia), quanto com o bruxismo.

Os eventos do bruxismo ocorrem preferentemente durante os estágios I e II do sono não REM, e raramente em períodos de sono profundo, estágios III e IV NREM (Rugh; Harlan, 1988; Alóe et al., 2003; Pereira et al., 2006; Silva; Cantisano, 2009). O bruxismo pode também ocorrer, mas em menor quantidade, durante a fase do sono REM. Entretanto, o sono REM tem como característica uma hipotonia muscular. Este fato representa um paradoxo, já que ocorre em um estágio de supressão motora quando o tônus muscular é mínimo. Por estes motivos há um entendimento de que os episódios do BS estariam relacionados à presença de breves e transitórias atividades de despertar do sono durante o estágio REM (Lavigne et al., 2003). Estes eventos de bruxismo durante o sono REM tem um potencial considerado por diversos autores, bastante destrutivo (Rugh; Harlan, 1988; Ware; Rugh, 1998; Alóe et al., 2003; Chagas et al., 2006; Pereira et al., 2006; Silva; Cantisano, 2009). Assim, quanto mais severo e crônico o bruxismo do sono, menor a chance de se ter um sono reparador (Alóe et al., 2003; Pereira et al., 2006; Rodrigues et al., 2006; Silva; Cantisano, 2009), às estruturas da ATM (Bisi et al., 2007).

O bruxismo pode ser fator etiológico de distúrbios da ATM e nestes casos é feito o diagnostico diferencial analisando-se os desgastes dentais fisiológicos, principalmente em crianças. Entre os sinais e sintomas encontram-se além dos danos dentais, danos periodontais, tissulares e dores de cabeça, também a otite média crônica pode ser causada pelo bruxismo (Gusson, 1998). Há evidências de 
que o bruxismo em crianças pequenas pode ser consequência da imaturidade do sistema mastigatório neuromuscular (Diniz et al., 2009).

Lobbezoo e Lavigne (1997) afirmaram que estabelecer uma relação de causa e efeito entre DTM e Bruxismo é extremamente difícil devido ao grande número de influências envolvidas. Acreditam que o bruxismo leva a sinais e sintomas característicos de um ou mais subtipos de DTM e sugerem também a utilização de polissonografia como critério para diferenciar o bruxismo do sono da normalidade.

Manfredini e Lobbezoo (2010), revisaram sistematicamente a literatura utilizando a Biblioteca Nacional de Medicina do banco de dados PubMed, de 1998 a 2008. Avaliaram o bruxismo relacionando-o às desordens temporomandibulares (DTM). Identificaram todos os estudos em humanos diagnosticados por diferentes abordagens. Incluíram 46 artigos agrupados nos formatos: estudos por questionário / auto-relato ( $n=21)$, avaliação clínica $(n=7)$, estudo experimental $(n=7)$, desgaste dental $(n=5)$, estudos por polissonografia $(n=4)$, ou por eletromiografia $(n=2)$. Em vários estudos, o nível de evidência ficou negativamente influenciado por um baixo nível de especificidade para a avaliação da relação Bruxismo-DTM, por causa da baixa prevalência de pacientes com DTM grave nas amostras estudadas, e pela utilização do diagnóstico pelo auto-relato do bruxismo poder gerar viés de diagnóstico. Investigações baseadas em auto-relato ou pelo diagnóstico clínico do bruxismo demonstraram uma associação positiva entre este e a dor das Desordens Temporomandibulares (DTM). Entretanto, em nível de diagnóstico, ficaram potencialmente caracterizados por viés e fatores de confusão quanto à dor como critério para o diagnóstico do bruxismo. Estudos baseados em métodos mais quantitativos e específicos para o diagnóstico do bruxismo mostraram uma associação muito menor com os sintomas de DTM. Quanto ao desgaste dental anterior, não foi possível concluir que o mesmo, seja um importante fator de risco para a DTM. O apertamento sustentado experimental da mandíbula pode provocar sensibilidade muscular aguda, mas esta não é análoga à dor de DTM de origem miogênica. Os autores concluíram que tais estudos não podem ajudar a esclarecer a relação clínica entre bruxismo e DTM. 


\subsection{Atividade Rítmica da Musculatura Mastigatória (ARMM)}

Várias atividades motoras orofaciais ocorrem durante o sono, tais como: deglutição, movimentos de lábio e língua, exalar respiração profunda, produzir um som gutural, entre outras.

Para Kato et al. (2011), apesar de o músculo masseter participar nos comportamentos complexos oromotores e coordenar, durante a vigília, a mastigação, durante o sono, a atividade eletromiográfica (EMG) diminui, mas não desaparece completamente. O BS é caracterizado pela ocorrência exagerada de Atividade Rítmica da Musculatura Mandibular ARMM.

A ARMM quando associada ao ranger de dentes é denominada BS. Pacientes BS apresentam aumento da atividade motora orofacial quando comparados a indivíduos não bruxômanos durante o sono. Os episódios de ARMM com ausência de ranger de dentes estão presentes em $60 \%$ dos indivíduos normais durante o sono (1,8 episódios por hora de sono), assim como também em vários distúrbios do sono (sonambulismo, terror noturno) (Lavigne et al., 2001b; Lavigne et al., 2003). Ocasionalmente, nos indivíduos portadores de bruxismo noturno, a ARMM está associada com o ranger dental (Huynhet al., 2006), e é desconhecido o motivo pelo qual estes indivíduos apresentam ARMM três vezes maior e mais frequente $(5,4$ episódios por hora de sono) quando comparados a indivíduos normais (Lavigne et al., 2003). A alta taxa e frequência de atividade eletromiográfica (EMG) podem levar a uma maior duração total, e maior frequência de ruídos de ranger de dentes (Lavigne, et al., 1996; Miyawaki et al., 2003).

A atividade muscular da mandíbula que ocorre durante os episódios do BS é semelhante à Atividade Rítmica da Musculatura Mandibular (ARMM). Os episódios de ARMM constituem séries repetitivas de contrações musculares fásicas, tônicas ou mistas. Os episódios fásicos, também chamados de rítmicos, são definidos por três ou mais contrações, com duração de 2 s a 0,25s e são observados em quase $60 \%$ dos indivíduos normais durante o sono (Lavigne et al., 2001b; Miyawaki et al., 2003). Os episódios tônicos caracterizam-se por contrações que duram no mínimo 2s. As contrações mistas incluem ambos os tipos: fásicas e tônicas (Lavigne et al., 2001b; 
Lavigne et al., 2003). Em pacientes BS, cada episódio de ARMM possui $70 \%$ a mais de contrações, os episódios de ARMM são quase três vezes mais frequentes, e os surtos musculares têm uma amplitude $40 \%$ a $60 \%$ maior do que os que ocorrem em pacientes normais, enquanto a duração é cerca de $40 \%$ menor. Isto sugere que ARMM, nestes indivíduos é uma atividade mais potente (Lavigne et al., 1996; Lavigne et al., 2001b; Lavigne et al., 2003; Miyawaki et al., 2003; Huynh et al., 2006).

Portanto, a atividade Rítmica dos Músculos da Mastigação (ARMM) ocorre durante o sono, mais frequentemente após uma micro-estimulação transitória espontânea, tanto em pacientes com BS, assim como em pacientes normais, porém, com maior frequência em BS. Estes movimentos rítmicos mandibulares (ARMM) ocorrem em surtos nos minutos que antecedem o movimento rápido dos olhos, o que sugere que algum mecanismo relacionado ao estágio transitório do sono exerça uma influência sobre os neurônios motores facilitando o início BS (Lavigne et al., 2008). Além do ranger de dentes dos bruxistas acontecer em $71 \%$ dos episódios de ARMM, estes parecem ser uma forma exagerada da atividade oromotora e estarem associados com micro-estimulações do sono. Os índices de micro-excitações e BS são maiores durante os ciclos do sono 2 e 3 . Dentro de cada ciclo, os índices de micro-excitações e ARMM nos bruxômanos evidenciam um aumento antes de cada ciclo de sono REM. É observada uma mudança no balanço simpático-vagal levando a um aumento da atividade do sistema nervoso simpático que começa 8 minutos antes da ocorrência do ranger de dentes. Os portadores de bruxismo noturno, de moderado ao severo, claramente apresentam um aumento da atividade simpática que precede o bruxismo do sono (Huynh et al., 2006).

Cerca de $90 \%$ dos episódios de ARMM, com ou sem ranger de dentes, estão associados a alterações do EEG (eletroencefalograma), EMG (eletromiografia) e relacionadas à microdespertares (Kato et al., 2001; Huynh et al., 2006). Adultos jovens portadores de BS apresentam sete vezes mais episódios com sons de ranger de dentes induzidos por estímulos artificiais de despertar quando comparados com voluntários normais, sugerindo que o BS é um dos eventos que ocorrem ao longo da sequência da ativação fisiológica associada aos microdespertares registrados ao EEG sendo, portanto, secundário a eles (Kato et al., 2001; Kato et al., 2003a). 
Em um artigo de revisão Lavigne et al. (2007), apresentaram uma hipótese para explicar o mecanismo que pode estar envolvido na gênese do bruxismo do sono (BS). Em humanos a atividade rítmica da musculatura mastigatória (ARMM) ocorre em uma frequência de $1 \mathrm{~Hz}$, e ocasionalmente pode ocorrer o ranger dental. Durante o sono leve, a maioria dos episódios do BS está relacionada a breves reativações cardíacas (atividade cardíaca simpática, 4 minutos antes à ARMM) e cerebrais (aumento na frequência da atividade eletroencefalográfica EEG, que ocorrem 4 segundos (3-15s) antes da ARMM. Os autores demonstraram que a ARMM é secundária a uma sequencia de eventos relacionados aos microdespertares do sono. No nível cardíaco há um aumento da atividade simpática autônoma (taquicardia 1 segundo antes da ARMM). Subsequentemente ocorre um aumento da atividade muscular suprahioidea (provavelmente responsável pela passagem de ar e abertura mandibular) 0,8 segundos antes da ARMM e o aumento da tonicidade dos músculos suprahioideos, para a abertura mandibular, finalizando com a ativação dos músculos responsáveis pelo fechamento da mandíbula, masseteres e temporais, através da Atividade Rítmica da Musculatura Mastigatória (ARMM), para seu fechamento (Kato et al., 2001; Kato et al., 2003a; Lavigne et al., 2003; Dubé et al., 2004; Lavigne et al., 2007). Suspeita-se que o início da ARMM esteja sob influência do sistema cerebral ascendente despertar-reticular, que contribui para o aumento da atividade cardíaca autônoma e neuronal motora (Kato et al., 2001; Lavigne et al., 2007).

Miyawaki et al. (2003) confirmaram em um estudo que a duração dos episódios de ARMM com produção de ruídos foi maior em pacientes BS, e os mesmos apresentaram maior frequência de eventos de deglutição durante o sono quando comparados a sujeitos normais. Em pacientes bruxômanos, aproximadamente $70 \%$ dos eventos de deglutição ocorreram durante um episódio ARMM e, além disso, 90\% dos episódios de ARMM foram observados nas posições de decúbito supino e lateral. Entretanto as atividades oromotoras foram três vezes mais frequentes na posição supina do que em decúbito lateral.

Khoury et al. (2008) aventaram a hipótese de que um aumento na respiração também caracteriza o começo de episódios de SB dentro da sucessão de estimulações cardíaca e cerebral. Estudaram 20 pacientes BS sem nenhuma 
desordem respiratória relacionada ao sono. Observaram que as medidas quanto à respiração mostraram alterações significativas ao longo do tempo. Quatro segundos antes da atividade rítmica da musculatura mastigatória (ARMM) houve um aumento na amplitude da respiração de 8 a 23\%. A elevação tornou-se maior no começo da atividade do músculo suprahioideo (60 a $82 \% 1 \mathrm{~s}$ antes de ARMM) e a elevação máxima ocorreu durante os episódios de ARMM (108 a 206\%) seguido por um rápido retorno aos níveis que precederam os movimentos rítmicos da musculatura mastigatória.

\subsection{Evidências para o Diagnóstico do Bruxismo por meio da Polissonografia}

Nem sempre é possível obter um diagnóstico clínico para o BS (Van Der Zaag et al., 2005; Camparis et al., 2006) acreditam que o instrumento ideal para a confirmação do diagnóstico clínico para o BS é a polissonografia. Esta consiste no padrão-ouro, o método objetivo e consagrado para o diagnóstico do bruxismo, que monitora as variáveis fisiológicas durante o sono, através do registro de três mínimos parâmetros: o eletrencefalograma, o eletro-oculograma e o eletromiograma submentoniano, para quantificar e qualificar o sono do indivíduo. A polissonografia registra minimamente a atividade elétrica cerebral, a respiração, os sinais indicativos do relaxamento muscular, os movimentos oculares, a oxigenação sanguínea, o batimento cardíaco entre outros. Este exame é realizado em um laboratório do sono e contribui para o diagnóstico de doenças relacionadas ao sono (Lavigne et al., 1996; Kato et al., 2003c; Camparis et al., 2006; Macedo, 2008).

Assim a American Academy of Sleep Medicine (AASM, 2005) recomenda o monitoramento através da polissonografia para a avaliação da atividade dos músculos masseter e temporal durante o sono. O bruxismo do sono é mais comum nos estágios 2 do sono não REM. Porém em algumas pessoas pode ocorrer predominantemente no estágio REM do sono. Na relação de critérios estão discriminados: a ativação da musculatura mandibular durante o sono, ausência de atividade epiléptica associada, além da ausência de outros distúrbios médicos ou mentais. Quanto à gravidade de ambos BS e BD: episódios leves (ocorrem menos 
de noite, sem evidências de lesão dentária ou comprometimento do funcionamento psicossocial; episódios moderados (ocorrem todas as noites, com evidência de leve comprometimento psicossocial); episódios graves (ocorrem todas as noites, com evidência de lesão dental, desordens da ATM, outras lesões físicas, ou envolvimento psicossocial de moderado a grave). Quanto aos critérios de duração: bruxismo agudo (7 dias ou menos); bruxismo subagudo (mais de 7 dias e menos de um mês); bruxismo crônico (1 mês ou mais).

No entanto, também ocorre um amplo espectro de atividades motoras durante o sono [(Sleep Motor Activities (SMA)] na região da cabeça e pescoço, e estas ainda não foram sistematicamente estimadas tanto no sono de indivíduos normais quanto no de bruxômanos do sono (BS) (Dutra et al., 2008).

Lavigne et al. (1996), relataram a necessidade de se diferenciar atividades oromotoras das atividades do bruxismo por meio dos resultados dos registros polissonográficos e registros audiovisuais de uma noite de sono. Objetivando validar a polissonografia com os critérios definidos pela ASDA, os autores selecionaram 18 indivíduos bruxômanos, e 18 não bruxômanos, distribuídos igualmente por sexo e idade (20 a 45 anos). Propuseram: caracterizar as variáveis motoras orofaciais durante o sono de indivíduos com bruxismo (diagnosticado clinicamente), e compará-las com os dados da população assintomática; estabelecer valores para a atividade eletromiográfica (EMG) indicadora do bruxismo do sono; e testar a sensibilidade e especificidade dos valores limítrofes estabelecidos para 0 diagnóstico do bruxismo do sono BS. Para o grupo de bruxômanos utilizaram os seguintes critérios de inclusão: ter idade entre 20 e 45 anos; ter apresentado nos últimos 6 meses, sons de ranger de dentes em ao menos 5 noites por semana. Acrescentaram a necessidade da ocorrência de ao menos um ou mais critérios subjetivos como: desgaste dental; superfícies brilhantes/polidas em restaurações metálicas; relato de fadiga ou dores na musculatura mastigatória ao despertar; ou ainda hipertrofia do músculo masseter. Dentre os critérios de exclusão utilizaram: ausência de 2 ou mais dentes (excluindo-se os terceiros molares); a utilização de prótese dentária; presença de má-oclusão severa; uso de medicação com possível efeito sobre a atividade motora durante o sono; estar sob tratamento físico ou dentário; apresentar grandes desordens neurológicas ou psiquiátricas e outras 
desordens do sono. Para o grupo controle os autores utilizaram os mesmos critérios de exclusão e ausência de qualquer sinal ou sintoma sugestivo de bruxismo. $O$ exame polissonográfico foi realizado por duas noites consecutivas tendo feita a anotação dos dados apenas da segunda noite de sono. De posse dos resultados, os autores verificaram que a polissonografia e os registros audiovisuais confirmaram uma atividade motora orofacial significativamente maior [ 3 vezes mais episódios de bruxismo/noite, e 6 vezes mais surtos (bursts) de bruxismo/hora] nos indivíduos do grupo experimental de bruxômanos, quando comparados ao grupo controle. Os autores observaram que os dados fornecidos pelo exame clínico, todos os pacientes do grupo experimental (bruxômanos) relataram ruídos típicos de ranger dental, enquanto no grupo controle, nenhum dos indivíduos os relatou. Na comparação com os resultados dos exames polissonográficos no grupo experimental, quatro pacientes não realizaram ruídos de ranger dental, e no grupo controle, um indivíduo os fez em cinco episódios. Mesmo apresentando divergências, ocorreu uma diferença estatisticamente significante para os episódios de bruxismo do sono entre os grupos experimental e controle quanto à realização de sons de ranger de dentes. Frente aos resultados, os autores elaboraram critérios para serem utilizados em polissonografias para o diagnóstico do bruxismo tais como: existência de ao menos 2 episódios de ARMM acompanhados de sons de ranger de dentes por noite de sono, seguidos de um ou mais dos seguintes critérios: mais de 4 episódios de ARMM/hora sono; mais de 5 surtos (bursts) eletromiográficos/hora/sono. Os autores verificaram que a maioria dos episódios de BS ocorreu durante os estágios 1 e 2 do sono não REM. Ficou evidente que durante o sono tanto em indivíduos bruxômanos, como em não bruxômanos, ocorrem episódios de ARMM, sendo a frequência dos eventos o fator de diferenciação dos grupos (Lavigne et al., 1996). Elaboraram critérios de diagnóstico para detectar BS através da polissonografia. São eles: pelo menos dois episódios de atividade rítmica dos músculos mastigatórios (ARMM) associados ao som de "ranger de dentes"; mais de quatro episódios de ARMM por hora de sono, sem som de "ranger os dentes"; mais de cinco burst eletromiográficos por episódios de ARMM; mais de 25 burst eletromiográficos por hora de sono.

Lavigne e Manzine (2000) relataram que os episódios do BS podem ter frequência variada ao longo do tempo. Isto significa que é possível que pacientes com BS passem várias noites e até mesmo semanas sem que ocorram episódios de 
ranger de dentes. Durante as atividades motoras dos músculos mandibulares (masseter e temporal), podem ocasionar ranger de dentes, de maneira fásica (rítmica) e/ou tônica (sustentada). Várias atividades orofaciais são frequentemente concomitantes com BS como: fazer caretas, movimentos labiais, movimentos de empurrar e protruir os lábios e língua.

Para Dutra et al. (2008), durante o sono ocorre uma alta atividade motora nas regiões de cabeça e pescoço tanto em indivíduos normais como em portadores de bruxismo (BS). Dentre as atividades motoras orofaciais pode-se citar a movimentação da cabeça, o ato de chupar os lábios, movimentos semelhantes aos da mastigação, o ato de engolir e o de piscar os olhos entre outras. Estas atividades, embora distintas da atividade rítmica da musculatura mandibular (ARMM) e do ranger dental, aliado à dificuldade de observação sem registros sonoros e em vídeo, podem confundir o pesquisador quanto à presença ou não do bruxismo. Em seu estudo os autores encontraram atividades motoras durante o sono (SMA) tanto em indivíduos normais como em BS. No entanto, as SMA encontradas na amostra foram menores em indivíduos normais quando comparada aos $B S(P<0,001)$. Até $85 \%$ de todas as atividades motoras durante o sono (SMA) em indivíduos normais foram relacionados com atividades orofaciais (OFA), enquanto que 30\% da SMA em pacientes BS foram relacionados com OFA $(P<0,001)$. Na avaliação da frequência da ARMM esta se apresentou sete vezes maior em pacientes com BS do que em indivíduos normais $(P<0,001)$. Os autores argumentaram que mesmo com o exame de polissonografia, na ausência de gravações de áudio-vídeo, é difícil de conseguir a discriminação de vários tipos de OFA e este fato pode conduzir a uma estimativa errada das atividades relacionadas ao BS. Assim, os autores consideram a polissonografia, acrescida de registros sonoros e em vídeo, como importantes instrumentos de diagnóstico para o bruxismo.

Frente aos fatos, é recomendado que, pela ocorrência da alta atividade motora orofacial durante o sono, entre outros fatores, deve-se utilizar o exame polissonográfico, e o monitoramento audiovisual para o estabelecimento e a validação dos critérios eletromiográficos e a especificidade da atividade motora orofacial (Lavigne et al., 2003; Dutra et al., 2008). 
Apesar da confiabilidade do diagnóstico de distúrbios do sono por meio da polissonografia, no Brasil o acesso a este instrumento é precário. Pequena parte da população tem acesso à medicina privada, e a grande maioria depende dos serviços públicos. A polissonografia como método de diagnóstico de predileção, ainda representa alto custo, sendo um exame inacessível para algumas pessoas. Poucos Estados oferecem este serviço através do Sistema Único de Saúde (SUS), portanto, poucos são os laboratórios a realizá-lo pela rede pública de saúde (Chagas et al., 2006; Musman, 2008).

\subsection{Diagnóstico Clínico do Bruxismo}

De acordo com a Classificação Internacional dos Distúrbios do Sono (CIDS2), o diagnóstico do BS pode ser realizado clinicamente e/ou em laboratório do sono. O diagnóstico clínico do BS é feito por meio dos sinais e sintomas presentes como, relato de sons de ranger de dentes durante a noite e deve estar associado a um ou mais dos seguintes parâmetros: desgaste anormal dos dentes, hipertrofia do músculo masseter durante o apertamento voluntário, desconforto, fadiga ou dor muscular nos maxilares e travamento da mandíbula ao acordar. Ainda outros sinais fazem parte das características clínicas do BS, entre eles: fratura dentária, endentação da língua, redução do fluxo salivar, mordeduras em lábios ou bochechas e queimação na língua. Dentre os sintomas são observados: cefaleia; hipersensibilidade dentária (ao quente e ao frio); presença de dor na ATM durante a palpação; redução da mobilidade mandibular; dificuldade de mastigação ao acordar; estresse e ansiedade (Lavigne; Manzine, 2000; AASM, 2005).

De acordo com a American Academy of Sleep Medicine (2005), devem ser adotados critérios para o diagnóstico do Bruxismo. Para o diagnóstico clínico devese observar a ocorrência de ranger ou apertamento dental durante o sono. A ele acrescenta-se um ou mais dos sintomas: desgaste dental anormal; sons associados ao bruxismo; desconforto da musculatura mandibular. 
A suspeita do bruxismo pode ocorrer já durante a anamnese, quando o paciente, ou seu acompanhante, relata os primeiros sinais/sintomas compatíveis com o bruxismo, e a presença de facetas de desgaste alinhadas, é um sinal clínico característico da presença da parafunção bruxismo (Attanásio, 1997). O exame clínico, a anamnese e os questionários são instrumentos comumente utilizados para estabelecer a presença do BS (Van Der Zaag et al., 2005). Assim seu diagnóstico pode ser realizado por meio do exame clínico e do relato de ruídos de ranger de dentes, pois, os sons causados pela fricção dental, durante os episódios de BS, são normalmente percebidos pelo parceiro de quarto ou membros da família (Lavigne et al., 2003).

O método de coleta de dados por entrevista ou questionário de auto-relato, embora de cunho subjetivo, pode ser considerado confiável, uma vez que parentes e/ou companheiros de quarto efetivamente relatem a ocorrência de ruídos de ranger dental, eliminando desta forma a existência de falso-positivos (Shinkai et al., 1998). No entanto, a prevalência do BS poder ser subestimada (Vanderas, 1995; Shinkai et al., 1998), caso não haja o relato por um companheiro de sono.

No entanto o diagnóstico clínico do bruxismo do sono pode apresentar-se complexo, pois o aparecimento de sinais e sintomas varia ao longo do tempo, dependendo dos surtos de agudização, assim como de sua cronicidade. As facetas de desgaste, observadas em exames clínicos, podem indicar uma história pregressa de bruxismo, entretanto, este pode não mais estar ocorrendo no momento do exame. Por outro lado, o início recente do hábito pode ainda não ter acarretado um desgaste denta (Vanderas, 1995; Shinkai et al., 1998) que sugira sua presença. O padrão de desgaste decorrente da mastigação tem como característica, o não alinhamento das facetas entre dentes antagônicos. Já o bruxismo acarreta um perfeito alinhamento das facetas de desgaste entre dentes antagonistas (Attanásio, 1997).

Ao longo dos anos alguns sinais e sintomas foram utilizados para o diagnóstico do bruxismo. Alguns deles foram reunidos por alguns autores, entidades e/ou associações na tentativa de formalizar uma padronização quanto aos critérios para seu diagnóstico. 
Hattab e Yassin em 2000 relataram que a ocorrência e o padrão de desgaste dental estão relacionados com fatores culturais, dietéticos, ocupacionais e geográficos. A etiologia do desgaste dental abrange a atrição, abrasão e erosão, onde a atrição consiste no desgaste fisiológico da superfície dental, resultante do contato entre dentes antagonistas, realizado durante a mastigação e intermediado por substâncias abrasivas. Esta atrição pode ser acelerada por hábitos parafuncionais (bruxismo e apertamento), pela dieta, pelo mascar (fumo, pó abrasivo), oclusão traumática (pacientes parcialmente edêntulos), mordida aberta anterior, mordida topo-a-topo e sobremordida. A observação de facetas polidas nas cúspides, cristas e faces incisais dos dentes, correspondem à primeira manifestação clínica do processo de atrição. Em casos severos pode ocorrer uma diminuição da altura da coroa dental, reduzindo desta forma a dimensão vertical de oclusão (DVO). Entretanto, caso ocorra erupção dentária compensatória, não haverá aumento da distância interoclusal ou diminuição da DVO. A erosão acarreta perda de superfície dental por um processo químico não tendo ação bacteriana envolvida. É causada pela exposição crônica a fatores de origem externa (ex. ácidos da dieta, preparações efervescentes), e fatores de origem interna (regurgitação gástrica, que ocorre na anorexia, bulimia nervosa e anormalidades do sistema gastrointestinal). Os modelos de estudo constituem o método mais confiável no monitoramento da progressão do desgaste dental, seguido de fotografias e índice de desgaste.

Para Holt et al. (2000), o bruxismo pode resultar em perda de superfície dental levando a exposição de dentina, em decorrência do atrito, conduzindo a sensibilidade ao frio e ao calor, sendo necessário sua restauração.

Cardoso et al. (2000), afirmaram que as lesões resultantes da erosão dental podem ter difícil reconhecimento quando a abrasão e a atrição estiverem presentes.

Para Watson e Burke (2000), a perda de substância dental é um problema crescente resultante da erosão, abrasão, atrição, onde geralmente atua mais de um destes fatores.

Para Chapotat et al. (2001), a atrição causada pelo bruxismo pode levar a uma perda de superfície dental patológica e tem como característica a ausência de atividade de cárie. É importante que o profissional seja hábil em reconhecer e 
diferenciar a perda fisiológica da patológica. Os desgastes fisiológicos, considerados normais, causam uma redução da altura vertical e do comprimento horizontal dos dentes, porém a dimensão vertical é mantida pela remodelação do osso alveolar resultando num alongamento do processo dento-alveolar. Os desgastes interproximais são compensados pela constante pressão de mesialização dental, fato que propicia a manutenção dos pontos de contato. $\mathrm{Na}$ ocorrência de desgaste vertical patológico é esperado encontrar uma redução da DVO; isto é, um aumento do espaço livre interdental, que posteriormente poderá ser agravado por um posicionamento mandibular anteriorizado. $\mathrm{O}$ desgaste dental patológico resulta em alteração da aparência do dente podendo apresentar sensibilidade a estímulos térmicos, diminuição da altura vertical, histórico de frequentes fraturas de dentes e restaurações, hipermobilidade, movimentação dentária e perda da estabilidade oclusal posterior. A atrição é a responsável pelo aplainamento de cúspides de suporte, em superfícies guias, bordas incisais, causando facetas de desgaste localizadas nas faces oclusais ou palatinas sendo que dentina e esmalte sofrem desgastes na mesma proporção.

Para Davies et al. (2002), em caso de bruxismo severo ocorre desgaste marcante da superfície oclusal podendo em alguns casos acarretar comprometimento do respectivo periodonto de suporte com consequente mobilidade dental, podendo também estar associado com espasmos musculares e fraturas de dentes e restaurações.

Yip (2003) em revisão de literatura e descrição de caso clínico sobre a reabilitação de bruxistas considerou que o desgaste dental está associado à sensibilidade dentinária, mudanças no relacionamento oclusal, redução excessiva da altura de coroa clínica e consequente ausência de distância interoclusal devido à compensação dento-alveolar.

Manfredine et al. (2003), compararam a prevalência do diagnóstico de bruxismo em voluntários portadores de DTM e em voluntários sem DTM. Um dos objetivos foi investigar quais formas de DTM são mais frequentemente associadas ao bruxismo. Os resultados revelaram uma associação significativa entre bruxismo e DTM, e uma alta prevalência de bruxismo em pacientes com diagnóstico de dor miofacial combinada com deslocamento de o disco articular (87,5\%), dor miofacial 
combinada com deslocamento de disco e outras condições articulares $(73,3 \%)$ e dor miofacial $(68,9 \%)$. Concluíram que o bruxismo exibe uma relação maior com desordens musculares do que com deslocamento de disco e outras patologias da articulação.

O bruxismo, idade e o sexo são fatores que estão associados a um alto índice de desgaste oclusal. O sexo masculino apresenta maior desgaste dental em relação ao feminino, provavelmente devido à maior força muscular do músculo masseter. Em estudo realizado na Pomerania (Alemanha) em 2004, Bernhardt et al. (2004) determinaram a prevalência de desgaste dental, avaliando fatores oclusais, sociodemográficos, idade e sexo como fatores de risco para o severo desgaste dental. Avaliaram 2.529 indivíduos dentados utilizando parâmetros sociodemográficos e anamnéticos como estado civil, nível educacional, desemprego, dieta e frequência de bruxismo. Foi realizada a classificação da maloclusão; avaliada a sintomatologia dolorosa dos músculos mastigatórios e das ATMs (DTM); e a existência de suporte oclusal remanescente. A avaliação do grau de desgaste dental foi realizada através de uma escala de 0 a 3 , onde 0 correspondia a nenhum ou pouco desgaste dental; 1 correspondia a atrição do esmalte com pontos em dentina; 2 correspondia a desgaste em dentina de 1/3 da coroa; 3 correspondia a desgaste em dentina de mais de $1 / 3$ da coroa ou desgaste excessivo em materiais dentários.Frente aos resultados concluíram que as variáveis independentes relacionadas com extenso desgaste oclusal foram: gênero masculino; alta frequência de bruxismo; perda de contato oclusal em molar; relação de incisivos topo-a-topo; relação cúspide-a-cúspide buco-lingual unilateral; e desemprego. O relato de bruxismo mostrou ser um fator de risco apenas para os homens. Os autores concluíram que além de alguns fatores oclusais, os principais fatores associados com o desgaste oclusal foram o bruxismo e o gênero. De forma contrastante, a mordida cruzada anterior, mordida cruzada posterior unilateral e o apinhamento anterior mostraram-se protetores do alto nível de desgaste oclusal.

Hirsch et al. (2004), realizaram trabalho para verificar se a premissa, desgaste incisal é sinal da existência de bruxismo, e este, representa fator de risco para que ocorra desordem da articulação temporomandibular (DTM). Os autores utilizaram uma população de crianças e adolescentes entre 10 e 18 anos com idade média de 
13,1 anos representada por $52 \%$ de meninas. A DTM foi definida por relatos de: dor na face; músculos mandibulares e da articulação temporomandibular. Os dados do desgaste dental incisal foram colhidos através do exame clínico, baseado na escala: 0 (ausência de desgaste), 1 (desgaste em esmalte), 2 (desgaste abrangendo a dentina) para dentes permanentes anteriores. Os autores concluíram que o desgaste oclusal dos incisivos não pode ser associado com as desordens da ATM (DTM).

Ahlberg et al. (2004), em um estudo longitudinal relacionaram sintomas de bruxismo e comportamentos biopsicossociais em funcionários de 30-50 anos de idade $(n=211)$ da Companhia de Radiodifusão da Finlândia (YLE). Os inquiridos responderam a questionários entre 1999 e 2000, contendo itens sobre dados demográficos, tabagismo, níveis de auto-percepção de bruxismo, transtornos afetivos, distúrbios do sono, sintomas somáticos, e sintomas de dor e disfunção temporomandibular (DTM). Observaram que o Bruxismo foi significativamente mais prevalente entre fumantes $(p=0,012)$. Não observaram associação com bruxismo para as variáveis, idade, estado civil e sexo. Porém notaram que no grupo de indivíduos que apresentavam bruxismo frequente $(n=74)$ os sintomas de DTM eram menos dolorosos $(p=0,004)$, enquanto que as perturbações afetivas e a insônia ocorriam com maior frequência do que a média.

Ahlberg et al. (2005), investigaram a prevalência, a percepção, e a gravidade da dor orofacial, enviando questionário padronizado a funcionários de uma emissora finlandesa e a um número igual de controles selecionados aleatoriamente nesta mesma empresa. O objetivo era analisar se a dor orofacial da atualidade estava associada a relatos de bruxismo e sintomas de insônia. Relacionaram os relatos de bruxismo, sintomas biopsicossociais (estresse, desordens de sono e sintomas de dor), o tabagismo e sintomas de disfunção temporomandibular (DTM), descobrindo que o estresse, desordens do sono, sintomas múltiplos de dor e sinais relacionados à DTM estavam associados ao frequente bruxismo.

Para Lopes et al. (2007), as facetas de desgaste normalmente são atribuídas a muitas variáveis que podem ocorrer simultaneamente ou não tais como: hábitos parafuncionais, regurgitação ácida, elementos da dieta, interferências e traumas oclusais. As facetas de desgaste causadas pela atrição dental se caracterizam pelo desgaste das estruturas duras do dente através do contato dentário. Já a abrasão 
dental ocorre graças à utilização de agentes abrasivos interpostos entre as superfícies dentárias. A erosão dental é geralmente caracterizada pela perda de estrutura dentária frente a agentes ácidos. Uma grande desvantagem da avaliação do bruxismo pelo desgaste dental consiste na ausência da comprovação tanto de um bruxismo em curso, como da realização do apertamento dental estático. 0 desgaste dentário é um registro cumulativo de ambas as atividades, funcionais e parafuncionais, acrescidos de fatores diversos, tais como idade, dieta e sexo e outros fatores a que a dentição está exposta (Shetty et al., 2010).

Suspeita-se que o bruxismo seja um fator de risco para a dor na disfunção temporomandibular (DTM). Schierz et al. (2007), investigaram a relação entre o desgaste dental anterior como um indicador para o bruxismo e a presença de dor de DTM. O estudo incluiu 646 participantes (35 a 44 anos) de um inquérito nacional de saúde bucal na Alemanha. O desgaste dental anterior foi aferido para cada dente anterior utilizando 4 parâmetros (nenhum desgaste, leve, moderado e grave). A DTM foi diagnosticada pelo auto-relato (último mês) de dor: no rosto; nos músculos da mandíbula e/ou ATM. Os resultados não demonstraram relação estatisticamente significativa e clinicamente relevante entre um aumento linear de desgaste dentário e risco de dor por DTM. Os autores concluíram que o desgaste dental anterior não está associado com o auto-relato de dor de DTM na amostra estudada. Parece não existir uma evidência clinicamente relevante que relacione bruxismo e dor de DTM, ao desgaste de dentes anteriores em longo prazo.

Ahlberg (2008), realizou uma revisão das publicações sobre o bruxismo, dos cinco anos precedentes, na base de dados da PubMed. A autora relacionou 35 estudos sobre o tema bruxismo do sono em que os sujeitos foram avaliados e monitorados por gravações durante a noite. Identificou 33 estudos sobre bruxismo sono / vigília, e os separou segundo diferentes critérios. Observou 13 publicações em que o bruxismo foi detectado pelo autorrelato, 10 publicações com o diagnostico do bruxismo realizado pelo auto-relato associando-o com sinais clínicos, além de 10 estudos experimentais. Realizou um estudo investigativo com profissionais da mídia (profissionais de jornalismo, radiodifusão, produção de programas, apoio técnico e administração), que reconhecidamente trabalhavam em estado de pressão, devido às intensas mudanças tecnológicas, organizacionais e econômicas. O estudo fez 
parte de uma investigação detalhada do trabalho em turnos, associando-o às consequências da alteração dos ciclos sono / vigília. Examinou entre os funcionários com trabalho por turnos irregulares a relação da qualidade do sono e do autorrelato do bruxismo, além de uma possível associação do bruxismo com a dor orofacial. Foi enviado a todos os funcionários com turnos irregulares ( $n=750 ; 57,0 \%$ homens), e a um número igual de controles selecionados aleatoriamente, com trabalho regular diurno de oito horas (42,4\% homens), um questionário com perguntas padronizadas que avaliou as características demográficas, dados sobre o emprego, o estado geral de saúde, o estado físico, os sintomas de dor, sintomas psicossomáticos, o estado psicossocial, o estresse, o desempenho e a satisfação no trabalho, além da percepção do sono e suas consequências quando em vigília. $O$ bruxismo foi detectado em $10,6 \%$ da amostra. O montante de $43,6 \%$ dos indivíduos relataram perturbações do sono e $36,2 \%$ relataram não ter sono reparador. A dor orofacial foi observada em $19,6 \%$ da população do estudo. A autora observou que o bruxismo frequente $(p<0,01)$ e o estresse grave $(p<0,001)$ tendem a ocorrer mais frequentemente entre sujeitos insatisfeitos com seu turno de trabalho. Os resultados também revelaram associação significativa entre o autorrelato do bruxismo e a ansiedade, e do bruxismo com a experiência de dor orofacial. Com base nas análises multivariadas, a autora conclui que as perturbações do sono e o bruxismo podem estar concomitantemente envolvidos no desenvolvimento da dor orofacial.

Baseados nas evidencias disponíveis na literatura, Sutin et al. (2010) elaboraram uma coletânea de sinais e sintomas, além de questões e critérios para o diagnóstico do BS. Dentre os sintomas elencaram: ranger de dentes acompanhados de sons característicos (geralmente relatados pelo companheiro de quarto); dores na ATM; dores na musculatura mastigatória e cervical; dores de cabeça (especialmente na região temporal ao acordar); hipersensibilidade dental; mobilidade dental; baixa qualidade do sono e cansaço. Quanto aos sinais mencionaram: desgaste dental anormal; endentações na lingual; linha Alba ao longo do plano de mordida; recessão gengival; presença de tórus maxilar e/ou mandibular; aumento da atividade muscular; hipertrofia dos músculos masseteres; redução do fluxo salivar; fraturas de dentes e/ou restaurações e limitação da abertura bucal. Os autores sugerem a utilização de questões tais: Você sabe se frequente ou ocasionalmente aperta ou range os dentes enquanto dorme; Alguém the falou que você range os dentes 
enquanto dorme; Você percebeu tensão ou fadiga em seus músculos faciais, dentes e gengivas ao acordar; Você já acordou com os maxilares travados, difíceis de serem abertos; Você acorda com dor de cabeça ou dores na nuca; Você percebeu um desgaste em seus dentes. Como critérios de diagnóstico para a detecção do BS os autores sugerem: ao menos dois episódios de bruxismo com sons audíveis; mais do que quatro episódios de bruxismo por hora de sono e/ou mais do que vinte e cinco surtos de bruxismo por hora de sono e/ou mais do que seis surtos de ARMM por episódio de bruxismo.

$\mathrm{Na}$ dificuldade de realizar o exame de polissonografia para o diagnóstico do bruxismo, principalmente devido ao seu alto custo (Van Der Zaag et al., 2005), alguns pesquisadores utilizam questionário de autorrelato e avaliação clínica para a detecção do bruxismo. Com o objetivo de avaliar a influência das placas intraorais na modulação da atividade muscular rítmica mastigatória (ARMM), e da dor muscular durante a mastigação, que pode ocorrer durante o BS, Pomponio (2010), avaliou clinicamente amostra de pacientes quanto aos sinais e sintomas do bruxismo do sono e dor orofacial, por meio de um questionário padronizado utilizado na Clínica da Equipe de Dor Orofacial/ATM, da Divisão de Odontologia do Hospital das Clínicas - FMUSP. Entre outras questões, a ficha inquiriu sobre: dor (periodicidade; intensidade; forma de aparecimento; duração e tipo; período/horário e localização). A investigadora questionou diferentes tipos de hábitos (morder língua, lábio, bochecha, objetos), e especificamente sobre o ranger de dentes. Colheu informações também sobre a ocorrência de cansaço ao acordar, ao mastigar, e percepção de dor ou ruídos na face ou ouvidos. Ao exame físico avaliou: assimetria facial; hipertrofia do músculo masseter; presença de mordida aberta, cruzada, sobremordida; desgastes dentais; linha media; ruídos na ATM (crepitação, estalos); movimentos articulares de lateralidade, abertura e protrusão. Realizou também manobras de palpação das ATMs e dos músculos masseteres. 


\subsection{Bruxismo, DTM e Dor Craniofacial}

Feinstein em (1970), adotou o termo comorbidade no sentido de indicar uma associação entre duas doenças em estudos clínicos. O conceito evoluiu e em 1994, Lipton e Silberstein (1994) agregaram o sentido de uma associação mais do que coincidente entre duas doenças. Assim, os BS apresentam geralmente comorbidades (Kampe et al., 1997b; Camparis; Siqueira, 2006) e características de dor crônica decorrentes da fadiga dos músculos masseter e temporal, em função do ranger de dentes (Kampe et al., 1997b).

A dor, definida pelo International Association for the Study of Pain (1986), é uma experiência sensorial e emocional desagradável e pode estar associada a lesões reais ou potenciais. Representa um aspecto subjetivo e é dependente da experiência pregressa individual. Ela apresenta os aspectos agudo e crônico. A dor aguda tem caráter protetor e ocorre geralmente quando há um dano tecidual, havendo um cessar do quadro álgico após a resolução do problema. Já a dor crônica é caracterizada pela persistência dos sintomas por mais de 6 meses, em que geralmente há um dano real (Antunes; Peres, 2006; Medeiros, 2010). A dor crônica não tem efeito protetor e pode desencadear estresse físico, emocional e social tanto para o indivíduo, quanto para seu círculo familiar e social (Sessle, 1987). Níveis elevados de tensão muscular podem levar a sensibilização dos caminhos da dor. As dores musculares de cabeça e pescoço geralmente induzem a uma dor reflexa secundária, passível de manifestar-se como dor dentária. Neste quadro, o local da dor pode ser diferente de seu local de origem. Desta forma, as dores dentais podem ser decorrentes de dores reflexas, pela ativação de "pontos de gatilho" provenientes dos músculos da mastigação, principalmente masseter e temporal (Medeiros, 2010). O método de autorrelato da dor não mensura a nocicepção dolorosa, mas sim, sua experiência, passíveis de influências de histórias prévias (Antunes; Peres, 2006; Medeiros, 2010).

A "disfunção" é uma característica de vários tipos de dores musculoesqueléticas, e uma adaptação protetora normal que não a causa da sintomatologia dolorosa. Portanto, a dor apresentada por indivíduos com BS ocorre 
devido à fadiga principalmente dos músculos da mastigação (masseter e temporal), e em decorrência do ranger de dentes (Kampe et al., 1997b). As disfunções temporomandibulares (DTM) podem ser definidas como um conjunto de condições dolorosas e/ou disfuncionais, que envolvem os músculos da mastigação e/ou as articulações temporomandibulares (ATM) (Branco et al., 2008).

As Desordens Temporomandibulares (DTM) abrangem um número de condições clínicas que envolvem a musculatura mastigatória ou a articulação temporomandibular (ATM) além das estruturas associadas. As DTMs são caracterizadas por desequilíbrios entre os elementos anatômicos do sistema estomatognático e estruturas adjacentes, com o comprometimento de seu funcionamento fisiológico normal (Fonseca et al., 1994; Barbosa et al., 2003; Medeiros, 2010). As desordens álgicas orofaciais da região da articulação temporomandibular (ATM) englobam fadiga nos músculos craniocervicofaciais, principalmente nos músculos da mastigação, presença de ruídos articulares e limitação dos movimentos mandibulares (Dworkin; Le Resched, 1992; Medeiros, 2010). Os músculos masseter e temporal frequentemente estão comprometidos na DTM. Trabalhos como os de Auerbach et al. (2001) e Glaros et al. (2005), destacam também os componentes emocionais e comportamentais no desenvolvimento e manutenção das DTMs.

O apertamento dental pode constituir um fator etiológico e de perpetuação de quadros clínicos de DTM (Abrão; Fornasari, 2005; Medeiros, 2010), além de induzir de forma secundária à hipertrofia do músculo masseter (Huynh et al., 2007). A condição clínica do apertamento dental é caracterizada por dor na região préauricular, das ATMs ou nos músculos da mastigação, podendo ocorrer limitação ou desvio durante a função mandibular, além da produção de sons (clicks/crepitação) na ATM (Pergamalian et al., 2003). Outros fatores etiológicos podem estar presentes de forma isolada ou concomitante nas Disfunções Temporomandibulares, tais como: alterações na oclusão, estresse, ansiedade e depressão (Garcia et al., 1997; Abrão; Fornasari, 2005; Medeiros, 2010).

Os pacientes que apresentam BS queixam-se frequentemente de dores crônicas na face e/ou cabeça (Van Der Zaag et al., 2005; Camparis; Siqueira, 2006). Porém, permanece obscuro se existe uma associação entre o bruxismo e Distúrbios 
da Articulação Temporomandibular (DTM). As dores de cabeça no bruxismo são muito mais comuns do que as causadas por enxaquecas, pois quando a mandíbula e a maxila estão pressionadas, ocorre uma isquemia crescente com queda da oxigenação e acúmulo de produtos metabólicos, o que ocasiona um estímulo das terminações nervosas, que geram a dor (Gimenes, 2008).

Lobbezoo e Lavigne (1997) e Lobbezoo et al. (2008) afirmaram não ser possível estabelecer uma relação de causa-efeito entre bruxismo e DTM, devido ao grande número de influências envolvidas, no entanto, acreditam que o bruxismo leva a sinais e sintomas característicos de um ou mais subtipos de DTMs, sugerindo uma participação do BS na dor e disfunção temporomandibular (Velly et al., 2003; Melo; Barbosa, 2009). Pergamalian et al. (2003), estudaram 84 indivíduos com diagnóstico prévio de DTM, de acordo com os Critérios Diagnósticos de Pesquisa para DTM (RDC / TMD). Por meio de entrevista coletaram dados da história bucal, dos hábitos orais, e avaliaram as facetas de desgaste. O bruxismo foi detectado com o auxílio de um questionário e teve sua frequência avaliada. Os autores observaram que os pacientes que relataram mínima ocorrência de bruxismo, apresentaram maior número de sítios dolorosos nas articulações (ATM), do que os pacientes que relataram bruxismo frequente. Concluíram então que, a condição clínica de DTM, que é caracterizada por dor na região da ATM, pode causar limitação ou desvios na função mandibular (trismo). Além disso, relataram que o bruxismo não está associado a maiores níveis de intensidade de dor muscular. Observaram também, uma associação inversa significativa, entre bruxismo e dor articular onde um mínimo de bruxismo está associado com maior severidade e níveis de dor nas ATMs .

Ciancaglini et al. (2001), investigaram a relação do bruxismo com a dor craniofacial e a sintomatologia no sistema mastigatório. A idade dos 438 voluntários variou de 18 a 75 anos. Foi aplicado um questionário sobre as condições orais, sintomas e distúrbios mastigatórios, dor craniofacial e dores no pescoço. Foi avaliada a prevalência do bruxismo em 31,4\%. Os autores associaram o bruxismo à dificuldade de abertura e fechamento da boca, ruídos da ATM, dor craniofacial, sensibilidade dolorosa durante a movimentação mandibular, rigidez ou fadiga mandibular e dor no pescoço. Os autores levantaram a hipótese de que muitos mecanismos podem induzir à dor craniofacial e à disfunção temporomandibular. 
Relataram também que o bruxismo, uma vez que induz a uma prolongada estimulação da atividade mecânica e neuromuscular no sistema mastigatório, têm lugar no rol das patogêneses que influenciam as dores faciais e as disfunções temporomandibulares. Indivíduos que apresentam BS têm de três a quatro vezes mais chances de desenvolver dor orofacial, sons articulares e travamento temporomandibular (Dao et al., 1994).

A dor orofacial tem associação com diversos sintomas psicológicos que podem levar ao sofrimento psíquico, agravando as manifestações dolorosas (Serralta et al., 2001) e o paciente com bruxismo parece apresentar importantes fixações orais e concentrar as tensões emocionais especificamente na região bucofacial. Seralta e Freitas (2002) avaliaram 20 bruxistas e 20 não bruxistas, emparelhados por sexo, estado civil e idade. Encontraram diferenças significativas quanto aos bruxômanos apresentarem personalidade mais ansiosa e depressiva que os controles, tendendo a dirigir a agressividade, a si próprio, e necessitando de mecanismos para o controle da raiva. Agressividade reprimida, tensões emocionais e ansiedade podem levar ao hábito parafuncional de apertar e ranger os dentes. Os autores concluíram que é inegável que fatores psicológicos, especificamente a expressão de emoções negativas, estão fortemente relacionados com o bruxismo e, portanto, requer atenção especial em seu tratamento.

Para Camparis e Siqueira (2006), a dor referida por bruxistas do sono tem características de dor crônica, e estes indivíduos, apresentam mais distúrbios emocionais, distúrbios do sono e/ou maior número de comorbidades (Kampe et al., 1997b). O bruxismo provavelmente é uma das causas ou fator de risco da dor orofacial e DTM. Porém, ainda não é possível estabelecer uma relação causa-efeito entre bruxismo e DTM (Lobbezoo; Lavigne, 1997; Lobbezoo et al., 2008), no entanto estudos tem mostrado uma associação entre queixas concomitantes de BS e dor da musculatura mastigatória, fato que pode sugerir algum grau de participação do bruxismo do sono na dor e disfunção temporomandibular (Velly et al., 2003).

Com o objetivo de melhor compreender a dor musculoesquelética crônica facial e sua relação com o bruxismo do sono, Camparis et al. (2006), compararam 40 pacientes distribuídos igualmente em dois grupos, portadores de bruxismo do sono com e sem dor miofacial. Utilizaram como instrumento o exame de polissonografia. 
Avaliaram o número de burst, a eficiência e a latência do sono, os episódios de bruxismo por hora, a duração dos episódios e a porcentagem de sono NREM e REM de cada indivíduo. Não encontraram diferenças estatisticamente significantes entre os grupos, com e sem sintomatologia dolorosa, para todas as variáveis. Ficou evidente para os autores que as características polissonográficos dos pacientes com bruxismo do sono, com e sem dor orofacial, são semelhantes, mas não esclareceram os motivos pelos quais alguns pacientes BS desenvolvem dor crônica miofacial, e outros não.

Schierz et al. (2007), declararam que o bruxismo é supostamente um fator de risco para a dor na disfunção temporomandibular (DTM). Investigaram a relação entre o desgaste dos dentes anteriores como um indicador para o bruxismo e a presença de dor DTM em 646 sujeitos na faixa etária de 35 a 44 anos por meio de um inquérito de saúde oral nacional na Alemanha. A presença da disfunção temporomandibular foi definida pelo autorrelato de dor no rosto, mandíbula músculos e/ou articulação temporomandibular (ATM) durante o último mês, de acordo com a versão alemã do Research Diagnostic Criteria for Temporomandibular Disorders ou da resposta a uma pergunta sobre a dor nos músculos da mastigação ou na ATM de acordo com o Índice de Helkimo. Após a análise dos dados os autores puderam concluir que o desgaste dental anterior não foi associado com o autorrelato de dor de DTM.

O bruxismo do sono (BS) e o apertamento dentário durante a vigília (BD) têm sido associados às desordens temporomandibulares (DTM), dores de cabeça, e queixas quanto ao sono e comportamentais. Com o objetivo de avaliar a prevalência dos fatores de risco destes sinais e sintomas em uma população de 7 - 17 anos de idade $(n=604)$, Carra et al. (2011), investigaram pacientes que procuravam tratamento ortodôntico. Os dados foram coletados por meio de questionário e por exame clínico, que avaliaram a morfologia craniofacial e a saúde bucal. O bruxismo do sono foi relatado por $15 \%$ da população, sendo o apertamento, durante a vigília (BD), mencionado por $12,4 \%$ indivíduos. O grupo BS ( $n=58)$ foi composto principalmente por crianças $(67,3 \% \leq 12$ anos de idade) e do grupo BD $(n=42)$ composto principalmente por adolescentes $(78,6 \%$ eram $\geq 13$ anos de idade). A morfologia craniofacial de mais de $60 \%$ dos indivíduos BS correspondeu ao modelo 
dental classe II, e $28,1 \%$ eram do tipo braquifacial. Comparados com os controles (n = 220), os indivíduos com BS apresentaram maior risco em sofrer de fadiga da musculatura mandibular [OR ajustado $(A O R)=10,5$ ]; dor de cabeça, $(A O R=4,3)$, e respiração ruidosa durante o sono $(A O R=3,1)$. Quando comparados com o grupo controle, os indivíduos com BD informaram a presença de "clicks" na ATM $(A O R=5)$; fadiga na musculatura mandibular $(A O R=13,5)$ e diversas queixas sobre o sono e comportamentais. Os autores concluíram que tanto $\circ \mathrm{BD}$ quanto $\circ \mathrm{BS}$ estão frequentemente associados com sinais e sintomas sugestivos de DTM, problemas com o sono e de comportamento.

Bender (2012) acredita que as dores de cabeça e a dor facial são comuns na população em geral. Em muitos casos, a dor facial pode ser decorrente de distúrbios da articulação temporomandibular. Estudos identificaram uma associação entre dores de cabeça e transtornos da articulação temporomandibular sugerindo a possibilidade de que estas duas entidades partilhem os mesmos mecanismos fisiopatológicos.

\subsection{Bruxismo e Oclusão}

Rodrigues et al. (2006) em dissertação de Mestrado objetivou avaliar o papel da guia anterior no desencadeamento da sintomatologia craniomandibular. Empregou dispositivos oclusais, placa anterior de mordida e plano de mordida anterior, para restaurar a guia anterior de pacientes que apresentavam deficiência da guia anterior com sintomatologia dolorosa craniomandibular. Os aparatos proporcionaram proteção oclusal posterior e conforto nos movimentos excêntricos da mandíbula, além de reduzir a um mínimo a sensação dolorosa e o tônus muscular. $O$ autor então observou a importância da guia anterior na estabilidade, conforto e harmonia do sistema estomatognático, sendo que sua ausência ou deficiência acarreta distúrbios dolorosos, espasmódicos e até psicológicos. 
Tanne et al. (1993) relataram a existência de uma associação entre mordida aberta, mordida cruzada posterior e mordida profunda, relacionada com a ocorrência de DTM.

\subsection{Bruxismo e Força de Mordida}

O quadro de DTM acarreta distúrbios no padrão do sono, o que pode desencadear um aumento da atividade parafuncional de ranger e/ou apertar os dentes. Durante os episódios de BS a força máxima de mordida se apresenta 3 a 4 vezes maior do que a realizada voluntariamente durante a vigília, em decorrência da redução dos controles inibitórios durante o sono.

Nishigawa et al. (2001) mediram a força de mordida em episódios de BS em 10 indivíduos. Nos resultados detectaram uma amplitude média nos eventos de bruxismo de 22,5 kgf. (s.d. $13.0 \mathrm{kgf}$.) com duração média de $7.1 \mathrm{~s}$ (s.d. $5.3 \mathrm{~s}$ ). A maior amplitude de força de mordida durante o sono noturno, observada individualmente foi de 42,3 kgf. (15,6-81,2 kgf.). A força máxima de mordida voluntária enquanto acordado (diurno) foi de 79,0 kgf. (51,8-99,7 kgf.) e a razão média da força máxima de mordida BS/BD foi de 53,1\% (17,3-111,6\%). Estes dados indicam que a força de mordida noturna durante a execução do bruxismo pode exceder a amplitude da força máxima de mordida voluntária durante o dia. Os autores ressaltaram que a força de contato dental noturno poderia exceder a amplitude da força máxima de apertamento voluntário durante o dia.

\subsection{Bruxismo e Hábitos Parafuncionais}

Os hábitos parafuncionais, por definição, são atividades realizadas além da atividade funcional. A musculatura tende a trabalhar mais, podendo entrar em fadiga, e desta forma, alterar sua função e gerar tensão, hiperatividade muscular e ocasionar dor e desconforto. Este quadro ocorre frequentemente em indivíduos com 
DTM. Geralmente resultam em microtraumas, ou seja, forças de pequena magnitude aplicadas repetidamente às estruturas articulares por um longo período de tempo. Caso as cargas persistam, alterações nos mecanismos de movimentação côndilodisco podem acontecer predispondo à ruptura da harmonia do sistema estomatognático, e levando-o ao desequilíbrio (Melo; Barbosa, 2009).

Os hábitos parafuncionais são comuns em crianças portadoras de bruxismo. Entre os hábitos parafuncionais podem ser citados: apertamento dental, mastigação unilateral, onicofagia (roer unhas), jogo mandibular, mascar chicletes, hábitos de morder o lábio ou bochechas, objetos, sucção de dedos, sucção sem finalidade nutritiva (chupeta), hábito de ranger os dentes durante o dia e o bruxismo do sono. Estes hábitos se persistentes podem ter efeitos profundos sobre as estruturas orofaciais, e são considerados fatores que contribuem para a manifestação de Disfunções Temporomandibulares (DTM). No entanto, a relação entre hábitos orais parafuncionais e DTM, ainda é controversa (Barbosa et al., 2008).

Widmalm et al. (1995), estudaram crianças de 4-6 anos, caucasianas $(n=153)$ e Africo-Americanas $(n=50)$, quanto aos sinais e sintomas de Distúrbios Craniomandibulares (DCM) e parafunções orais. Na análise dos dados encontraram uma manifestação de dor recorrente na ATM em 8\% (1-2 vezes por semana), 5\% tinham dor de garganta recorrente, sendo mais frequente nas crianças AfroAmericanas ( $p<0,05)$. A dor de cabeça recorrente ocorreu em $17 \%$ das crianças. Três por cento tiveram dor de ouvido, recorrentes. Relataram dor ou cansaço nos maxilares durante a mastigação $25 \%$ das crianças, sendo mais frequente em Afro-Americanas do que em caucasianas $(P<0,001)$, e com frequência maior em meninas do que em meninos $(p<0,05)$. A dor durante a abertura da mandíbula ocorreu em $10 \%$ da amostra, sendo mais frequente em Afro-Americanos do que no grupo caucasiano $(p<0,001)$. Treze por cento das crianças tinham problemas em abrir a boca e $2 \%$ tinham limitação da abertura bucal. Encontrada também dor à palpação na área lateral da ATM em 16\%, na área posterior da ATM em 25\%, nas áreas dos músculos temporal e masseter em $10 \%$ da amostra. Admitiram ruídos no ouvido, 34\% dos Afro-Americanos, e $15 \%$ das crianças caucasianas ( $p<0,01$ ). Os autores encontraram uma correlação significativa entre bruxismo, onicofagia, sucção do polegar e desordens temporomandibulares. 
Ferreira e Toledo (1997) avaliaram 427 crianças, de 3 a 6 anos, de ambos os sexos, para verificar a relação entre o tempo de aleitamento materno e a etiologia de hábitos bucais parafuncionais. As mães responderam a um questionário declarando os hábitos alimentares, tempo de aleitamento e desmame. As crianças foram submetidas ao exame clínico para verificar a oclusão e a prevalência de hábitos nocivos, por um único avaliador. Observaram que quanto mais prolongado o tempo do aleitamento materno, menor a ocorrência de hábitos orais nocivos, como o bruxismo.

Gavish et al. em 2000 investigaram em 248 meninas de escola secundária, entre 15 e 16 anos, a prevalência de hábitos parafuncionais severos e sua associação com o desenvolvimento de sinais e sintomas de DTM. Avaliaram clinicamente a presença de facetas de desgaste em canino, endentações na língua, sensibilidade muscular à palpação e ruídos na ATM. Através de questionário levantou dados sobre sintomas de DTM, hábitos bucais de mascar chiclete, roer unhas, morder objetos, comer sementes, triturar gelo, apoio da mandíbula, "jogar a mandíbula" (pequenos movimentos mandibulares sem contato oclusal), apertamento e bruxismo. Observaram uma alta prevalência do hábito de mascar chicletes, pelo odor, prazer e relaxamento, sendo que $92 \%$ das estudantes mascavam diariamente e $48 \%$ delas mascavam por mais de três horas por dia. Este hábito foi associado à sensibilidade muscular e aos ruídos articulares. O hábito de "jogar a mandíbula" foi associado aos distúrbios articulares. Os autores concluíram que este hábito constitui-se em potencial danoso aos músculos da mastigação e à ATM. A prevalência de bruxismo diurno consciente foi de $22 \%$ e a de bruxismo noturno consciente foi de $12,7 \%$. Não encontraram associação entre presença de bruxismo e sensibilidade muscular à palpação ou distúrbios da ATM. Entretanto não encontraram uma associação significante entre o bruxismo diurno e o bruxismo noturno relatado. Quanto ao desgaste dental causado pelo bruxismo, $18,4 \%$ apresentaram desgaste em esmalte e dentina nas cúspides dos caninos e 38,4\% apresentaram desgaste apenas em esmalte. Constataram uma associação positiva entre movimentos mandibulares sem toque oclusal, e distúrbios da ATM como estalos e tensão da mesma. 
Cauás et al. (2004) acreditam que os hábitos parafuncionais são frequentemente fatores contribuintes da DTM, e podem levar a uma oclusão traumática predisponente à disfunção.

Para analisar a predição de bruxismo, outras parafunções e o desgaste dental, Carlsson et al. (2003), realizaram um estudo com indivíduos avaliados clinicamente e por questionário 20 anos antes, isto é, aos 7, 11 e 15 anos. Do grupo original, 402 indivíduos, foram contatados 378 (94\%) pessoas, com 27, 31 e 35 anos. Destes, 320 indivíduos (85\%) devolveram o questionário preenchido. Do grupo de 35 anos, 100 pessoas (81\%) foram reavaliadas através de exame clínico, focando os fatores de oclusão, a função e disfunções do sistema mastigatório. O questionário era constituído de perguntas sobre: presença de sintomas no sistema mastigatório, dores de cabeça, estresse, depressão, parafunções orais, trauma prévio na face, tratamento de DTM neste período e necessidade de tratamento atual. Os parâmetros de avaliação clínica: extensão dos movimentos e grau de desgaste oclusal. Os resultados sugeriram uma possibilidade três vezes maior da presença de bruxismo no primeiro exame se confirmar após 20 anos. Os autores concluíram: a) relatos subjetivos de bruxismo em crianças (definido como apertamento durante 0 dia e/ou ranger noturno); apenas apertamento; ranger apenas noturno; onicofagia e/ou outras parafunções, predizem a mesma parafunção oral 20 anos mais tarde; b) os prognosticadores de dois componentes do bruxismo, apertamento diurno e ranger noturno, não são os mesmos, o que apoia a hipótese de que estas sejam parafunções diferentes; c) o desgaste dental na infância prediz um desgaste maior de dentes anteriores na fase adulta; d) uma interferência no lado de balanceio reduz o risco de desgaste dentário excessivo em dentes anteriores nos pacientes de 35 anos.

Miyake et al. (2004) realizaram um estudo para investigar se as parafunções orais estão associadas com os sintomas de desordens temporomandibulares em 3.557 estudantes universitários japoneses, com idades entre 18 e 26 anos. Observaram a prevalência de estalos na articulação temporomandibular de 41,7\%; dor da ATM de cerca de 16,0\% e a limitação da abertura bucal de 16,3\%. A parafunção mais prevalecente foi a de dormir sobre um dos lados, que apresentou 
porcentagem de 60,2\%, seguida do apoio mandibular (44,8\%). As mulheres apresentaram DTM em maior proporção que os homens.

A abrasão dentária e a hipertrofia dos músculos masseteres podem ser utilizadas para a confirmação do diagnóstico clínico do bruxismo do sono, além do relato de ranger dental fornecido pelo parceiro de sono. No entanto, a validade destas alterações é considerada fraca, pois a hipertrofia poderia ser secundária ao hábito do apertamento durante o estado de vigília. Huynh et al. (2007) afirmaram que o diagnóstico definitivo para o BS baseia-se principalmente no relato dos ruídos característicos realizados durante o sono, e na percepção de dor ou tensão na musculatura da face ao despertar. A hipertrofia idiopática do músculo masseter é um raro distúrbio de causa desconhecida. Alguns autores associam ao hábito de mascar chiclete, a disfunção da articulação temporomandibular, hipertrofias congênitas e funcionais e distúrbios emocionais (estresse e nervosismo). Segundo Rispolib et al. (2008), o diagnóstico da hipertrofia do músculo masseter pode ser realizado a partir de exame clínico, de entrevista dirigida (com avaliação da assimetria facial) e da palpação muscular, entre outros. O diagnóstico consistiu na palpação muscular intra e extraoral. Há avaliação extraoral observa-se, um aumento de volume que varia da consistência mole, na região do masseter, que se torna rígido, enquanto o paciente cerra seus dentes. A proeminência durante a contração muscular revela o aumento de volume no caso da hipertrofia. A avaliação intra-oral é realizada com a boca relaxada e ligeiramente aberta. Por meio da palpação com as duas mãos pode-se identificar a localização intramuscular da hipertrofia. Geralmente os pacientes que tem hipertrofia acentuada do músculo masseter apresentam queixa da alteração estética decorrente da assimetria facial (rosto quadrado), e podem apresentar sintomas como trismo, protrusão e bruxismo.

Hábitos bucais (sucção de dedo, onicofagia, morder objetos), podem ser comuns e ocorrer de forma transitória. Crianças que não apresentam hábitos bucais tem uma maior prevalência de bruxismo sugerindo que essa parafunção pode atuar como uma alternativa para o alívio do estresse. No entanto, quando a execução do hábito excede a tolerância fisiológica do sistema estomatognático, este pode entrar em colapso e prejudicar a saúde do indivíduo. Na investigação do bruxismo em populações jovens a coleta dos dados, geralmente é realizada por meio de 
entrevistas com as crianças, do preenchimento de questionários com os responsáveis e também pela avaliação dos desgastes dentários causados pelo bruxismo. Gonçalves et al. (2010) avaliaram a relação entre bruxismo excêntrico, fatores oclusais e hábitos bucais em crianças e adolescentes, alunos da rede pública da cidade de Brasília/DF. Utilizaram um grupo de 680 escolares, de ambos os gêneros, na faixa etária de 4 a 16 anos, selecionados aleatoriamente. Os dados foram coletados através da avaliação clínica e da aplicação de questionários aos responsáveis pelos alunos. Quanto aos aspectos morfológicos da oclusão foram avaliados entre outros a mordida cruzada anterior e posterior, uni ou bilateral. Frente aos resultados obtidos, na amostra estudada, os autores concluíram que não houve relação estatisticamente significante entre o bruxismo e fatores oclusais tais como mordidas cruzadas. No entanto, observaram relação estatisticamente significativa entre o bruxismo e especificamente o hábito bucal de sucção de chupeta.

\subsection{Bruxismo e Qualidade de Vida}

Qualidade de vida é definida como a "percepção do indivíduo de sua posição na vida, no contexto da cultura e sistema de valores nos quais ele vive e em relação aos seus objetivos, expectativas, padrões e preocupações". (The WHOQOL Group, 1998). Existem diferentes instrumentos para avaliar a qualidade de vida, entre eles, a versão simplificada em português do Oral Health Impact Profile (OHIP-14) em que são avaliados: a satisfação com a saúde; a dimensão do incômodo causado por dores físicas; a frequência da necessidade de atendimento médico; a percepção do aproveitamento e do sentido de viver; a capacidade de concentração e sensação de segurança; a salubridade do meio ambiente; a satisfação com a disponibilidade de energia vital diária, capacidade econômica, de locomoção, de atividades de lazer; a satisfação com o sono, capacidade de trabalho; a satisfação pessoal, com amigos, parentes e colegas de trabalho; aspectos da satisfação sexual, do local de moradia, do acesso aos serviços de saúde; o posicionamento frente à qualidade dos meios de transporte utilizados; além da frequência de experiência de sentimentos negativos. 
A odontologia prioriza a utilização de recursos clínicos para diagnosticar as condições de saúde bucal, entretanto, o impacto que estas condições geram na qualidade de vida dos indivíduos geralmente não é levado em consideração ou informado (Bortoli et al., 2003). Em um estudo, Oliveira et al. (2003) avaliou o impacto da dor na vida de indivíduos portadores de DTM em que observou que a mesma, adiciona um aspecto negativo à qualidade de vida do indivíduo.

Rugh e Harlan (1988) afirmaram que, embora os episódios de bruxismo do sono pareçam ocorrer mais acentuadamente no estágio II do sono NREM estando relacionados a atividades de microdespertar, os episódios de bruxismo que se manifestam durante o sono REM podem causar maiores danos às ATMs.

Kato et al. (2003a) estudando pacientes com bruxismo do sono demonstraram que, os mesmos possuem sono dentro dos padrões de normalidade, porém, apresentam indução do despertar mais frequente, seguido de episódios de ARMM. Confirmaram então que, o bruxismo do sono é uma atividade motora exacerbada associada a um micro-despertar. As recentes evidências fisiológicas sugerem uma associação entre o sono e as excitações do BS, em que ocorre uma mudança sequencial autonômica (cardíaca) e atividades corticais cerebrais que precedem a atividade motora da mandíbula.

A hipertrofia dos músculos masseteres, além da abrasão dentária pode ser utilizada para a confirmação do diagnóstico clínico do bruxismo do sono, acrescidos do relato de ranger de dentes, fornecido pelo parceiro de sono. No entanto, a validade destas alterações é considerada fraca, pois a hipertrofia poderia ser secundária ao hábito do apertamento durante o estado de vigília (Huynh et al., 2007).

Rugh e Ware (1986) examinaram os registros polissonográficos de pacientes bruxômanos, com e sem sintomatologia dolorosa. Pretenderam determinar a ocorrência de alterações nos padrões do bruxismo e seu relacionamento com os diferentes estágios do sono. Os autores não identificaram diferenças significativas em relação ao tempo de atividade, nem ao tipo de bruxismo executado (BS e/ou BD). O grupo com sintomatologia dolorosa apresentou episódios de bruxismo durante a fase REM do sono, o que sugere que bruxistas com surtos na fase REM 
podem apresentar maior sintomatologia dolorosa e disfunção temporomandibular (DTM).

Coelho et al. (2009), argumentaram que pelo fato do bruxismo ocorrer durante o sono pode-se gerar incertezas quanto à interferência deste comportamento parafuncional na qualidade do sono. Assim, com o objetivo de verificar a relação entre o BS e a qualidade do sono, elaboraram um estudo em que o diagnóstico para o bruxismo foi realizado por meio de questionários e exame clínico. Os distúrbios do sono foram determinados pelo Índice de Qualidade de Sono de Pittsburgh. Para o diagnóstico do BS fizeram uma adaptação dos critérios adotados por Rugh e Harlan (1988), Lavigne et al. (1996) e Carvalho et al. (2008). Os autores consideraram bruxistas os pacientes com presença de facetas incisais ou oclusais alinhadas e com desgastes em grau 1, 2 ou 3 (incompatíveis com idade e função), associadas à presença de pelo menos um dos seguintes sinais e sintomas: história de ruídos de ranger durante o sono (nos últimos seis meses), confirmada por um companheiro de quarto; relato da musculatura mandibular rígida ou fatigada durante a noite e/ou ao despertar; sensibilidade dolorosa à palpação nos músculos masseter e/ou temporal e hipertrofia dos músculos masseteres.De acordo com os resultados obtidos neste estudo, os autores puderam concluir que, para o grupo específico estudado, a prevalência do bruxismo do sono foi de $31,11 \%$, e que não houve uma associação significante entre o BS e os distúrbios do sono, que foram avaliados subjetivamente. Concluíram, portanto, que a atividade do bruxismo parece não interferir na qualidade do sono daqueles que o possuem.

Simões-Zenariet e Bitar (2010), afirmaram que o bruxismo tem trazido prejuízos para a qualidade de vida das pessoas. Porém, suas implicações para a motricidade orofacial e a fala em crianças ainda não estão bem estabelecidas. As autoras realizaram um estudo com o objetivo de investigar a ocorrência de bruxismo e de fatores associados como: hábitos bucais, motricidade orofacial, funções de mastigação, respiração e deglutição em crianças de 4 a 6 anos. Participaram 141 crianças de três centros de educação infantil paulistas. As crianças passaram por avaliação da motricidade orofacial e o grupo de pesquisa foi composto pelas crianças cujos pais indicaram qualquer frequência de ranger ou apertamento de dentes, durante o sono ou não. Frente aos resultados, as autoras observaram uma 
elevada ocorrência de bruxismo (55,3\%), tendo por fatores associados: sialorreia durante o sono; uso de chupeta; hábito de morder os lábios; roer unhas; tônus de bochechas e tipos de mordidas alterados; além da participação da musculatura perioral durante a deglutição de líquidos. Também encontraram alta ocorrência, nos dois grupos, de queixa de dor de cabeça frequente $(76 \%)$, e que as crianças dormiam menos do que o recomendado para a idade (35\%). Concluíram que existe uma relação entre bruxismo, hábitos orais e aspectos alterados da motricidade orofacial de crianças da faixa etária estudada. O sono tem influência sobre o bem estar psicológico, assim como efeitos fisiológicos significativos e inúmeros processos estão a ele relacionados. É uma função biológica fundamental na consolidação da memória, na visão binocular, na termorregulação, na conservação e restauração da energia, e restauração do metabolismo energético cerebral. Devido a essas importantes funções, as perturbações do sono podem acarretar alterações significativas no funcionamento físico, ocupacional, cognitivo e social do indivíduo, além de comprometer substancialmente a qualidade de vida. 


\section{PROPOSIÇÃO}

O objetivo principal deste trabalho é o de determinar quais fatores do exame clínico estão relacionados especificamente ao bruxismo.

O objetivo secundário foi o de determinar se o bruxismo afeta a qualidade de vida. 


\section{MATERIAL E MÉTODOS}

A pesquisa consistiu em um estudo retrospectivo caso-controle, com andamento através das etapas de: submissão do Projeto de Pesquisa ao Comitê de Ética; recepção dos pacientes; aplicação do Termo de Consentimento Livre Esclarecido (Anexo B); imposição dos critérios de inclusão e exclusão; aplicação de questionário de Auto-relato (Anexo $\mathrm{C}$ ); questionário de Qualidade de Vida, The WHOQOL Group (1998) (Anexo D); execução de exame clínico (Anexo E); tratamento estatístico dos dados; análise e discussão dos resultados.

O Projeto de Pesquisa Clínica recebeu Parecer de Aprovação do Comitê de Ética em Pesquisa da Faculdade de Odontologia da Universidade de Sâo Paulo, e encontra-se protocolado sob o número FR 265058, Protocolo 91/2009, de 14 de setembro de 2009, (Anexo A).

\subsection{Características da Amostra}

O universo dos sujeitos da pesquisa foi constituído por 110 indivíduos, entre alunos, funcionários e pacientes da Faculdade de Odontologia da Universidade de São Paulo, situada na Av. Prof. Lineu Prestes, 2227 - Cidade Universitária - São Paulo - SP. Os sujeitos da pesquisa foram selecionados aleatoriamente, leram, tiveram suas dúvidas esclarecidas, concordaram e assinaram o Termo de Consentimento Livre e Esclarecido. Posteriormente os mesmos foram submetidos aos critérios de inclusão: ter de 18 a 65 anos, ambos os gêneros, estar físico e psicologicamente apto para responder aos questionários, submeter-se ao exame clínico, ter compreendido, aceito e assinado o Termo de Consentimento Livre Esclarecido (Anexo B). Foram excluídos os portadores de quadro psicótico; deficiência mental, portadores de periodontite e com ausências dentárias maiores que 2 dentes por quadrante (exceto $3^{\circ}$ molar). 
Da amostra inicial, apenas 85 indivíduos satisfizeram os critérios de inclusão e exclusão, tornando-se elegíveis a participar do projeto de pesquisa.

\subsection{Instrumentos de Coleta de Dados}

De acordo com a Classificação Internacional dos Distúrbios do Sono (CIDS2), o diagnóstico do BS pode ser realizado clinicamente e/ou em laboratório do sono (AASM, 2005). O exame ideal para a avaliação da presença do bruxismo é a polissonografia (Lavigne et al., 2003; Camparis; Siqueira, 2006; Camparis et al., 2006; Dutra et al., 2008). Este é reportado como o "padrão-ouro", considerado o método mais preciso para seu diagnóstico. A polissonografia verifica, estabelece e valida, através do monitoramento audiovisual, os critérios eletromiográficos estabelecidos e a especificidade da atividade motora orofacial. Desta maneira atividades motora como a deglutição, sucção de lábios, movimentos de cabeça, respiração bucal, bocejos, que representam 30\% das atividades orais, e podem ser confundidas com o BS, seriam descartadas (Lavigne et al., 2003; Dutra et al., 2008). Entretanto este é um método de alto custo, e exige o deslocamento do paciente (Carvalho et al., 2008) para um laboratório do sono.

Embora de cunho subjetivo, o conjunto de exames composto pelo questionário de auto-relato, entrevista, anamnese e avaliação clínica, são instrumentos considerados confiáveis, pois eliminam a existência de diagnósticos falso-positivos (Shinkai et al., 1998) e são instrumentos comumente utilizados para estabelecer a presença do BS (Carlsson et al., 2003; Van Der Zaag et al., 2005; Camparis et al., 2006; Pomponio, 2010). 


\subsection{Questionário de Auto-relato (ANEXO C)}

Para a elaboração do questionário de Auto-relato foi pesquisado na literatura quais os critérios e características observadas para o diagnóstico do bruxismo, utilizados por associações internacionais como a American Academy of Sleep Medicine (2005), a versão em português do questionário Research. Diagnostic Criteria for Temporomandibular Disorders (RDC/TMD): Axis II, desenvolvida por Dworkin e Le Resched (1992), assim como o protocolo utilizado pela equipe de dor orofacial/ATM - Divisão de Odontologia do Hospital das Clínicas- FMUSP (Pomponio 2010). Também diferentes autores reconhecidamente realizaram o diagnostico do BS sem o auxílio da polissonografia, mas lançando mão de anamnese e questionários de auto-relato e/ou avaliação clínica (Shinkai et al., 1998; Gavish et al., 2000; Pergamalian et al., 2003; Ahlberg et al., 2004; Sutin et al., 2010), aplicado inclusive via telefone (Ohayon et al., 2001).

Assim, dentre os critérios estabelecidos pela American Academy of Sleep Medicine (2005) e pela American Sleep Disorders Association (1990) para detectar a presença do Bruxismo constam: ocorrência de ranger dental durante o sono; acrescido da ocorrência de pelo menos um dos sinais: desgaste anormal dos dentes, sons associados ao ranger de dentes, desconforto nos músculos mandibulares. A versão em português do Research. Diagnostic Criteria for Temporomandibular Disorders (RDC/TMD): Axis II Dworkin e Le Resched (1992) inquire sobre a presença, nas últimas quatro semanas, de dor na face (mandíbula, queixo, lados da cabeça, frente do ouvido e/ou ouvido); travamento mandibular; interferência na capacidade de mastigar; percepção de estalos ao mastigar, abrir/fecha a boca; percepção ou relato de outros sobre o ranger ou apertar dos dentes durante o sono/vigília; sensibilidade/cansaço mandibular ao acordar; desconforto ao encostar os dentes; ocorrência de pancada ou trauma na face ou na mandíbula. Também há o questionamento sobre os últimos 6 meses quanto a dores de cabeça ou enxaqueca; dores na parte inferior das costas; musculatura dolorida, além de dificuldade em adormecer (Dworkin; Le Resched, 1992). Na ficha clínica utilizada pela equipe de dor orofacial/ATM - Divisão de Odontologia do Hospital das 
Clínicas- FMUSP (Pomponio, 2010), constam questões sobre a percepção de cansaço e/ou dor ao mastigar; dor de cabeça e/ou pescoço e/ou ombro e/ou face.

Com a somatória dos sinais e sintomas clínicos mais frequentemente elencados formulamos o questionário de Auto-relato (Anexo C):

- Apertamento dental (Lavigne et al., 2003; Pergamalian et al., 2003; Van Der Zaag et al., 2005; Cuccia, 2008; Lavigne et al., 2008; Pomponio, 2010; Carra et al., 2011).

- Ranger de dentes (Attanasio, 1997; Lavigne et al., 2001a; Ohayon, et al., 2001; Lavigne et al., 2003; Pergamalian et al., 2003; AASM, 2005; Van Der Zaag et al., 2005; Cuccia, 2008; Pomponio, 2010; Sutin et al., 2010).

- Ocorrência de ranger dental com produção de sons durante o sono, relatado pelo companheiro de quarto (ASDA) 1990; Dworkin; Le Resched, 1992; Kampe et al., 1997b; Bader, Lavigne, 2000; Lavigne et al. 2001a; Lavigne et al., 2003; Winocur et al., 2003; AASM, 2005; Van Der Zaag et al., 2005; Saletu et al., 2005; Van Der Zaag et al., 2007; Cuccia, 2008; Macedo, 2008; Lavigne et al., 2008; Pomponio, 2010; Sutin et al., 2010; de La Hoz-Aizpurua et al., 2011).

- Tensão na musculatura da face ao despertar (Dworkin; Le Resched, 1992; Winocur et al., 2003; AASM, 2005; Van Der Zaag et al., 2005; Huynh et al., 2007; Lavigne et al., 2007; Van Der Zaag et al., 2007; Cuccia, 2008; Lavigne et al., 2008; Pomponio, 2010).

- Dor, fadiga na musculatura mandibular (Rugh; Harlan, 1988; Dworkin; Le Resched, 1992; Kampe et al., 1997b; Shinkai et al., 1998; Ciancaglini et al., 2001; Lavigne et al., 2003; Pergamalian et al., 2003; Winocur et al., 2003; Van Der Zaag et al., 2005; Lavigne et al., 2007; Rompré et al., 2007; Van Der Zaag et al., 2007; Cuccia, 2008; Lavigne et al., 2008; Pomponio, 2010; Yachica et al., 2012).

- Dor de cabeça e/ou pescoço e/ou ombro e/ou face (Rugh; Harlan, 1988; Dworkin; Le Resched, 1992; Kampe et al., 1997b; Ciancaglini et al., 2001; Pergamalian et al., 2003; Van der Zaag et al., 2005; 
Camparis; Siqueira, 2006; Cuccia, 2008; Silva; Cantisano, 2009; Pomponio, 2010; Sutin et al., 2010).

- Dor de cabeça (Rugh; Harlan, 1988; Dworkin; Le Resched, 1992; Kampe et al., 1997b; Lavigne et al., 2003; Cuccia, 2008; Pomponio, 2010)

- Dores na nuca, costas, garganta ou ombros (Kampe et al., 1997b; Ciancaglini et al., 2001).

- Clicks, estalidos nas ATMs (Rugh; Harlan, 1988; Dworkin; Le Resched, 1992; Kampe et al., 1997b; Ciancaglini et al., 2001; Pergamalian et al., 2003; Van Der Zaag et al., 2005; Lavigne et al., 2007; Cuccia, 2008; Pomponio, 2010; Sutin et al., 2010).

- Desconforto dental ao toque (Dworkin; Le Resched, 1992).

- Fratura/perda de restaurações (Rugh; Harlan, 1988; Attanasio, 1997; Kampe et al., 1997; Sutin et al., 2010).

- Desgaste anormal dos dentes (ASDA, 1990; Teixeira et al., 1994; Attanasio, 1997; Kampe et al., 1997b; Shinkai et al., 1998; Lobbezoo; Naeije, 2001; Lavigne et al., 2003; AA, 2005; Van Der Zaag et al., 2005; Lavigne et al., 2007; Cuccia, 2008; Silva; Cantisano, 2009; Pomponio, 2010; Sutin et al., 2010).

- Cansaço e/ou dor ao mastigar (Dworkin; Le Resched, 1992; Ciancaglini et al., 2001; Pomponio, 2010).

- Dor na ATM (próximo aos ouvidos) (Rugh; Harlan, 1988; Dworkin; Le Resched, 1992; Attanasio, 1997; Kampe et al., 1997b; Shinkai et al., 1998; Pergamalian et al., 2003; Van Der Zaag et al., 2005; Camparis; Siqueira, 2006; Lund, 2006; Rompré et al., 2007; Cuccia, 2008; Sutin et al., 2010).

- Limitação, rigidez no movimento mandibular (trismo) (Rugh; Harlan, 1988; Dworkin; Le Resched, 1992; Kampe et al., 1997b; Ciancaglini et al., 2001; Lavigne et al., 2003;Pergamalian et al., 2003; Van Der Zaag et al., 2005; Lavigne et al., 2007; Cuccia, 2008; Pomponio, 2010).

Baseados nestes conceitos foram considerados bruxômanos os sujeitos de pesquisa que responderam "SIM" a qualquer uma das questões $1,2,3,4$, acrescido 
de no mínimo uma ou mais das questões sobre dores ou fadiga na musculatura facial (músculos temporal e masseter) ao despertar; travamento (trismo) mandibular; percepção de desgaste dental; sensibilidade próxima aos ouvidos (região préauricular - ATM); cansaço e/ou dor muscular para mastigar logo após o despertar; presença de "clicks" na ATM, constantes no (Anexo C). Sob estes critérios ficou estabelecido o Grupo dos Bruxômanos, ( $n=57)$.

Os demais sujeitos da pesquisa que não se enquadraram nesses quesitos compuseram um segundo Grupo, o dos Não Bruxômanos, que recebeu também a denominação de Grupo Controle, $(\mathrm{n}=28)$.

\subsection{Questionário Qualidade de Vida (Anexo D)}

Posteriormente a aplicação do questionário de Auto-relato foi aplicada a versão em português do instrumento de avaliação, proposto pela OMS, de Qualidade de Vida (The WHOQOL Group, 1998), versão simplificada em português do Oral Health Impact Profile (OHIP-14) The WHOQOL Group (1998) preconizado por Slade (1997) (Anexo D). O questionário versa sobre como o paciente se sente a respeito da sua qualidade de vida, saúde e de outros aspectos da vida. Também pede que 0 indivíduo tenha em mente valores, aspirações, prazeres e preocupações, tomando como referência as duas últimas semanas.

\subsection{Questionário Anamnético e Exame Clínico (Anexo E)}

A anamnese e o exame clínico, intra e extraoral, foram realizados com a utilização dos tradicionais recursos para diagnosticar as condições de saúde bucal dos sujeitos da pesquisa (dados objetivos). Buscou-se a existência de interferências oclusais nos deslocamentos de protrusão e lateralidade direita e esquerda (lado de trabalho e balanceio); a existência de guia de caninos (bilateral, unilateral ou sem guia de canino); a presença ou não de desvios de linha média; a presença de 
facetas de desgaste alinhadas entre dentes antagônicos nas faces incisais e oclusais dos dentes anteriores e posteriores (ASDA, 1990; Teixeira et al., 1994; Attanasio, 1997; Kampe et al., 1997; Shinkai et al., 1998; Lobbezoo; Naeije, 2001; Lavigne et al., 2003; American Academy of Sleep Medicine, 2005; Van Der Zaag et al., 2005; Lavigne et al., 2007; Cuccia, 2008; Coelho et al., 2009; Silva; Cantisano, 2009; Pomponio, 2010; Sutin et al., 2010), fraturas de dentes e/ou restaurações (Attanasio, 1997; Kampe et al., 1997; Rugh; Harlan, 1998; Sutin et al., 2010); a existência de mobilidade dental (Rugh; Harlan, 1988; Attanasio, 1997); recessões gengivais (Sutin et al., 2010); abfrações (Sutin et al., 2010); a presença de clicks ou crepitações (Dworkin; Le Resched, 1992; Lavigne et al., 2003; American Academy of Sleep Medicine, 2005; Huynh et al., 2007; Sutin et al., 2010); limitações da abertura bucal (Rugh; Harlan, 1988; Dworkin; Le Resched, 1992; Kampe et al., 1997a; Kampe et al., 1997b; Ciancaglini et al., 2001; Lavigne et al., 2003); a existência de contatos prematuros e/ou interferências oclusais; presença de guias de desoclusão, em protrusiva e lateralidade; mordida aberta anterior; mordida cruzada anterior; mordida cruzada posterior; sobremordida; sobressaliência; evidências de salto condilar; ruídos articulares (Rugh; Harlan, 1988; Dworkin; Le Resched, 1992; Kampe et al., 1997b; Ciancaglini et al., 2001; Sutin et al., 2010); incrementos na assimetria facial normal; hipertrofia/hipertonia dos músculos masseteres (Lavigne et al., 1996; Kampe et al., 1997a; Kampe et al., 1997b; Gavish et al., 2000; Silva; Cantisano, 2009) (palpação digital bilateral); presença de sulcos dentais nas bordas da língua (endentações) (Kampe et al., 1997a; Silva; Cantisano; 2009; Sutin et al., 2010); a existência de linha de oclusão na mucosa jugal (Kampe et al., 1997a; Kampe et al., 1997b; Silva; Cantisano, 2009; Sutin et al., 2010). Também foi avaliada a existência concorrente de outros hábitos parafuncionais como: roer unhas, morder objetos, chupar e/ou morder os lábios (Pomponio, 2010). Alguns quesitos da ficha de anamnese e avaliação clínica foram embasados no questionário de perguntas para detecção de sintomas de DTM utilizadas por Tomacheski et al. (2004), e outras constantes da versão em português do questionário Research. Diagnostic Criteria for Temporomandibular Disorders (RDC/TMD) (Dworkin; Le Resched, 1992). 


\subsection{Calibração do Examinador}

Somente um examinador efetuou a coleta de dados clínicos e aplicou os questionários. O mesmo passou por processo de calibração em que ocorreram repetições dos exames, em cerca de $10 \%$ da amostra, sem que houvesse a identificação do paciente. Posteriormente foi realizada a comparação entre cada par de exames utilizando sempre o mesmo critério. Uma vez detectadas grandes discrepâncias, todo o exercício foi repetido até que o examinador estivesse plenamente familiarizado com todos os procedimentos de exames e registros; critérios de diagnóstico; formulários de registro; e manejo de instrumentos e materiais (Manual de Calibração de Examinadores, 2000). A concordância foi medida pelo coeficiente Índice Kappa de Cohen (2009) e resultou em uma concordância $(K=0,92)$. 


\section{RESULTADOS}

As variáveis qualitativas foram obtidas por meio dos questionários de Autorelato (Anexo C), Qualidade de Vida (Anexo D) (OHIP-14) e pelo Inventário de Exame Clínico (Anexo E).

Os dados foram submetidos à Análise de Variância com medidas repetidas (ANOVA), utilizadas para comparar as variáveis entre os dois grupos, bruxômanos e não bruxômanos, com nível de significância de $5 \%(p<0,05)$.

\subsection{Questionário de Auto-relato (ANEXO C)}

Frente as variáveis avaliadas no Questionário de Auto-percepção (Autorelato), e embasadas pelos critérios de diagnóstico e sinais e sintomas para o bruxismo descritos pela American Academy of Sleep Medicine (2005); pelo Diagnostic Criteria for Temporomandibular Disorders (RDC/TMD): Axis II (Dworkin; Le Resched, 1992), versão em português; assim como, o protocolo utilizado pela HC-FMUSP (Pomponio, 2010), entre outros autores, foi possível realizar algumas observações.

$O$ apertamento dental $(p=0,000)$, fator causal mais frequente de sinais $e$ sintomas em pacientes bruxômanos (Kampe et al., 1997b), o ranger de dentes $(p=0,000)$ ou ambos, apertamento e rangimento $(p=0,000)$, apresentaram diferenças estatisticamente significantes quando comparados, o grupo de pacientes bruxistas contra o grupo de não bruxistas. Estes resultados estão de acordo com os relatos de (Rugh; Harlan, 1988; Teixeira et al., 1994; Vanderas, 1995; Attanasio, 1997; Lavigne et al., 2001a; Ohayon et al., 2001; Pergamalian et al., 2003; Bernhardt et al., 2004; Van Der Zaag et al., 2005; Lopes et al., 2007; Pomponio, 2010; Sutin et al., 2010; Carra et al., 2011. Também o relato de ranger durante o sono fornecido pelo companheiro de quarto $(p=0,002)$, obteve diferença estatisticamente significante na comparação entre os dois grupos, apresentando a mesma observação realizada por 
(Shinkai et al., 1998; Ohayon et al., 2001; Lavigne et al., 2003; Ahlberg et al., 2004; American Academy of Sleep Medicine, 2005; Pomponio, 2010).

Ainda o questionário de auto-percepção permitiu observar que houve diferença estatisticamente significante quanto ao cansaço muscular matinal $(p=0,000)$ estando em consonância com os relatos de (Dworkin; Le Resched, 1992; Teixeira et al., 1994; Vanderas, 1995; Kampe et al., 1997b; Ciancaglini et al., 2001; Ohayon et al., 2001; Manfredine et al., 2003; Hirsch et al., 2004; American Academy of Sleep Medicine, 2005; Rompré et al., 2007; Silva; Cantisano, 2009; Pomponio, 2010). Os dados sobre as dores de cabeça, ombro e pescoço $(p=0,000)$, apresentaram diferenças estatisticamente significantes e estão de acordo com os achados e relatos de (Kampe et al., 1997b; Ciancaglini et al., 2001; Ohayon et al., 2001; Lavigne et al., 2003; Hirsch et al., 2004; Camparis; Siqueira, 2006; Silva; Cantisano, 2009.

Já quanto ao parâmetro clicks ou estalidos nas ATMs ( $p=0,592)$, não houve diferença estatisticamente significante, e os mesmos estão em desacordo com os relatos de (Rugh; Harlan, 1988; Dworkin; Le Resched, 1992; Teixeira et al., 1994; Kampe et al., 1997b; Gavish et al., 2000; Ciancaglini et al., 2001; Silva; Cantisano, 2009) que afirmam ocorrer frequentemente no bruxismo crepitações ou estalos nas ATMs. Estes dados permitem-nos dizer que na amostra avaliada, a presença de ruídos ou clicks nas ATMs não apresentaram diferenças entre os dois grupos e podem estar presentes em ambos os grupos indistintamente.

Também os valores observados sobre o desconforto dental ao despertar $(p=0,000)$ estão de acordo com os relatos de (Dworkin; Le Resched, 1992; Teixeira et al., 1994; Ciancaglini et al., 2001) e apresentaram diferenças estatisticamente significantes entre o grupo de Bruxômanos e não Bruxômanos.

Observamos para a variável, presença de fraturas e/ou perda de restaurações $(p=0,008)$, que ocorreu uma diferença estatisticamente significante entre as amostras estudadas, estando estes dados compatíveis com as afirmações de (Rugh; Harlan, 1988; Teixeira et al., 1994; Attanasio, 1997; Kampe et al., 1997b; Silva; Cantisano, 2009. 
Da mesma forma, no questionário de autopercepção, a deteç̧ão pelo próprio indivíduo da presença de facetas de desgaste $(p=0,000)$, demonstrou diferenças estatisticamente significantes e compatíveis com as observações e relatos (Rugh; Harlan, 1988; Dworkin; Le Resched, 1992; Teixeira et al., 1994; Attanasio, 1997; Kampe et al., 1997b; Carlsson et al., 2003; Lavigne et al., 2003; Bernhardt et al., 2004; Hirsch et al., 2004; American Academy of Sleep Medicine, 2005; Silva; Cantisano, 2009; Sutin et al., 2010) estando em desacordo, contrastantemente com os resultados observados por Pergamalian et al. (2003).

Os autores (Dworkin; Le Resched, 1992; Teixeira et al., 1994; Vanderas, 1995; Kampe et al., 1997b; Ciancaglini et al., 2001; Ohayon et al., 2001; Manfredine et al., 2003; Hirsch et al., 2004; American Academy of Sleep Medicine, 2005; Rompré et al., 2007; Silva; Cantisano, 2009; Pomponio, 2010) afirmaram que o hábito do bruxismo pode causar desconforto à mastigação ao acordar e observamos nos resultados da variável, dor matinal ao mastigar $(p=0,000)$, que estas apresentaram diferenças estatisticamente significantes entre o grupo controle e o de bruxistas.

Quanto às dores na região dos ouvidos $(p=0,017)$, os dados apresentaram diferenças estatisticamente significantes permitindo a observação de que a sensibilidade muscular à palpação e as dores na região da ATM estão entre os sinais clínicos mais comuns do bruxismo e compatíveis com os dizeres de (Rugh; Harlan, 1988; Dworkin; Le Resched, 1992; Teixeira et al., 1994; Vanderas, 1995; Attanasio, 1997; Kampe et al., 1997b; Gavish et al., 2000; Ciancaglini et al., 2001; Manfredine et al., 2003; Cuccia, 2008; Silva; Cantisano, 2009; Sutin et al., 2010).

No bruxismo, a sensibilidade da musculatura mastigatória, especialmente à palpação, pode acarretar uma limitação dos movimentos mandibulares ao despertar o que pode ser caracterizado pelo trismo mandibular como relatado por (Rugh; Harlan, 1988; Dworkin; Le Resched, 1992; Teixeira et al., 1994; Kampe et al., 1997b; Ciancaglini et al., 2001; Lavigne et al., 2003). Neste estudo observamos que a presença de travamento mandibular $(p=0,008)$, apresentou diferença estatisticamente significante, ou seja, o grupo dos bruxistas estudado apresentou trismo de maneira mais consistente quando comparado ao grupo de não 
bruxômanos, entretanto, em desacordo com os resultados encontrados por Pergamalian et al. (2003).

Frente ao conjunto de resultados do questionário de Auto-relato, observamos que na amostra estudada, foi possível estabelecer o diagnóstico para o bruxismo com as variáveis elencadas, exceto para a variável, presença de clicks ou estalidos nas ATMs.

\subsection{Questionário Anamnético e Exame Clínico (ANEXO E)}

Na análise estatística das respostas ao Questionário Avaliação Clínica,para os quesitos: Dor na musculatura facial $(p=0,001$; Sensibilidade/Estresse Funcional dental $(p=0,000)$; Guia Canino Unilateral $(p=0,036)$; Ausência de Guia Canino $(p=0,038)$; presença de Facetas de Desgaste $(p=0,000)$; presença de Fraturas dentais $(p=0,000)$; Perda/fratura de Restaurações $(p=0,000)$; presença de Abfrações $(p=0,003)$; Hipertrofia/Hipertonia dos músculos masseteres $(p=0,003)$; Endentações nas bordas linguais $(p=0,034)$; presença de Linha Alba $(p=0,001)$, os dados obtidos apresentaram diferença estatisticamente significante.

Já para os quesitos: Interferência Oclusal no movimento de Protrusão $(p=0,828)$; Interferência Oclusal no movimento de Lateralidade $(p=0,671)$; presença de Guia de Incisivos( $p=0,799)$; presença de Guia de Caninos Bilateral $(p=0,568)$; presença de Desvio de Linha Média $(p=0,078)$; presença de Mobilidade $\operatorname{Dental}(p=0,322)$; presença de Recessão Gengival $(p=0,403)$; presença de Mordida Aberta Anterior $(p=0,189)$; presença de Mordida Cruzada Anterior $(p=0,733)$; presença de Mordida Cruzada Posterior Unilateral $(\mathrm{p}=0,566)$; presença de Sobremordida $(p=0,109)$ : presença de Sobressaliência $(p=0,087)$; presença de Salto Condilar( $p=0,596)$; presença de Clicks (ruídos) nas $\operatorname{ATMs}(p=0,469)$; Limitação da Abertura Bucal $(p=0,270)$; presença de Assimetria Facial $(p=0,073)$ e presença de Hábitos Parafuncionais (onicofagia; sucção de dedos/lábio/língua/objetos; morder objetos) $(p=0,497)$, não houve diferenças estatisticamente significantes. 
Nenhum dos 85 sujeitos de pesquisa apresentou mordida cruzada posterior bilateral.

\subsection{Questionário de Qualidade de Vida (ANEXO D)}

$\mathrm{Na}$ observação dos resultados auferidos pelo questionário de avaliação da Qualidade de Vida, [Versão em Português dos Instrumentos de Avaliação de Qualidade de Vida (The WHOQOL Group, 1998), não houve diferença significativa entre o grupo de Bruxômanos e não Bruxômanos, exceto para a variável, falta de energia, cansaço, representada pela questão, "Você tem energia suficiente para o seu dia-a-dia?" $(p=0,020)$, onde o grupo dos não bruxômanos apresentou valor médio inferior ao do grupo dos bruxômanos. 


\section{DISCUSSÃO}

O bruxismo, uma desordem funcional dentária prevalente e um relevante problema de saúde, considerada uma atividade parafuncional de origem antiga (Cariola, 2006), e a mais deletéria (Attanasio, 1997; Lobbezoo; Lavigne, 1997; AASM, 2005), complexa e destrutiva, caso as forças desencadeadas excedam a capacidade adaptativa do sistema estomatognático (de La Hoz-Aizpurua et al., 2011). As diferentes entidades Bruxismo do Sono e Bruxismo Diurno possuem diferentes patogêneses (Rugh; Harlan, 1988) que são de difícil distinção clínica (Rugh; Harlan, 1988; Bader; Lavigne, 2000).

O BD (apertamento) ocorre geralmente de forma consciente em momentos de vigília. O bruxismo do sono (BS) ocorre no estado inconsciente, durante o sono, e tem por características o rangimento e/ou apertamento denta com a possibilidade de emissão de sons (Teixeira et al., 1994).

A polissonografia é o instrumento padrão ouro para a confirmação do diagnóstico clínico para o BS (Van Der Zaag et al., 2005; Camparis et al., 2006; Lavigne et al., 2008). Já para Macedo (2008), o diagnóstico clínico do BS pode ser complementado pela polissonografia. Pelo seu intermédio é realizado o monitoramento de ondas cerebrais, estágio do sono, respiração, movimentos oculares, nível de oxigênio no sangue além de outros distúrbios relacionados ao sono e excluindo as OFA (atividades motoras orofaciais que ocorrem na porcentagem de 30\%), tanto em bruxômanos como em não bruxômanos (Lavigne et al., 2003; Dutra et al., 2008; Macedo, 2008). Durante a realização do exame polissonográfico a verificação, por meio do monitoramento audiovisual, como o utilizado por (Dutra et al., 2008), permite estabelecer a especificidade da atividade motora orofacial (Lavigne et al., 2003; Dutra et al., 2008).

Registros sonoros e em vídeo, assim como a polissonografia, são importantes instrumentos de diagnóstico para o bruxismo (Huynh et al., 2007; Dutra et al., 2008). Porém, para a realidade Brasileira, a polissonografia ainda representa alto custo (Carvalho et al., 2008b) e é um exame ainda inacessível para muitas pessoas, além de existir poucos laboratórios que o realizam pela rede pública de saúde (Chagas et 
al., 2006), sem que haja custo para o usuário. Por este motivo abstivemo-nos de fazer uso deste instrumento e optamos por utilizar o questionário de Auto-relato para o diagnostico do bruxismo e o questionário anamnético com as variáveis passíveis de estudo para a obtenção dos dados desta pesquisa.

Alguns fatores periféricos American Academy of Sleep Medicine (2005), ou seja, de origem morfológica, embora possuam pouco ou nenhum papel na etiologia do bruxismo (Kato et al., 2003a), foram avaliados nesta pesquisa. Observamos não haver diferenças estatisticamente significantes, isto é não ocorreu diferenças entre os grupos de bruxômanos e controles quanto à variável, interferências oclusais nas diferentes situações: em posição protrusiva $(p=0.828)$; interferência oclusal nos movimentos de lateralidade, direita e esquerda $(p=0,671)$; presença de guia de incisivos ( $p=0,799)$; presença de guia de canino bilateral $(p=0,568)$; desvio de linha média ( $p=0,078)$; presença de mobilidade dental $(p=0,322)$; presença de recessão gengival $(p=0,403)$; presença de mordida aberta anterior $(p=0,189)$; presença de mordida cruzada anterior $(p=0,733)$; presença de mordida cruzada posterior unilateral $(p=0,566)$; presença de sobremordida $(p=0,109)$; presença de sobressaliência $(p=0,087)$; limitação da abertura bucal $(p=0,270)$; presença de assimetria facial $(p=0,073)$. Na amostra populacional avaliada neste trabalho não foi possível correlacionar estes fatores à ocorrência ou não do bruxismo. Apenas a variável que abarca a ausência de guia de canino bilateral apresentou diferença estatisticamente significante $(p=0,038)$.

A perda de substância dental geralmente é resultante dos processos de erosão, abrasão e atrição (Watson; Burke, 2000), e normalmente atuam mais de um destes fatores podendo tornar difícil o reconhecimento de quando a atrição estiver presente (Cardoso et al., 2000). Um sinal clínico característico do bruxismo do sono é a presença de facetas de desgaste alinhadas entre dentes antagônicos (Attanasio, 1997; Cariola, 2006), causadas pela atrição. Estas podem indicar uma história pregressa (Rugh; Harlan, 1988) do bruxismo, pois, as sequelas têm caráter permanente e independem do momento em que foram geradas. Este fato dificulta afirmar se as facetas de desgaste denotam um bruxismo do passado ou atual (Lavigne et al., 1996; Sutin et al., 2010). Por outro lado, o início recente do hábito pode ainda não ter acarretado alterações visíveis (Vanderas, 1995; Shinkai et al., 
1998) e dificultar o diagnóstico clínico do bruxismo. Para Shetty et al. (2010) dentre todos os mecanismos que causam desgaste dental, raramente apenas um atua sozinho.

As facetas de desgaste dentárias são características amplamente encontradas na população (Lopes et al., 2007), e normalmente há uma interação entre atrição, erosão e a abrasão no desenvolvimento destes desgastes. Porém, Holt et al. (2000), afirmaram que o bruxismo pode resultar em perda de superfície dental levando a exposição de dentina, em decorrência do atrito. Portanto, a avaliação das facetas de desgaste como fator de previsão do bruxismo pode ser controversa. No entanto (Rugh; Harlan, 1988; Teixeira et al., 1994; Attanásio, 1997; Ware; Rugh, 1998; Lavigne et al., 2003; Miyawaki et al., 2003; Winocur et al., 2003; Cuccia, 2008; Gimenes, 2008; Diniz et al., 2009; Sutin et al., 2010), relataram que os desgastes oclusais e/ou incisais são decorrentes da experiência patológica do bruxismo. Como os efeitos do bruxismo podem ser observados na dentição na forma de desgaste de facetas e fraturas de dentes e restaurações (Chapotat et al., 2001), observamos neste estudo que no questionário de exame clínico as variáveis: presença de facetas de desgaste $(p=0,000)$, assim como para a presença de fraturas $(p=0,000)$ e/ou perda de restaurações $(p=0,000)$, apresentaram diferenças estatisticamente significantes, demonstrando uma franca tendência a que sejam detectadas de forma mais acentuada em bruxômanos do que no grupo controle de não bruxômanos.

$\mathrm{Na}$ investigação da relação entre fatores oclusais e o bruxismo, Sari e Sonmez (2001) verificaram que nas dentições permanente e mista em crianças, fatores oclusais como: sobressaliência maior que $6 \mathrm{~mm}$ (overjet), sobremordida maior que $5 \mathrm{~mm}$ (overbite), mordida aberta na dentição permanente e a mordida cruzada (plano anteroposterior) estiveram relacionados com o bruxismo. Diferentemente, neste estudo foi observado que parâmetros como mordida aberta anterior $(p=0,189)$, mordida cruzada anterior ( $p=0,733)$, mordida cruzada posterior unilateral $(p=0,566)$, sobremordida $(p=0,109)$ e sobressaliência $(p=0,87)$, não apresentaram diferença estatisticamente significante entre o grupo de bruxômanos e o de não bruxômanos. Estes dados parecem estar de acordo com a afirmação de Lobbezoo e Naeije (2001) e Demir et al. (2004) de que fatores etiológicos de origem periférica (morfológicos) 
como a mutilação da oclusão, desempenham papel muito pequeno na etiologia do bruxismo.

No levantamento epidemiológico realizado por Shinkai et al. (1998), os autores verificaram que a presença de hábitos bucais parafuncionais como: sugar o dedo/chupeta/lábio; morder lábio/objetos e roer unhas, entre outros, não puderam ser correlacionados ao bruxismo. Da mesma forma neste estudo, observamos que os hábitos parafuncionais $(p=0,497)$, não apresentaram diferença estatisticamente significante entre os indivíduos do grupo de bruxômanos e os do grupo controle estudados.

Segundo Attanasio (1997), Kampe et al. (1997b), Lobbezoo e Lavigne (1997), Ware e Rugh (1998), Lavigne et al. (2003), Van der Zaag et al. (2005), Camparis e Siqueira (2006), Bisi et al. (2007) e Diniz et al. (2009) as dores crônicas faciais, de cabeça, pescoço, e ouvido estão entre as queixas mais comuns relatadas por pacientes bruxômanos. Observamos no questionário de exame clínico que as dores musculares na face $(p=0,001)$, assim como o estresse funcional $(p=0,000)$ frente ao bruxismo apresentaram diferenças estatisticamente significantes entre os grupos estudados.

Teixeira et al. (1994) assim como Roeters e Stel (2000), observaram que em bruxômanos pode ocorrer perda de substância dental na interface esmalte-cemento, e estas podem dar lugar a lesões de abfração. De maneira similar foi observado nos resultados deste estudo que, as lesões não cariosas de abfração $(p=0,003)$, apresentaram diferenças estatisticamente significantes quando confrontado o grupo de bruxistas com o grupo dos não bruxistas.

Kampe et al. (1997a) e Sutin et al. (2010) observaram ulcerações e sulcamento na mucosa jugal (linha Alba) em bruxômanos. Da mesma forma observamos que o grupo dos bruxômanos apresentou diferença estatisticamente significante quanto à presença da linha Alba $(p=0,001)$, quando comparado ao grupo de não bruxômanos, revelando uma tendência a ocorrer de forma mais acentuada em bruxômanos na população que representou os grupos estudados.

Sutin et al. (2010) observaram a ocorrência de endentações na borda lingual de indivíduos bruxômanos. Observamos que a variável presença de endentações 
nas bordas linguais $(p=0,034)$ apresentou diferenças estatisticamente significantes, sugerindo uma tendência a que ocorram de forma mais acentuada em bruxômanos do que em não bruxômanos.

Kampe et al. (1997a), Davies et al. (2002) e Alóe et al. (2003), alegam que pode ocorrer mobilidade dentária, em pacientes portadores de bruxismo, e que esta é causada pelo comprometimento periodontal. Entretanto, nos grupos estudados de bruxômanos e controles, a mobilidade dental avaliada $(p=0,322)$ não apresentou diferenças estatisticamente significantes.

A hipertrofia do músculo masseter pode causar assimetrias faciais significativas em decorrência das alterações faciais estéticas, e foram relatadas por Teixeira et al. (1994), Kampe et al. (1997a) e Rispolib et al. (2008). Na avaliação da variável, hipertrofia do músculo masseter $(p=0,003)$ foi observada diferença estatisticamente significante entre os grupos estudados. Entretanto, para o fator, assimetria facial ( $p=0,073)$, não foi observada diferença estatisticamente significante, fato que parece contraditório, mas também detectado por Li et al. (2008). Este autor registrou uma ocorrência mais elevada de assimetria nos sujeitos com bruxismo, quando comparados aos sem bruxismo, embora sem significância estatística.

Lavigne et al. (1996), referem que ainda permanece obscuro com que frequência ocorre sequelas no BD. Durante o BS pode ocorrer uma redução do fluxo salivar (Rugh; Harlan, 1988; Silva; Cantisano, 2009), o que pode acentuar o desenvolvimento de desgastes dentais, o que é reportado como o sinal clínico mais frequentemente mencionado tanto no bruxismo agudo, quanto no crônico (Teixeira et al., 1994). Em consonância, observamos uma diferença estatisticamente significante quanto à presença de facetas de desgaste $(p=0,000)$ no questionário de exame clínico, além da presença de fraturas de dentes e restaurações $(p=0,000)$ e $(p=0,008)$, respectivamente nos questionários de exame clínico e de auto-relato.

Dao et al. (1994), Manfredine et al. (2003) e Pergamalian et al. (2003), afirmaram que o bruxismo pode estar associado a ruídos na ATM. No entanto, nos resultados deste estudo não observamos diferenças significativas estatisticamente quanto à presença de salto condilar $(p=0,596)$ e sons articulares $(p=592)$, tanto para indivíduos bruxômanos quanto em controles nas amostras avaliadas. 
A hipertrofia do músculo masseter pode ser secundária ao hábito do apertamento dental que ocorre principalmente enquanto o paciente está em vigília (Huynh et al., 2007). A hipertrofia é revelada pelo aumento de seu volume quando se realiza o apertamento dental (Rispolib et al., 2008). Neste estudo obsevamos uma diferença estatística significante quanto à hipertrofia muscular entre bruxômanos e não bruxômanos $(p=0,003)$, indicando que bruxômanos apresentam maior incidência de hipertrofia do músculo masseter.

As perturbações do sono podem comprometer a qualidade de vida Kampe et al. (1997b) e Bader e Lavigne (2000) acreditam que cerca de $70 \%$ a $80 \%$ das pessoas diagnosticadas com BS apresentam sintomas de sono fragmentado, sonolência excessiva diurna, despertares noturnos, sudorese ou pesadelos sono além de sono não restaurador. Porém, Kato et al. (2003a) e Kato et al. (2003b) assim como Coelho et al. (2009), concluíram que pacientes com bruxismo do sono demonstram sono dentro dos padrões de normalidade. Observamos em nossos resultados que tanto bruxômanos, como não bruxômanos, não denotaram incômodo, ou perda de qualidade do sono, não havendo diferença estatisticamente significante entre os grupos estudados $(p=0,370)$.

Barbosa et al. (2008) acreditam que a relação entre hábitos orais parafuncionais e Bruxismo ainda é controversa, enquanto, Ferreira e Toledo (1997) relatam que quanto mais prolongado o tempo do aleitamento materno, menor a ocorrência de hábitos orais nocivos, como o bruxismo. Já Widmalm et al. (1995), encontraram uma correlação significativa entre bruxismo, onicofagia e sucção do polegar. Mas hábitos parafuncionais são comuns em crianças portadoras de bruxismo e, se persistentes, podem trazer sequelas sobre as estruturas orofaciais. Autores como Simões-Zenari e Bitar (2010) afirmam a existência de uma relação entre bruxismo, hábitos orais e aspectos alterados da motricidade orofacial de crianças. Entretanto, os dados neste estudo demonstraram que não houve diferença estatisticamente significante quanto à presença de outros hábitos parafuncionais e o hábito do bruxismo $(p=0,497)$ entre os grupos especificamente estudados.

Seria interessante visualizar a totalidade das variáveis analisadas no exame clínico, por intermédio de um instrumento de comparação entre as características dos bruxômanos frente à de não bruxômanos. No gráfico de barras fica evidente que 
parâmetros como: dor na musculatura da face; estresse funcional dental; presença de facetas de desgaste; fraturas de dentes ou restaurações e lesões de abfração ocorrem com maior predomínio em indivíduos bruxistas do que em não bruxistas (Gráfico 6.1).

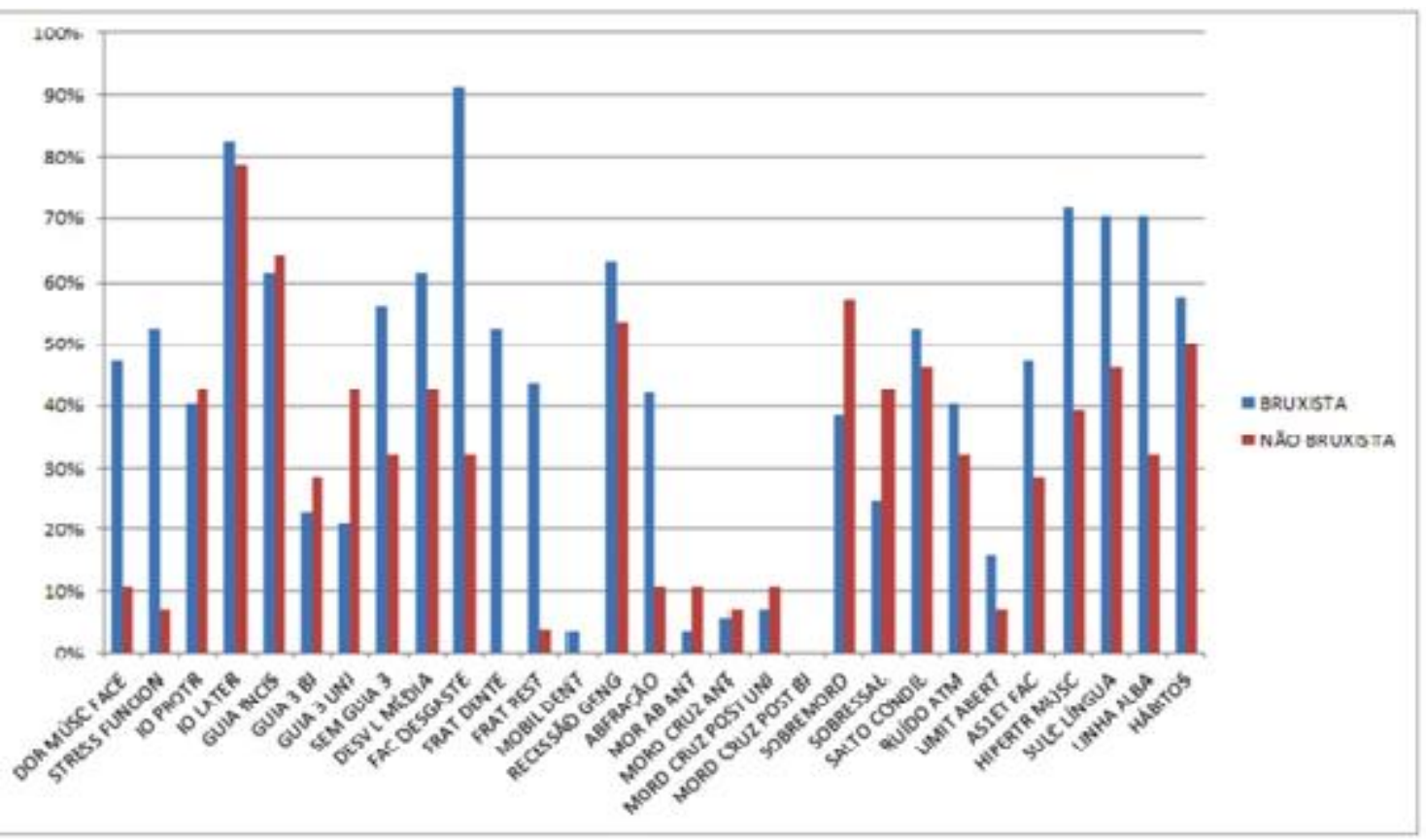

Gráfico 6.1 - Comparativo da ocorrência dos fatores observados no exame clínico entre os 2 grupos (\%)

A qualidade de vida depende de fatores que variam de pessoa para pessoa, da avaliação qualitativa das condições de vida dos seres humanos, da satisfação das necessidades e expectativas e está sujeita a influências do cotidiano, de onde vive, além dos hábitos e estilo de vida (Rugiski et al., 2012).

Alguns estudos se preocuparam com o impacto e o efeito do bruxismo na qualidade de vida das pessoas. Autores como Hublin et al. (1998); Pereira et al. (2006); Müller, Guimarães (2007); Simões-Zenariet, Bitar (2010); Sutin et al. (2010) e Kato et al. (2011), afirmaram que o bruxismo tem trazido prejuízos para a qualidade de vida das pessoas, especialmente quanto a pobre qualidade do sono (Pereira et al., 2006; Müller; Guimarães, 2007; de La Hoz-Aizpurua et al., 2011) e ao cansaço físico decorrente do mesmo (de La Hoz-Aizpurua et al., 2011). 
Neste estudo, entretanto, foi observado não haver diferença significativa estatisticamente quanto às diversas questões relacionadas à qualidade de vida, exceto quanto ao quesito, cansaço, energia necessária para a execução das atividades diárias estando de acordo com os relatos de, de La Hoz-Aizpurua et al., 2011. Na amostra deste estudo, os indivíduos bruxômanos relataram sentir insuficiência de energia para desempenhar suas atividades do dia-a-dia $(p=0,020)$. Assim é possível visualizar no gráfico o desempenho das diversas variáveis relacionadas à qualidade de vida comparativamente aos dois grupos, bruxômanos e não bruxômanos (Gráfico 6.2).

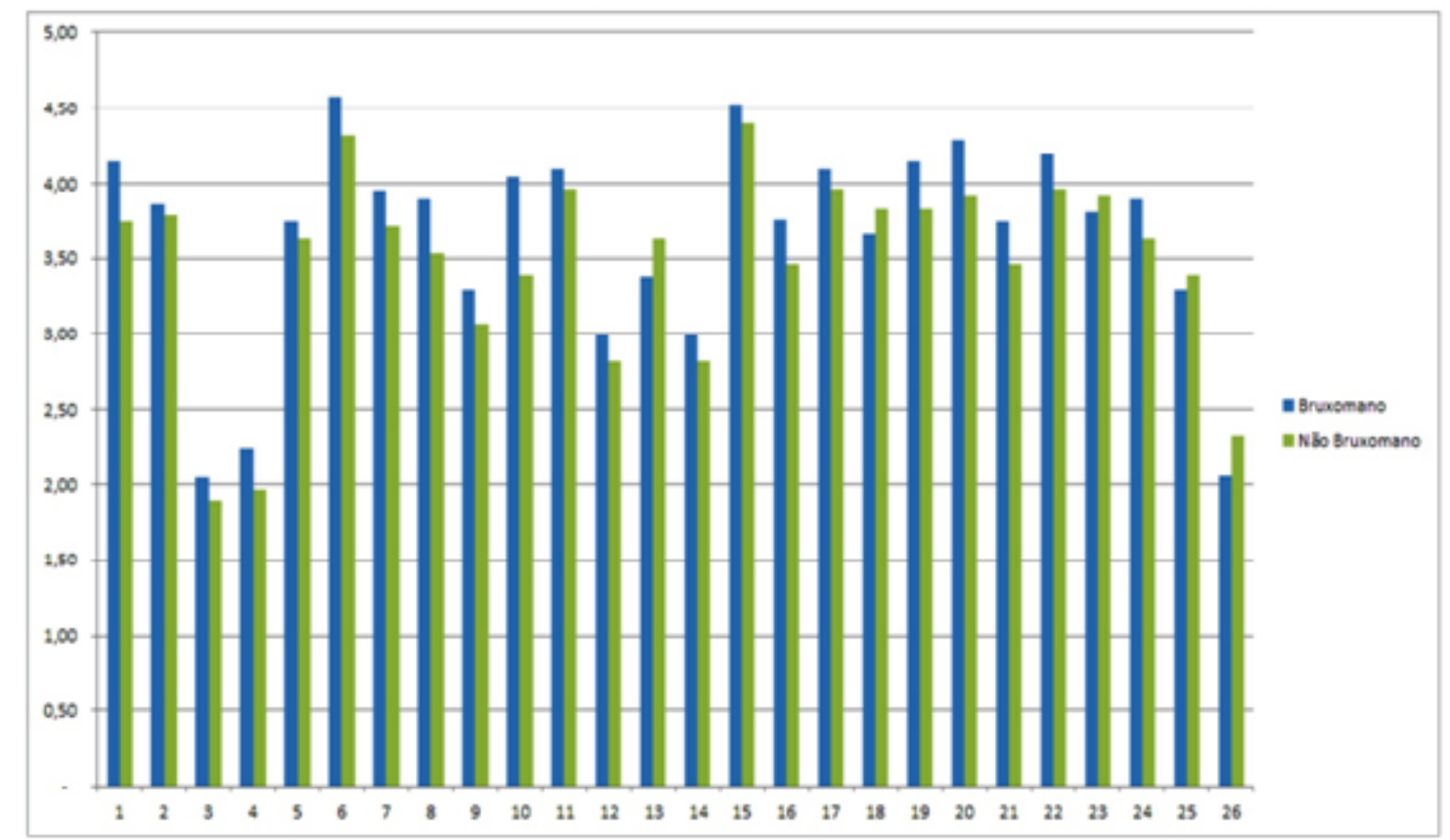

Gráfico 6.2 - Scores médios observados no questionário de Qualidade de Vida entre os dois grupos

Este estudo teve como ponto forte a avaliação de diferentes características descritas na literatura como fazendo parte da "síndrome do bruxismo", pois o mesmo, geralmente vem acompanhado de sintomas característicos, e de sinais que poderão se estabelecer de acordo com sua frequência e intensidade.

Ficou evidente a dificuldade de se realizar o diagnóstico clínico para o bruxismo pela inconsciência de sua existência, como relatado na literatura (Kampe 
et al., 1997b; Rodrigues et al., 2006), podendo-se subestimar e sub-diagnosticar casos falso-negativos de bruxismo. 


\section{CONCLUSÕES}

Frente à amostra avaliada e dadas as limitações desta pesquisa foi possível concluir:

1. Entre o grupo controle e o grupo de bruxômanos, não houve diferenças estatisticamente significantes para a presença de interferência oclusal em posição protrusiva; interferência oclusal em posição de lateralidade direita/esquerda; presença de guia de incisivos; presença de guia de caninos bilateral; desvio de linha média; mobilidade dental; recessão gengival; mordida aberta anterior; mordida cruzada anterior; mordida cruzada posterior unilateral; sobremordida; sobressaliência; salto condilar; clicks/estalos na ATM (no questionário de auto-relato e ao exame clínico); ruídos na ATM; limitação da abertura bucal; assimetria facial e para outros hábitos bucais (onicofagia, morder lábios, morder objetos).

2. Entre o grupo controle e o grupo de bruxômanos, houve diferenças estatisticamente significantes para a dor na musculatura face; estresse funcional dental; guia de canino unilateral; ausência de guias de caninos; presença de facetas de desgaste; fraturas de dentes e/ou restaurações; presença de abfração; hipertonia do músculo masseter; endentações na borda lingual e para a presença de linha Alba.

3. Frente aos questionamentos quanto às interferências do bruxismo na qualidade de vida das pessoas, apenas o quesito "cansaço" apresentou diferença estatística significante maior no grupo de bruxômanos. 


\section{REFERÊNCIAS ${ }^{2}$}

Abrão SD, Fornasari CA. Avaliação da posição da cabeça no plano de Frankfurt na disfunção da ATM por meio de fotometria. RBO. 2005;62(1/2):82-4.

Ahlberg J, Savolainen A, Rantala M, Lindholm H; Könönen M. Reported bruxism and biopsychosocial symptoms: a longitudinal study. Community Den Oral Epidemiol. 2004 Aug;32(4):307-11.

Ahlberg K. Self-Reported Bruxism. Associated factors among media personnel with or without irregular shift work. Helsinki: Faculty of Medicine of the University of Helsinki; 2008 [cited 2011 Nov 9]. Available from:

http://www.tsr.fi/tsarchive/files/TietokantaTutkittu/2004/104242Loppuraportti.pdf.

Ahlberg K, Ahlberg J, Könönen M, Alakuijala A, Partinen M, Savolainen A. Perceived orofacial pain and its associations with reported bruxism and insomnia symptoms in media personnel with or without irregular shift work. Acta Odontol Scand. 2005 Aug;63(4):213-7.

Alóe F, Gonçalves LR, Azevedo A, Barbosa RC. Bruxismo durante o Sono. Rev Neurociências. 2003;11(1):4-17.

American Academy of Orofacial Pain. Orofacial pain-guidelines for assessment, diagnosis, and management. [S.I.]: Quintessence Publishing; 1996. 285 p.

American Academy of Sleep Medicine. International classification of sleep disorders, 2nd ed: Diagnostic and coding manual, American Academy of Sleep Medicine, Westchester, IL 2005 [citado 15 fev. 2009]. Disponível em:

http://www.esst.org/adds/ICSD.pdf.

American Sleep Disorders Association. Diagnostic Classification Steering Committee. International Classification of Sleep Disorders: diagnostic and coding manual.

Rochester, M. N.: Allen Press, American Sleep Disorders Association; 1990.

Antunes JLF, Peres MA. Fundamentos de Odontologia: epidemiologia da saúde bucal. Rio de Janeiro: Guanabara Koogan; 2006.

\footnotetext{
${ }^{2}$ De acordo com Estilo Vancouver.
} 
Attanasio R. Nocturnal bruxism and its clinical managment. Dent Clin North Am. 1991 Jan;35(1):245-52.

Attanasio R. An overview of bruxism and its management. Dent Clin North Am. 1997 Apr;41(2):229-41.

Auerbach S, Laskin DM, Frantsve LME, Orr T. Depression, Pain, Exposure to Stressful Life Events, and Long-Term Outcomes in Temporomandibular Disorder Patients. J Oral Maxillofac Surg. 2001 Jun;59(6):628-33.

Bader G, Lavigne G. Sleep bruxism; an overview of an oromandibular sleep movement disorder. Sleep Med Rev. 2000 Feb;4(1):27-43.

Barbosa GAS, Barbosa KVM, Badaró Filho CR, Neves FD, Fernandes Neto AJ. Recursos fisioterápicos disponíveis para o tratamento das disfunções temporomandibulares. JBA J Multidiscip Dor Crânio-Fac. 2003 out.-dez.; 3(11): 25762.

Barbosa TS, Miyakoda LS, Pocztaruk RL, Rocha CP, Gavião MBD. Temporomandibular disorders and bruxism in childhood and adolescence: Review of the literature. Int J Pediatr Otorhinolaryngol. 2008 Mar;72(3):299-314.

Bender SD. Temporomandibular disorders, facial pain, and headaches. Headache. 2012 May;52 Suppl 1:22-5.

Bernhardt O, Gesch D, Splieth C, Schwahn C, Mach F, Kocher T, Meyer G, John U, Kordass B. Risk factors for high occlusal wear scores in a population-based sample: results of the Study of Health in Pomerania (SHIP). Int J Prosthodont. 2004 MayJun;17(3):333-9.

Bisi MA, Selaimen CMP, Martins EA, Pinto DV, Butzke KW, Valente HR. Características polissonográficas em pacientes bruxômanos. RFO. 2007 set./dez.;12(3):74-8.

de Boever JA, Carlsson GE. Etiologia e diagnóstico diferencial. In: Zarb GA, Carlsson GE, Sessle BJ, Mohl ND, editores. Disfunções da articulação temporomandibular e dos músculos da mastigação. 2a ed. São Paulo. Editora Santos; 2000. p 171-4. 
Bortoli D, Locatelli FA, Fadel CB, Baldani MH. Associação entre percepção de saúde bucal e indicadores clínicos subjetivos: estudo em adultos de um grupo de educação continuada da terceira idade. Publ UEPG Ci Biol Saúde, Ponta Grossa. 2003 set./dez.;9(3/4):55-65.

Branco RS, Branco CS, Tesch RS, Rapoport A. Frequência de relatos de parafunções nos subgrupos diagnósticos de DTM de acordo com os critérios diagnósticos para pesquisa em disfunções temporomandibulares (RDC/TMD). $R$ Dental Press Ortodon Ortop Facial. 2008 mar./abr.;13(2):61-9.

Camparis CM, Formigoni G, Teixeira MJ, Bittencourt LRA, Tufik S, Siqueira JTT. Sleep bruxism and temporomandibular disorder: clinical and polysomnographic evaluation. Arch Oral Biol. 2006 Sept;51(9):721-8.

Camparis CM, Siqueira JT. Sleep bruxism: clinical aspects and characteristics in patients with and without chronic orofacial pain. Oral Surg Oral med Oral Pathol Oral Radiol Endod. 2006 Feb;101(2):188-93.

Cardoso AC, Canabarro S, Myers SL. Dental erosion: diagnostic-based noninvasive treatment. Pract Periodontics Aesthet Dent. 2000 Mar;12(2):223-8.

Cariola TC. O desenho da figura humana de crianças com bruxismo. Bol Psicol. 2006 jun.;55(124):37-52.

Carlsson GE, Egermark I, Magnusson T. Predictors of bruxism, other oral parafunctions, and tooth wear over a 20-year follow-up period. J Orofac Pain. 2003 Winter;17(1):50-7.

Carra MC, Huynh N, Morton P, Rompré PH, Papadakis A, Remise C, Lavigne GJ. Prevalence and risk factors of sleep bruxism and wake-time tooth clenching in a 7- to 17-yr-old population. Euro J Oral Sci. 2011 Oct;119(5):386-94.

Carvalho ALA, Del Bel-Cury AA, Rodrigues-Garcia RCM. Prevalence and association of bruxism and emotional stress in Brazilian police officers. Braz Oral Res. 2008 JanMar;22(1):31-5.

Carvalho SCA, Carvalho ALA, Lucena SC, Coelho JPS, Araújo TPB. Associação entre bruxismo e estresse em policiais militares. Rev Odonto Ciênc. 2008b abr.jun.;23(2):125-9. 
Cauás M, Alves IF, Tenório K. Incidência de hábitos parafuncionais e posturais em pacientes de disfunção da articulação craniomandibular. Rev Cir Traumatol BucoMaxilo-Fac. 2004 abr.-jun.;4(2):118-24.

Chagas EA, Stuginski-Barbosa J, Leite RA, Faleiros FBC, Oliveira Bozzo RO. Falhas em implantes dentários e bruxismo: revisão de literatura. Innov Implant $\mathrm{J}$ - Biomater Esthet. 2006 maio;1(1):29-33 [citado 5 abr. 2012]. Disponível em: http://www.innovationsjournal.com.br/pdf/13.pdf.

Chapotat B, Lin JS, Robin O, Jouvet M. Bruxisme du sommeil: aspects fondamentaux et cliniques. J Parodontologie d'implantologie Orale. 2001;18(3/99):277-89.

Chen Wh, Lu YC, Lui CC, Liu JS. A proposed mechanism for diurnal/nocturnal bruxism: hypersensitivity of presynaptic dopamine receptors in the frontal lobe. J Clin Neurosci. 2005 Feb;12(2):161-3.

Ciancaglini R, Gherlone EF, Radaelli G. The relationship of bruxism with craniofacial pain and symptoms from the masticatory system in the adult population. J Oral Rehabil. 2001 Sept;28(9):842-8.

Coelho JPS, Lucena SC, Carvalho ALA, Lopes FF, Oliveira AEF. Bruxismo do sono e sua associação com distúrbios do sono em policiais. Cienc Odontol Bras. 2009 jan./mar.;12(1):31-6.

Cuccia AM. Etiology of sleep bruxism: a review of the literature. Recenti Prog Med. 2008 Jun;99(6):322-8.

Dalberto CS, Mengatto CM, Scherer L, Botega DM, Sanada JT, Scheere B, De Barros SGS. Association between bruxism and symptom of heartburn. IADR; 2012 Jun 2023; Iguaçu Falls, BR [cited 2012 Jul 9]. Available from:

http://iadr.confex.com/iadr/2012rio/webprogram/Paper164793.html.

Dao TT, Lund JP, Lavigne GJ. Comparison of pain and quality of life in bruxers and patients with myofascial pain of the masticatory muscles. J Orofac Pain. 1994 Fall;8(4):350-6.

Davies SJ, Gray RJM, Qualtrough AJE. Management of tooth surface loss. Br Dent J. 2002 Jan;192(1):11-23. 
de La Hoz-Aizpurua JL, Díaz-Alonso E, Latouche-Arbizu R, Mesa-Jiménez. J. Sleep bruxism. Conceptual review and update. Med Oral Patol Oral Cir Bucal. 2011 Mar;16(2):e 231-8.

Demir A, Uysal T, Guray E, Basciftci FA. The relationsship between bruxism and occlusal factors among seven- to 19- year-old Turkish children. Angle Orthod. 2004 Oct;74(5):672-6.

Diniz MB, Silva RC, Zuanon ACC. Bruxismo na infância: um sinal de alerta para odontopediatras e pediatras. Rev Paul Pediatr 2009 set.;27(3):329-34.

Dubé C, Rompré PH, Manzini C, Guitard F, de Grandmont P, Lavigne GJ.

Quantitative polygraphic controlled study on efficacy and safety of oral splint devices in tooth-grinding subjects. J Dent Res. 2004 May;83(5):398-403.

Dutra KM, Pereira FJ Jr, Rompré PH, Huynh N, Fleming N, Lavigne GJ. Oro-facial activities in sleep bruxism patients and in normal subjects: a controlled polygraphic and audio-video study. J Oral Rehabil. 2008 Feb;36(2):86-92.

Dworkin SF, Le Resched L. Research diagnostic criteria for temporomandibular disorders: review, criteria, examinations and specifications, critique. J Craniomandib Disord. 1992 Fall; 6(4):301-55.

Feinstein AR. The pretherapeutic classification of comorbity in chronic disease. J Chronic Dis. 1970 Dec;23(7):455-68.

Ferreira MI, Toledo OA. Relação entre tempo de aleitamento materno e hábitos bucais. Rev ABO Nac. 1997 out./nov.;5(5):317-20.

Fonseca DM, Bonfante G, Valle AL, Freitas SFT. Diagnóstico pela anamnese da disfunção craniomandibular. RGO. 1994 jan.-fev.; 42(1):23-8.

Frohman BS. The application of psychotherapy to dental problems. Dent Cosmos. $1931 ; 73(1117-22)$.

Garcia AR, Lacerda Júnior N, Pereira SLS. Grau de disfunção da ATM e dos movimentos mandibulares em adultos jovens. Rev APCD. 1997 jan.-fev.;51(1):46-51.

Garcia PP, Corona SA, Santos-Pinto A, Sakima T. Verificação da incidência de bruxismo em pré-escolares. Odontol Clin. 1995;5:119-22. 
Gavish A, Halachml M, Winocur E, Gazit E. Oral habits and their association with signs and symptoms of temporomandibular disorders in adolescent girls. J Oral Rehabil. 2000 Jan;27(1):22-32.

Gimenes MCM. Bruxismo: aspectos clínicos e tratamento. 2008 [citado 27 nov. 2011]. Disponível em: http://www.portaleducacao.com.br/odontologia/artigos/2909/bruxismoaspectos-clinicos-e-tratamento.

Glaros AG, Williams K, Lausten L, Friesen LR. Tooth contact in patients with Temporomandibular Disorders. Cranio. 2005 Jul;23(3):188-93.

Gonçalves LPV, de Toledo AO, Otero SAM. Relação entre bruxismo, fatores oclusais e hábitos bucais. Dental Press J Orthod. 2010 mar./apr.;15(2):97-104.

Goulet JP, Lund JP, Montplaisir J. Daily clenching nocturnal bruxism and stress and their association with TMD symptoms. J Oralfac Pain. 1998;7:120-7.

Gusson DGD. Bruxismo em crianças. J Bras Odontoped Odonto Bebe. 1998;1(2):7597.

Haddad AE, Correa MSNP, Fazzi R. Bruxismo em crianças. Rev Odontopediatr. 1994;3(2):91-8.

Hattab FN, Yassin OM. Etiology and diagnosis of tooth wear: a literature review and presentation of selected cases. Int J Prosthodont. 2000 Mar-Apr;13(2):101-7.

Hirsch C, John MT, Lobbezzo F, Setz JM, Schaller HG. Incisal tooth wear and SelfReported TMD Pain in childrem and Adolescents. Int J Prosthodont. 2004 MarAbr;12(2):205-10.

Holt R, Roberts G, Scully C. Dental damage, sequelae, and prevention. Br Med J. 2000 Jun;24(320):1717-9.

Hublin C, Kaprio J. Genetic aspects and genetic epidemiology of parasonias. Sleep Med Rev. 2003 Oct;7(5):413-21.

Hublin C, Kaprio J, Partinen M, Koskenvuo M. Sleep bruxism based on a self-report in a nationwide twin cohort. J Sleep Res. 1998 Mar;7(1):61-7. 
Huynh N, Lavigne GJ, Lanfranchi PA. The effect of 2 sympatholytic medications propranolol and clonidine - on sleep bruxism: experimental randomized controlled studies. Sleep. 2006 Mar;29(3):307-16.

Huynh N, Manzini C, Rompré PH, Lavigne GJ. Weighing the potential effectiveness of various treatments for sleep bruxism. J Can Dent Assoc. 2007 Oct;73(8):727-30 [cited 2012 Jul 19]. Available from: http://www.cda-adc.ca/jcda/vol-73/issue8/727.pdf.

International Association for the Study of Pain. Classification of chronic pain. Descriptions of chronic pain syndromes and definitions of painterms. Prepared by the International Association for the Study of Pain, Subcommittee on Taxonomy. Pain Suppl. 1986;3:S5.

Índice Kappa de Cohen [cited 2009 Feb 23]. Available from: http:/www.youtube.com/watch?v=6sdu1MhxbJo.

Inocente NJ. Psicodiagnóstico: bruxismo, sono e aspectos emocionais. In: Reimão R. Tópicos selecionados de medicina do sono. São Paulo: Associação Paulista do Sono; 2002 [citado 19 ago. 2007]. Disponível em: http://www.sppc.med.br/psicodia.html.

Kampe T, Edman G, Tagdae T, Karlsson S. Personality traits in a group of subjects with long-standing bruxing behaviour. J Oral Rehabil. 1997a Aug;24(8):588-93.

Kampe T, Tagdae T, Bader G, Edman G. K. S. Reported symptoms and clinical findings in a group of subjects with longstanding bruxing behaviour. J Oral Rehabil. 1997b Aug;24(8):581-7.

Kato T, Blanchet PJ, Montplaisir JY, Lavigne GJ. Sleep bruxism and other disorders with orofacial activity during sleep. In: Chokroverty S, Hening WA, Walters AS, editors. Sleep and movement disorders. Philadelphia: Butterworth Heinemann; 2003c. p. 273-85.

Kato T, Masuda Y, Yoshida A, Morimoto T. Masseter EMG activity during sleep and sleep bruxism. Arch Ital Biol. 2011 Nov;149(4):478-91.

Kato T, Montplaisir JY, Guitard F, Sessle BJ, Lund JP, Lavigne GJ. Evidence that experimentally induced sleep bruxism is a consequence of transient arousal. J Dent Res. 2003b Apr;82(4):284-8. 
Kato T, Rompré PH, Montplaisir JY, Sessle BJ, Lavigne GJ. Sleep bruxism: an oromotor activity secondary to micro-arousal. J Dent Res. 2001 Oct;80(10):1940-4.

Kato T, Thie NM, Huynh N, Miyawaki S, Lavigne GJ. Topical review: sleep bruxism and the role of peripheral sensory influences. J Orofac Pain. 2003a Summer;17(3):191-213.

Khoury S, Rouleau GA, Rompré PH, Mayer P, Montplaisir JY, Lavigne GJ. A significant increase in breathing amplitude precedes sleep bruxism. Chest. 2008 Aug;134(2):332-7.

Lavigne GJ, Guitard F, Rompré PH, Montplaisir JY. Variability in sleep bruxism activity over time. J Sleep Res. 2001a Sept;10(3):237-44.

Lavigne GJ, Huynh N, Kato T, Okura K, Adachi K, Yao D, Sessle B. Genesis of sleep bruxism: motor and autonomic-cardiac interactions. Arch Oral Biol. 2007 Apr;52(4):381-4.

Lavigne GJ, Kato T, Kolta A, Sessle BJ. Neurobiological mechanisms involved in sleep bruxism. Crit Rev Oral Biol Med. 2003;14(1):30-46.

Lavigne GJ, Khourys ABES, Yamaguchi T, Raphael K. Bruxism physiology and pathology: an overview for clinicians. J Oral Rehabil. 2008 Jul;35(7):476-94.

Lavigne GJ, Manzine C. Sleep bruxism and concomitant motor activity; in Kryger MH, Roth T, Dement WC (eds): Principles and practice of sleep medicine. Philadelphia: W.B. Saunders Co; 2000. p. 773-85.

Lavigne GJ, Rompré PH, Guitard F, Sessle BJ, Kato T, Montplaisir JY. Lower number of K-complexes and K-alphas in sleep bruxism: a controlled quantitative study. Clin Neurophysiol. 2002 May;113(5):686-93.

Lavigne GJ, Rompré PH, Montplaisir JY. Sleep bruxism: validity of clinical research diagnostic criteria in a controlled polysomnographic study. J Dent Res. 1996 Jan;75(1):546-52.

Lavigne GJ, Rompré PH, Poirer G, Huard H, Kato T, Montplaisi JY. Rhythmic mastigatory muscle activity during sleep in humans. J Den Res. 2001b Feb;80(2):443-8. 
Li XL, Lin XF, Teng W, Li SH. The characteristics of masticatory muscle activity in bruxers. West China J Stomatology. 2008 Dec;26(6):640-3. Chinese.

Lipton RB, Silberstein SD. Why study the comorbidity of migraine? Neurology 1994 Oct;44(10 Suppl):S4-S5.

Lobbezoo F, Lavigne GJ. Do bruxism and temporomandibular disorders have a cause-and-effect relatioship?. J Orofacial Pain. 1997 Winter;11(1):15-23.

Lobbezoo F, Lavigne GJ, Tanguay R, Montplaisir JY. The effect of catecholamine precursor L-dopa on sleep bruxism: a controlled clinical trial. Mov Disord. 1997 Jan;12(1):73-8.

Lobbezoo F, Naeije M. Bruxism is mainly regulated centrally, not peripherally. J Oral Rehabil. 2001 Dec;28(12):1085-91.

Lobbezoo F, van der Zaag J, van Selms MK, Hamburger HL, Naeije M.

Principles for the management of bruxism. J Oral Rehabil. 2008 Jul;35(7):50923.

Lopes FAM, Araújo CRP, Conti PCR, Cristiane Tomasi C. Prevalência das facetas de desgaste e sua relação com aspectos oclusais e hábitos parafuncionais. Rev Odontol UNESP. 2007 jan.-mr.; 36(1):47-52.

Lund JP. Muscular Pain and Dysfunction. In: Laskin DM, Greene CS, Hylander WL. TMDs: an evidence based approach to diagnosis and treatment. Chicago: Quintessence; 2006. p. 99-103.

Macedo CR. Bruxismo do sono. Rev Dent. Press Ortodon Ortop Facial. 2008 mar./apr.;13(2):18-22.

Machado E, Machado P, Cunal PA, Dal Fabbro C. Bruxismo do sono: possibilidades terapêuticas baseadas em evidências. Dental Press J Orthod. 2011 mar.apr;16(2):58-64.

Manfredini D, Cantini E, Romagnoli M, Bosco M. Prevalence of Bruxism in patients with different research diagnostic criteria for temporomandibular disorders (RDC/TMD) diagnoses. Cranio. 2003 Oct;21(4):279-85. 
Manfredini D, Lobbezoo F. Relationship between bruxism and temporomandibular disorders: a systematic review of literature from 1998 to 2008. Oral Surg, Oral Med, Oral Pathol, Oral Radiol Endod. 2010 Jun;109(6):e26-50.

Manual de Calibração de Examinadores. 2000. p. 72 [citado 23 fev. 2009].

Disponível em: http://bvsms.saude.gov.br/bvs/publicacoes/condSB man cali.pdf.

Marques C, Nardi AE, Figueira I, Mendlowicz M, Andrade Y, Camissåo C, Versiani M. Comorbidade: conceito e implicaçöes na pesquisa clínica em psiquiatria. Série Psicofarmacologia, 23. J Bras Psiquiatr. 1994 mar.;43(3):117-21.

Medeiros CGG. Protocolo de biofeedback para pacientes com dor muscular na região orofacial por apertamento dental parafuncional [dissertação]. Uberlândia: Universidade Federal de Uberlândia; 2010.

Melo GM de, Barbosa JFS. Parafunção × DTM: a influência dos hábitos parafuncionais na etiologia das desordens temporomandibulares. POS - Perspect Oral Sci. 2009 ago.;1(1) [citado 18 mar. 2012]. Disponível em:

http://www.ortosite.com.br/downloads/Etiologia-parafuncoes\%20para\%20alunos.pdf.

Miyake R, Ohkubo R, Takehara J, Morita M. Oral parafunctions and association with symptoms of temporomandibular disorders in Japanese university students. J Oral Rehabil. 2004 Jun;31(6):518-23.

Miyawaki S, Lavigne GJ, Mayer P, Guitard F, Montplaisir JY, Kato T. Association Between Sleep Bruxism, Swallowing-Related Laryngeal Movement, and Sleep Positions. Sleep. 2003 Jun;26(4):461-5.

Molina OF, Gaio DC, Cury MDN, Cury SE, Gimenez SRM, Salomão EC, Pinesci E. Uma análise crítica dos sistemas de classificação sobre o bruxismo: implicações com o diagnóstico, severidade e tratamento dos sinais e sintomas de DTM associados com o hábito. JBA. 2002 jan./mar.;2(5):61-9.

Müller MR, Guimarães SS. Impacto dos transtornos do sono sobre o funcionamento diário e a qualidade de vida. Estud Psicol. 2007 out.-dez.;24(4):519-28.

Musman S. Avaliação de modelo de predição para a apneia do sono em pacientes submetidos a polissonografia [dissertação]. Belo Horizonte: Universidade Federal de Minas Gerais, Faculdade de Medicina; 2008 [citado 5 abr. 2012]. Disponível em: http://www.bibliotecadigital.ufmg.br/dspace/bitstream/1843/ECJS-

7FYNXR/1/silvio_musman.pdf. 
Nishigawa K, Bando E, Nakano M. Quantitative study of bite force during sleep associated bruxism. J Oral Rehabil. 2001 May;28(5):485-91.

Ohayon MM, LI KK, Guilleminault C. Risk factors for sleep bruxism in the general population. Chest. $2001 \mathrm{Jan} ; 119(1): 53-61$.

Okeson JP. Fundamentos de oclusão e desordens temporomandibulares. 2a ed. São Paulo. Artes Médicas; 1992.

Okeson JP. Temporomandibular disorders in children. Pediatr Dent. 1989 Dec;11(4):325-9.

Oliveira AS, Bermudez CC, Souza RA, Souza CMF, Dias EM, Castro CES, Bérzin F. Impacto da dor na vida de portadores de disfunção temporomandibular. J Appl Oral Sci. 2003 apr.-jun.;11(2):138-143.

Oliveira W. Disfunções temporomandibulares. São Paulo: Artes Médicas; 2002.

Pereira RPA, Negreiros WA de, Scarparo HC, Pigozzo MN, Consani RLX, Mesquita MF. Bruxismo e qualidade de vida. Rev Odonto Ciência. 2006 abr./jun.;21(52) [citado 28 fev. 2009]. Disponível em:

http://revistaseletronicas.pucrs.br/ojs/index.php/fo/article/viewFile/1071/847.

Pergamalian A, Rudy TE, Zaki HS, Greco CM. The association between wear facets, bruxism, and severity of facial pain in patients with temporomandibular disorders. J Prosthet Dent. 2003 Aug;90(2):194-200.

Petit D, Touchette E, Tremblay RE, Boivin M, Montplaisir J. Dyssomnias and parasomnias in early childhood. Pediatrics. 2007 May;119(5):e1016-25.

Pizzol KEDC, Carvalho JCQ, Konishi F, Marcomini EMS, Giusti JSM. Bruxismo na infância: fatores etiológicos e possíveis tratamentos. Rev Odontol UNESP. 2006 abr.-jun.; 35(2):157-63.

Pomponio FB. Bruxismo do sono: estudo polissonográfico na avaliação da eficácia de placas intraorais [dissertação]. São Paulo: Universidade de São Paulo, Faculdade de Medicina; 2010 [citado 27 fev. 2012]. Disponível em: www.teses.usp.br/teses/disponiveis/.../FernandaBrunaPomponio.pdf. 
Rispolib DZ, Camargo PM, Pires JL Jr, Fonseca VR, Mandelli KK, Pereira MAC. Hipertrofia benigna do músculo masseter. Rev Bras Otorrinolaringol. 2008 set./out.;74(5):790-3.

Rodrigues CK, Ditterich RG, Shintcovsk RL, Tanaka O. Bruxismo: uma revisão da literatura. Publ UEPG Ci Biol Saúde, Ponta Grossa. 2006 set.;12(3):13-21.

Roeters J, Stel M. Adhesive techniques in the treatment of tooth wear due to bruxism. Ned Tijdschr Tandheelkd. 2000 Jul;107(7):308-11.

Rompré PH, Daigle-Landry D, Guitard F, Montplaisir JY, Lavigne GJ. Identification of a sleep bruxism subgroup with a higher risk of pain. J Dent Res. 2007 Sep;86(9):83742.

Rugh JD, Harlan J. Nocturnal bruxism and temporomandibular disorders. Adv Neurol. 1988;49:329-41.

Rugh JD, Ware JC. Polysomnographic comparison of nocturnal bruxists with and without facial pain. J Dent Res. 1986; 65:180-97.

Rugiski M, Pilatti LA, Scandelari L. O instrumento de avaliação da Qualidade de Vida da Organização Mundial da Saúde, o WHOQOL-100, e sua utilização [citado 23 ago. 2012]. Disponível em:

http://pg.utfpr.edu.br/dirppg/ppgep/ebook/producao1/2_Marcelo_Rugiski.pdf.

Saletu A, Parapatics S, Saletu B, Anderer P, Prause W, Putz H, Adelbauer J, SaletuZyhlarz G. On the pharmacotherapy of sleep bruxism: placebo-controlled polysomnographic and psychometric studies with clonazepam. Neuropsychobiology. 2005;51,(4):214-25.

Sári S, Sonmez H. The relationship between occlusal factors and bruxism in permanent and mixed dentition in Turkish children. J Clin Pediat Dent. 2001 Spring;25(3):191-4.

Schierz O, John MT, Schroeder E, Lobbezoo F. Association between anterior tooth wear and temporomandibular disorder pain in a German population. J Prosthet Dent. 2007 May;97(5):305-9. 
Schneider C, Schaefer R, Ommerborn MA, Giraki M, Goertz A, Raab WH, Franz M. Maladaptive coping strategies in patients with bruxism compared to non-bruxing controls. Int J Behav Med. 2007;14(4):257-61.

Seraidarian PI, Assunção ZLV, Jacob MF. Bruxismo: uma atualização dos conceitos, etiologia, prevalência e gerenciamento. JBA. Curitiba, v.1, n.4, p.290-295, out./dez. 2001.

Serralta FB, Freitas PRR de. Bruxismo e afetos negativos: um estudo sobre ansiedade, depressão e raiva em pacientes bruxômanos. JBA, Curitiba. 2002 jan./mar.;2(5):20-5.

Serralta FB, Martins EA, Ávila JF. Adaptação de um instrumento de triagem para problemas psicológicos em pacientes com disfunção craniomandibular e dor orofacial. JBA, Curitiba. 2001 jan./mar.;1(1):80-5.

Sessle BJ. The neurobiology of facial and dental pain: present knowledge, future directions. J Dent Res. 1987 May;66(5):962-81.

Shetty S, Pitti V, Satish Babu CL, Surendra Kumar GP, Deepthi BC. Bruxism: a literature review. J Indian Prosthodont Soc. 2010 Sept;10(3):141-8.

Shinkai RS, Santos LM, Silva FA, Santos MN. Contribuição ao estudo da prevalência de bruxismo excêntrico noturno em crianças de 2 a 11 anos de idade. Rev Odontol Univ São Paulo. 1998 jan./mar.;12(1):29-37.

Silva NR, Cantisano MH. Bruxismo: etiologia e tratamento. Rev Bras Odontol. 2009 jul./dez.;66(2):223-7.

Simões-Zenari M, Bitar ML. Fatores associados ao bruxismo em crianças de 4 a 6 anos. Pró-Fono Rev Atual Cient. 2010 out.-dez.;22(4):465-72.

Slade GD. Derivation and validation of a short-form oral health impact profile. Community Dent Oral Epidemiol. 1997;25:284-90.

Sutin AR, Terracciano A, Ferrucci L, Costa PT Jr. Teeth grinding: is emotional stability related to bruxism?. J Res Pers. 2010 Jun;44(3):402-5. 
Tanne K, Tanaka E, Sakuda M. Association between malocclusion and temporomandibular disorders in orthodontic patients before treatment. J Orofac Pain. 1993 Spring;7(2):156-62.

Teixeira M, Ribeiro CP, Queiroz A, Perdomo GW. Bruxismo: o desgaste dental em resposta à interferência oclusal. ROBRAC. 1994 dez.;4(13):8-13.

The WHOQOL Group. Development of the World Health Organization WHOQOLbref. Quality of Life assessment. Psychol Med. 1998;28:551-8.

Tomacheski DF, Barboza VL, Fernandes M do R, Fernandes F. Disfunção têmporomandibular: estudo introdutório visando estruturação de prontuário odontológico. Publ. UEPG Ci Biol Saúde, Ponta Grossa. 2004 jun.;10(2):17-25 [citado 23 fev. 2009]. Disponível em: http://www.propesp.uepg.br/publicatio/bio/2004_2/02.pdf.

Van der Zaag J, Lobbezoo F, Van der Avoort PG, Wicks DJ, Hamburger HL, Naeije $M$. Effects of pergolide on severe sleep bruxism in a patient experiencing oral implant failure. J Oral Rehabil. 2007 May;34(5):317-22.

Van Der Zaag J, Lobbezoo F, Wicks DJ, Visscher CM, Hamburger HL, Naeije M. Controlled assessment of the efficacy of occlusal stabilization splints on sleep bruxism. J Orofac Pain. 2005 Spring;19(2):151-8.

Vanderas AP. Relationship between craniomandibular dysfunction and oral parafunctions in Caucasian children with and without unpleasant life events. J Oral Rehabil. 1995 Apr;22(4):289-94.

Vaughn BV. Sleep Bruxism. MedLINK Neurology [cited 2009 Feb 19]. Available from: http://www.medlink.com/medlinkcontent.asp.

Velly AM, Gornitsky M, Philippe P. Contributing factors to chronic myofascial pain: a case-control study. Pain. 2003 Aug;104(3):491-9.

Ware JC, Rugh JD. Destructive bruxism: sleep stages relationship. Sleep. 1998 Apr;11(2):172-81.

Watson ML, Burke FJ. Investigation and treatment of patients with teeth affected by tooth substance loss: a review. Dent Update. 2000 May;27(4):175-83. 
Widmalm SE, Christiansen RL, Gunn SM, Hawley LM. Prevalence of signs and symptoms of craniomandibular disorders and orofacial parafunction in 4-6-year-old African-American and Caucasian children. J Oral Rehabil. 1995 Feb;22(2):87-93.

Wigdorowicz-Makowerowa N, Grodzki C, Panek H, Máslanka T, Plonka K, Palacha A. Epidemiological studies on prevalence and etiology of functional disturbances of the masticatory system. J Prosthet Dent. 1979 Jan;41(1):76-82.

Winocur E, Gavish A, Voikovitch M, Emodi-Perlman A, Eli I. Drugs and bruxism: a critical review. J Orofac Pain. 2003 spring;17(2):99-111.

Wolf SMR. Psicologia no consultório odontológico. São Paulo: Editora Unimar; 2000.

Yachica W, Castrillon EE, Baad-Hansen L, Jensen R, Arima T, Tomonaga A, Ohata $\mathrm{N}$, Svensson P. Craniofacial pain and jaw-muscle activity during sleep. J Dent Res. 2012 Jun;91(6):562-7.

Yip HKK. Rehabilitating a patient with bruxism-associated tooth tissue loss: a literature review and case report. Gen Dent. 2003 Jan-Feb;51(1):70-4.

Zuanon ACC, Campos CGA, Giro EMA, Pansani CA. Bruxismo infantil. Odont Clin. 1999;9(1):41-4. 
ANEXO A - Aprovação Comitê de Ética em Pesquisa

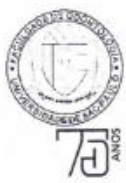

Universidade de São Paulo

Faculdade de Odontologia

Comitê de Ética em Pesquisa

\section{PARECER DE APROVAÇÃO \\ FR 265058}

Protocolo 91/2009

Com base em parecer de relator, o Comitê de Ética em Pesquisa APROVOU ○ protocolo de pesquisa "Diferenças entre dentes de bruxômano e năo bruxômano", de responsabilidade do(a) Pesquisador(a) Elizabeth Puliti, sob orientação do(a) Prof.(a) Dr.(a.) Glauco Fioranelli Vieira.

Tendo em vista a legislação vigente, devem ser encaminhados a este Comitê relatórios anuais referentes ao andamento da pesquisa $e$ ao término cópia do trabalho em "cd". Qualquer emenda do projeto original deve ser apresentada a este CEP para apreciação, de forma clara e sucinta, identificando a parte do protocolo a ser modificada e suas justificativas.

Săo Paulo, 14 de setembro de 2009. 
ANEXO B - Termo de Consentimento Livre e Esclarecido

Título do Estudo: Diferenças Entre Dentes de Bruxômano e não Bruxômano.

Orientador: Prof. Dr. Glauco Fioranelli Vieira - FOUSP

Pesquisadora:Elizabeth Puliti

Instituição/Departamento: Faculdade de Odontologia da USP / Departamento de Dentística

Telefone para contato: 11-92474732

Local da coleta de dados: Faculdade de Odontologia da USP: Av Prof. Lineu Prestes, 2227 - Cidade Universitária - São Paulo - S.P.

Prezado(a) Senhor(a):

- Você está sendo convidado(a) a participar desta pesquisa e a responder às perguntas de um questionário e ser submetido à exame clínico de forma totalmente voluntária.

- Antes de concordar em participar desta pesquisa e responder ao questionário e de ser examinado clinicamente, é muito importante que você compreenda as informações e instruções contidas neste documento.

- O pesquisador deverá responder a todas as suas dúvidas antes de você se decidir a participar.

- Você tem o direito de desistir de participar da pesquisa a qualquer momento, sem nenhuma penalidade e sem perder os benefícios aos quais tenha direito.

Objetivos do estudo: Esta pesquisa visa identificar a proporção da parafunção bruxismo (hábito de ranger ou apertar os dentes). Este estudo também pretende detectar as alterações dentais que ocorrem na presença do bruxismo e sua autopercepção, e a presença de DTM. Este hábito, dependendo de sua freqüência, é capaz de causar acentuado desgaste dos dentes naturais e de materiais restauradores.

Procedimentos: Sua participação consiste no preenchimento de um questionário, posterior exame clínico intra e extra-bucal além de fotografias de seus dentes.

Benefícios: Como benefício esta pesquisa trará maior conhecimento sobre a presença e as consequências do bruxismo.

Riscos: O preenchimento deste questionário e o exame clínico não representam qualquer risco de ordem física ou psicológica. Durante o período da pesquisa, você poderá esclarecer qualquer dúvida com o pesquisador.

Custos: Você não terá nenhum custo para a realização desta pesquisa. 
Sigilo: As informações fornecidas e referentes a você serão mantidas confidenciais e serão de conhecimento apenas dos investigadores responsáveis pela pesquisa. Os sujeitos da pesquisa não serão identificados, mesmo quando da divulgação dos resultados da pesquisa em qualquer forma.

Nome

RG

Assinatura do Sujeito da pesquisa

Data 120 
ANEXO C- Questionário de Auto-relato (Auto-percepção). Inquérito para a detecção do Bruxismo.

Sexo:

Idade:

Profissão:

1. Você aperta os dentes durante o dia?

SIM $\square$ NÃO $\square$

2. Você range os dentes?

SIM $\square$ NÃO $\square$

3. Você aperta e range os dentes?

SIM $\square$ NÃO $\square$

4. Seu companheiro(a) ou familiar se queixa de

$\operatorname{SIM} \square$ NÃO $\square$

sons ou ranger de dentes enquanto você dorme?

5. Você se sente cansada ou com dor nos músculos

$\square$ SIM $\square N A ̃ O$ da face ao despertar?

6. Tem dor de cabeça/ pescoço/ ombro/ face rotineiramente ? SIM $\square$ NÃO $\square$

7. Tem clicks/ estalidos na articulação temporomandibular? SIM $\square$ NÃO $\square$

8. Você sente desconforto nos dentes ao despertar? SIM $\square$ NÃO $\square$

9. Tem histórico de fraturas/perda de restaurações? SIM $\square$ NÃO $\square$

10. Percebeu um desgaste dos seus dentes? SIM $\square$ NÃO

11. Tem cansaço/dor muscular quando mastiga? SIM $\square$ NÃO $\square$

12. Tem dor de ouvido ou dores próximas ao ouvido? SIM $\square$ NÃO $\square$

13. Você acorda pela manhã ou durante a noite com SIM $\square$ NÃO $\square$ as mandíbulas travadas? 
ANEXO D - Versão em português dos instrumentos de avaliação de qualidade de vida (WHOQOL) 1998

\title{
WHOQOL - ABREVIADO
}

\author{
Versão em Português
}

\section{PROGRAMA DE SAÚDE MENTAL ORGANIZAÇÃO \\ MUNDIAL DA SAÚDE GENEBRA}

Coordenação do GRUPO WHOQOL no Brasil

Dr. Marcelo Pio de Almeida Fleck

Professor Adjunto

Departamento de Psiquiatria e

Medicina Legal Universidade Federal

do Rio Grande do Sul Porto Alegre -

RS - Brasil 


\section{Instruções}

Este questionário é sobre como você se sente a respeito de sua qualidade de vida, saúde e outras áreas de sua vida. Por favor, responda a todas as questões. Se você não tem certeza sobre que resposta dar em uma questão, por favor, escolha entre as alternativas a que lhe parece mais apropriada. Esta, muitas vezes, poderá ser sua primeira escolha.

Por favor, tenha em mente seus valores, aspirações, prazeres e preocupações. Nós estamos perguntando o que você acha de sua vida, tomando como referência as duas últimas semanas . Por exemplo, pensando nas últimas duas semanas, uma questão poderia ser:

\begin{tabular}{|l|c|c|c|c|c|}
\hline & nada & $\begin{array}{c}\text { muito } \\
\text { pouco }\end{array}$ & médio & muito & completamente \\
\hline $\begin{array}{l}\text { Você recebe dos outros o apoio de que } \\
\text { necessita? }\end{array}$ & 1 & 2 & 3 & 4 & 5 \\
\hline
\end{tabular}

Você deve circular o número que melhor corresponde ao quanto você recebe dos outros o apoio de que necessita nestas últimas duas semanas. Portanto, você deve circular o número 4 se você recebeu "muito" apoio como abaixo.

\begin{tabular}{|l|c|c|c|c|c|}
\hline & nada & $\begin{array}{c}\text { muito } \\
\text { pouco }\end{array}$ & médio & muito & completamente \\
\hline $\begin{array}{l}\text { Você recebe dos outros o apoio de que } \\
\text { necessita? }\end{array}$ & 1 & 2 & 3 & 4 & 5 \\
\hline
\end{tabular}

Você deve circular o número 1 se você não recebeu "nada" de apoio.

Por favor, leia cada questão, veja o que você acha e circule no número e lhe parece a melhor resposta.

\begin{tabular}{|l|l|c|c|c|c|c|}
\hline & & $\begin{array}{c}\text { muito } \\
\text { ruim }\end{array}$ & ruim & $\begin{array}{c}\text { nem ruim } \\
\text { nem boa }\end{array}$ & $\begin{array}{c}\text { boa } \\
\text { boa }\end{array}$ \\
\hline 1 & $\begin{array}{l}\text { Como você avaliaria sua qualidade de } \\
\text { vida? }\end{array}$ & 1 & 2 & 3 & 4 & 5 \\
\hline
\end{tabular}

\begin{tabular}{|c|c|c|c|c|c|c|}
\hline & & $\begin{array}{l}\text { muito } \\
\text { insatisfeito }\end{array}$ & insatisfeito & $\begin{array}{l}\text { nem satisfeito } \\
\text { nem insatisfeito }\end{array}$ & satisfeito & $\begin{array}{c}\text { muito } \\
\text { satisfeit } \\
\text { o }\end{array}$ \\
\hline 2 & $\begin{array}{l}\text { Quão satisfeito(a) você está } \\
\text { com a sua saúde? }\end{array}$ & 1 & 2 & 3 & 4 & 5 \\
\hline
\end{tabular}




\begin{tabular}{|l|l|c|c|c|c|c|}
\hline & & nada & $\begin{array}{c}\text { muito } \\
\text { pouco }\end{array}$ & $\begin{array}{c}\text { mais ou } \\
\text { menos }\end{array}$ & $\begin{array}{c}\text { bastant } \\
\text { e }\end{array}$ & extremamente \\
\hline 3 & $\begin{array}{l}\text { Em que medida você acha que sua dor } \\
\text { (física) impede você de fazer o que você } \\
\text { precisa? }\end{array}$ & 1 & 2 & 3 & 4 & 5 \\
\hline 4 & $\begin{array}{l}\text { O quanto você precisa de algum } \\
\text { tratamento médico para levar sua vida } \\
\text { diária? }\end{array}$ & 1 & 2 & 3 & 4 & 5 \\
\hline 5 & O quanto você aproveita a vida? & 1 & 2 & 3 & 4 & 5 \\
\hline 6 & $\begin{array}{l}\text { Em que medida você acha que a sua vida } \\
\text { tem sentido? }\end{array}$ & 1 & 2 & 3 & 4 & 5 \\
\hline 7 & O quanto você consegue se concentrar? & 1 & 2 & 3 & 4 & 5 \\
\hline 8 & $\begin{array}{l}\text { Quão seguro(a) você se sente em sua vida } \\
\text { diária? }\end{array}$ & 1 & 2 & 3 & 4 & 5 \\
\hline 9 & $\begin{array}{l}\text { Quão saudável é o seu ambiente físico } \\
\text { (clima, barulho, poluição, atrativos)? }\end{array}$ & 1 & 2 & 3 & 4 & 5 \\
\hline
\end{tabular}

As questões seguintes perguntam sobre quão completamente você tem sentido ou é capaz de fazer certas coisas nestas últimas duas semanas.

\begin{tabular}{|c|l|c|c|c|c|c|}
\hline & & nada & $\begin{array}{l}\text { muito } \\
\text { pouco }\end{array}$ & médio & muito & completamente \\
\hline 10 & Você tem energia suficiente para seu dia-a-dia? & 1 & 2 & 3 & 4 & 5 \\
\hline 11 & Você é capaz de aceitar sua aparência física? & 1 & 2 & 3 & 4 & 5 \\
\hline 12 & $\begin{array}{l}\text { Você tem dinheiro suficiente para satisfazer suas } \\
\text { necessidades? }\end{array}$ & 1 & 2 & 3 & 4 & 5 \\
\hline 13 & $\begin{array}{l}\text { Quão disponíveis para você estão as } \\
\text { informações que precisa no seu dia-a-dia? }\end{array}$ & 1 & 2 & 3 & 4 & 5 \\
\hline 14 & $\begin{array}{l}\text { Em que medida você tem oportunidades de } \\
\text { atividade de lazer? }\end{array}$ & 1 & 2 & 3 & 4 & 5 \\
\hline
\end{tabular}

As questões seguintes perguntam sobre quão bem ou satisfeito você se sentiu a respeito de vários aspectos de sua vida nas últimas duas semanas.

\begin{tabular}{|l|l|c|c|c|c|c|}
\hline & & $\begin{array}{c}\text { muito } \\
\text { ruim }\end{array}$ & ruim & $\begin{array}{c}\text { nem ruim } \\
\text { nem bom }\end{array}$ & $\begin{array}{c}\text { bom } \\
\text { bom }\end{array}$ \\
\hline 15 & Quão bem você é capaz de se locomover? & 1 & 2 & 3 & 4 & 5 \\
\hline
\end{tabular}

\begin{tabular}{|c|l|c|c|c|c|c|}
\hline & & $\begin{array}{c}\text { muito } \\
\text { insatisf }\end{array}$ & insatisfeito & $\begin{array}{c}\text { nem } \\
\text { satisfeito }\end{array}$ & satisfeito & $\begin{array}{c}\text { muit } \\
\text { o }\end{array}$ \\
\hline 16 & $\begin{array}{l}\text { Quão satisfeito(a) você está com o seu } \\
\text { sono? }\end{array}$ & 1 & 2 & 3 & 4 & 5 \\
\hline
\end{tabular}




\begin{tabular}{|c|l|c|c|c|c|c|}
\hline 17 & $\begin{array}{l}\text { Quão satisfeito(a) você está com sua } \\
\text { capacidade de desempenhar as atividades } \\
\text { do seu dia-a-dia? }\end{array}$ & 1 & 2 & 3 & 4 & 5 \\
\hline 18 & $\begin{array}{l}\text { Quão satisfeito(a) você está com sua } \\
\text { capacidade para o trabalho? }\end{array}$ & 1 & 2 & 3 & 4 & 5 \\
\hline 19 & $\begin{array}{l}\text { Quão satisfeito(a) você está consigo } \\
\text { mesmo? }\end{array}$ & 1 & 2 & 3 & 4 & 5 \\
\hline 20 & $\begin{array}{l}\text { Quão satisfeito(a) você está com suas } \\
\text { relaç̃es pessoais (amigos, parentes, } \\
\text { conhecidos, colegas)? }\end{array}$ & 1 & 2 & 3 & 4 & 5 \\
\hline 21 & $\begin{array}{l}\text { Quão satisfeito(a) você está com sua vida } \\
\text { sexual? }\end{array}$ & 1 & 2 & 3 & 4 & 5 \\
\hline 22 & $\begin{array}{l}\text { Quão satisfeito(a) você está com o apoio } \\
\text { que você recebe de seus amigos? }\end{array}$ & 1 & 2 & 3 & 4 & 5 \\
\hline 23 & $\begin{array}{l}\text { Quão satisfeito(a) você está com as } \\
\text { condições do local onde mora? }\end{array}$ & 1 & 2 & 3 & 4 & 5 \\
\hline 24 & $\begin{array}{l}\text { Quão satisfeito(a) você está com o seu } \\
\text { acesso aos serviços de saúde? }\end{array}$ & 1 & 2 & 3 & 4 & 5 \\
\hline 25 & $\begin{array}{l}\text { Quão satisfeito(a) você está com o seu } \\
\text { meio de transporte? }\end{array}$ & 1 & 2 & 3 & 4 & 5 \\
\hline
\end{tabular}

As questões seguintes referem-se a com que frequiência você sentiu ou experimentou certas coisas nas últimas duas semanas.

\begin{tabular}{|l|l|c|c|c|c|c|}
\hline 26 & nunca & $\begin{array}{c}\text { algumas } \\
\text { vezes }\end{array}$ & frequientemente & $\begin{array}{c}\text { muito } \\
\text { frequientemente }\end{array}$ & sempre \\
$\begin{array}{l}\text { Com que freqüência você tem } \\
\text { sentimentos negativos tais como mau } \\
\text { humor, desespero, ansiedade, } \\
\text { depressão? }\end{array}$ & 1 & 2 & 3 & 4 & 5 \\
\hline
\end{tabular}

Alguém Ihe ajudou a preencher este

questionário?.

Quanto tempo você levou para preencher este

questionário?

\section{Você tem algum comentário \\ sobre o questionário? \\ OBRIGADO PELA SUA \\ COLABORAÇÃO}


ANEXO E - Questionário Anamnético e Exame Clínico

\begin{tabular}{|c|c|c|}
\hline 1.DOR MUSCULATURA FACE & SIM $\square$ & NÃO $\square$ \\
\hline 2.SENSIBILIDADE (ESTRESSE FUNCIONAL DENTAL) & $\operatorname{SIM} \square$ & NÃO $\square$ \\
\hline \multicolumn{3}{|l|}{ 3.INTERFERÊNCIA OCLUSAL } \\
\hline PROTRUSIVA & SIM $\square$ & NÃO $\square$ \\
\hline LATERALIDADE & SIM $\square$ & NÃO $\square$ \\
\hline 4.GUIA INCISIVOS & $\sin \square$ & NÃO $\square$ \\
\hline 5.GUIA CANINO_ & BILATERAL $\square$ & UNILATERAL $\square$ \\
\hline 6.DESVIO DE LINHA MÉDIA_ & $\operatorname{SIM} \square$ & NÃO $\square$ \\
\hline 7.FACETAS DE DESGASTE_ & SIM $\square$ & NÃO $\square$ \\
\hline 8.FRATURAS DENTAIS & SIM $\square$ & NÃO $\square$ \\
\hline 9.FRATURAS RESTAURAÇÕES & $\sin \square$ & NÃđ $\square$ \\
\hline 10.MOBILIDADE DENTÁRIA & SIM $\square$ & NÃO $\square$ \\
\hline 11.RECESSÃO GENGIVAL & SIM $\square$ & NÃO $\square$ \\
\hline 12.ABFRAÇÃO & SIM $\square$ & NÃO $\square$ \\
\hline 13.MORDIDA ABERTA ANTERIOR_ & $\operatorname{siM} \square$ & NÃO $\square$ \\
\hline 14.MORDIDA CRUZADA ANTERIOR_ & $\mathrm{SIM} \square$ & NÃO $\square$ \\
\hline 15.MORDIDA CRUZADA POSTERIOR & $\sin \square$ & NÃO $\square$ \\
\hline 16.SOBREMORDIDA & $\operatorname{SIM} \square$ & NÃO $\square$ \\
\hline 17.SOBRESSALIÊNCIA & $\sin \square$ & NÃO $\square$ \\
\hline 18.SALTO CONDILAR_ & SIM $\square$ & NÃO $\square$ \\
\hline 19.RUÍDOS ARTICULARES & SIN $\square$ & NÃO $\square$ \\
\hline 20.LIMITAÇÃO ABERTURA BUCAL_ & SIM $\square$ & NÃO $\square$ \\
\hline 21.ASSIMETRIA FACIAL & SIM $\square$ & NÃO $\square$ \\
\hline 22.HIPERTROFIA MUSCULAR & SIM $\square$ & NÃO $\square$ \\
\hline 23. SULCOS DENTAIS (BORDAS DA LÍNGUA) & $\operatorname{siM} \square$ & NÃO $\square$ \\
\hline 24. LINHA DE OCLUSÃO (FACE INTERNA BOCHECHAS)_ & SIM $\square$ & NÃO $\square$ \\
\hline 25.HÁBITOS(ROER UNHAS/MORDER OBJETOS/CHUPAR LÁBI & $\sin \square$ & NÃO $\square$ \\
\hline
\end{tabular}

